San Jose State University

SJSU ScholarWorks

Master's Theses

Master's Theses and Graduate Research

2007

\title{
Chromated copper arsenate's impact on construction workers and the environment
}

Kenneth Steve Nowak

San Jose State University

Follow this and additional works at: https://scholarworks.sjsu.edu/etd_theses

\section{Recommended Citation}

Nowak, Kenneth Steve, "Chromated copper arsenate's impact on construction workers and the environment" (2007). Master's Theses. 3580.

DOI: https://doi.org/10.31979/etd.prm7-dnuf

https://scholarworks.sjsu.edu/etd_theses/3580

This Thesis is brought to you for free and open access by the Master's Theses and Graduate Research at SJSU ScholarWorks. It has been accepted for inclusion in Master's Theses by an authorized administrator of SJSU ScholarWorks. For more information, please contact scholarworks@sjsu.edu. 


\title{
CHROMATED COPPER ARSENATE'S \\ IMPACT ON CONSTRUCTION WORKERS AND THE ENVIRONMENT
}

\author{
A Thesis \\ Presented to \\ The Faculty of the Department of Civil and Environmental Engineering \\ San José State University \\ In Partial Fulfillment \\ of the Requirements for the Degree \\ Master of Science
}

by

Kenneth Steve Nowak

May 2007 
UMI Number: 1445255

Copyright 2007 by

Nowak, Kenneth Steve

All rights reserved.

\section{INFORMATION TO USERS}

The quality of this reproduction is dependent upon the quality of the copy submitted. Broken or indistinct print, colored or poor quality illustrations and photographs, print bleed-through, substandard margins, and improper alignment can adversely affect reproduction.

In the unlikely event that the author did not send a complete manuscript and there are missing pages, these will be noted. Also, if unauthorized copyright material had to be removed, a note will indicate the deletion.

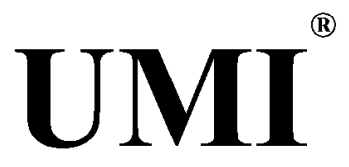

UMI Microform 1445255

Copyright 2007 by ProQuest Information and Learning Company.

All rights reserved. This microform edition is protected against unauthorized copying under Title 17, United States Code.

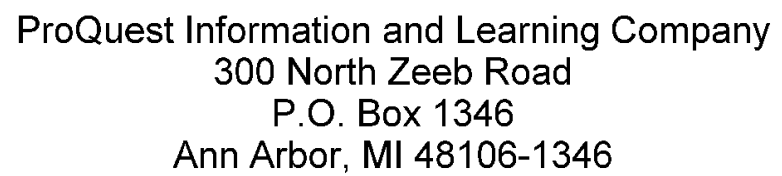


(C) 2007

Kenneth Steve Nowak

ALL RIGHTS RESERVED 
APPROVED FOR THE DEPARTMENT OF

CIVIL AND ENVIRONMENTAL ENGINEERING

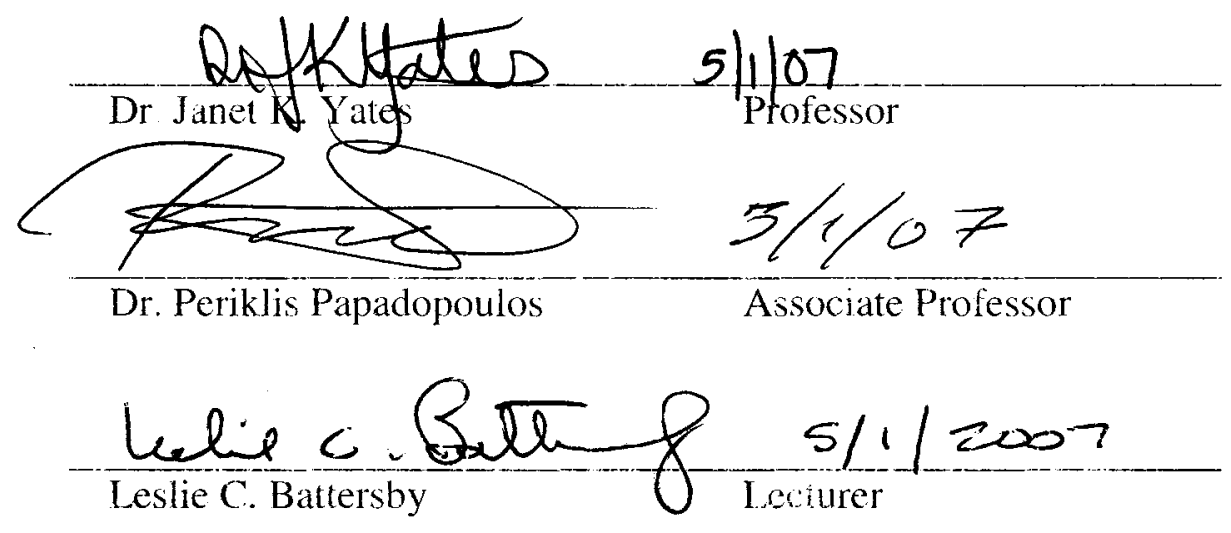

APPROVED FOR THE UNIVERSITY Panel CStuda 


\section{ABSTRACT \\ CHROMATED COPPER ARSENATE'S \\ IMPACT ON CONSTRUCTION WORKERS AND THE ENVIRONMENT \\ by Kenneth Steve Nowak}

This research project investigated whether Chromated Copper Arsenate (CCA), which is a wood preservative used in pressure treated wood, is dangerous to the health of construction and wood treatment industry workers. The research also examined the effects of federal exemptions in the hazardous solid waste laws for arsenical preserved wood that allows dumping of CCA waste in unlined landfills. The contamination of water supplies from the leaching wood waste at landfills is degrading the quality of aquifers. This thesis analyzes the toxic effect of wood treated with CCA for the entire life cycle of the wood products that are used in construction projects. As part of the research a Mat-Ranger Decision Support System was developed that allows construction personnel to examine the potential toxic effects of different construction materials along with comparing the cost of the materials to the potential environmental degradation that could result from using each potential material. 


\section{ACKNOWLEDGEMENTS}

This research is dedicated to all my family and friends who believed, encouraged, and assisted me to attain this second master's degree, and finish this master's thesis. I am grateful to all those who support my future goals in the civil engineering industry. May those achievements be ecologically-friendly and lead us away from consumption toward a sustainable way of life.

- Dr. Janet K. Yates, SJSU Professor, Construction Engineering, now at Ohio University.

- Dr. Periklis Papadopoulos, Associate Professor, Mechanical and Aerospace Engineering.

- Leslie C. Battersby, Lecturer, Civil and Environmental Engineering.

- Family: Mom, Grandma T., Grandma N., Dad, Kristi, Tim, Tony, Dawson, Jaden, Dave L.et al.

- Friends: Paul, Evrett, Daryl, Joe, Rich, Spencer.

- Wendy: MBA, CTC (Certified Technical Communicator), and Artist assisted this thesis project as: Business Consultant, Cheerleader, Chef, Confidante, Dishes Coordinator, Documenter (Photographer), Editor, Exercise Buddy, Feng Shui Consultant, Laundry Goddess, Personal Shopper, Project Manager, Software Trainer, Tech Writer. Thanks for the expert stress relief and for believing in me. 


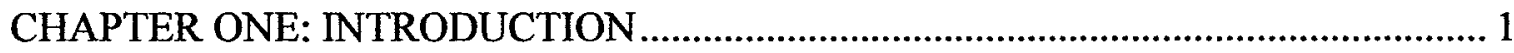

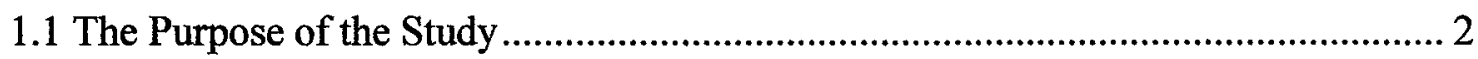

1.2 Research Objective …….................................................................................... 3

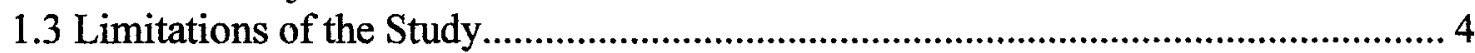

1.4 Organization of the Study .................................................................................... 4

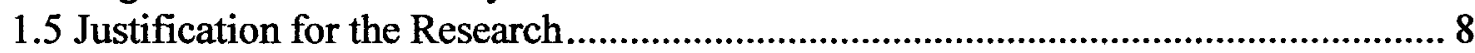

CHAPTER TWO: METHODOLOGY ................................................................ 10

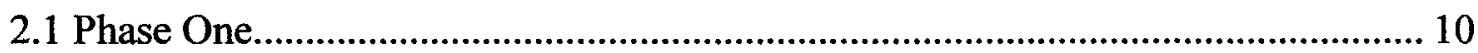

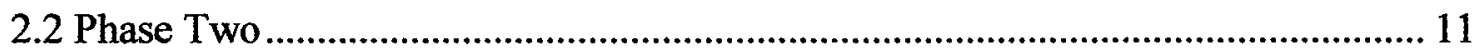

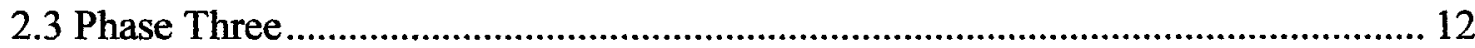

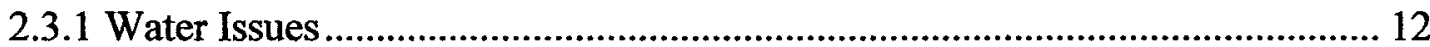

2.3.2 Scientific Advisory Board, Children's Exposure to CCA ................................. 13

2.3.3 Conference Papers and Articles ...................................................................... 13

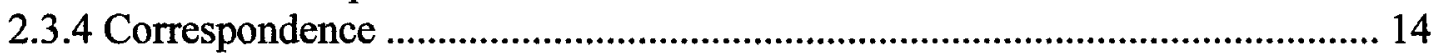

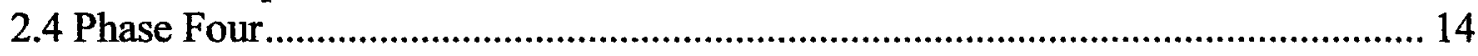

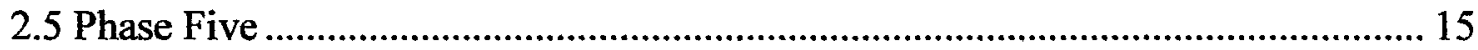

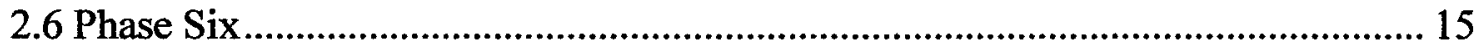

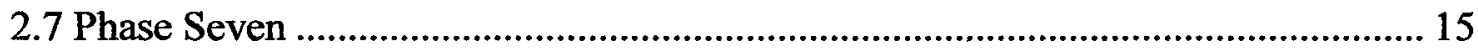

2.8 Phase Eight............................................................................................... 15

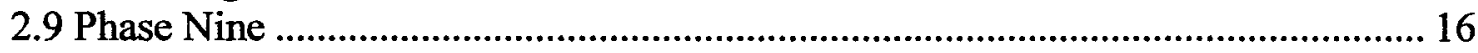

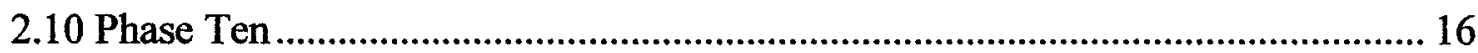

CHAPTER THREE: BACKGROUND INFORMATION ……..................................... 17

3.1 Arsenic and Chromium ........................................................................................ 17

3.1.1 Health Effects from Arsenic and Chromium ................................................. 19

3.2 National Priority List (NPL) and Water Quality.................................................... 21

3.2.1 Agency for Toxic Substances and Disease Register (ATSDR)........................ 22

3.2.2 Toxicological Profiles.............................................................................. 22

3.3 EPA Regulation of Arsenic and Chromium............................................................ 24

3.3.1 The Occupational Safety and Health Administration (OSHA) and Arsenic ... 25

3.3.2 The OSHA and Chromium ....................................................................... 26

3.3.3 Insecticide, Fungicide, and Rodenticide Act (FIFRA) and Registration......... 26

3.3.3.1 Rebuttable Presumption Against Re-registration......................................... 27

3.3.3.2 The EPA Registrants................................................................................. 27

3.4 Re-registration of Toxic Products....................................................................... 28

3.4.1. Re-registration Phases................................................................................. 29

Phase 1: List Active Ingredients. ...................................................................... 29

Phase 2: Declare Intent and Identify Studies...................................................... 29

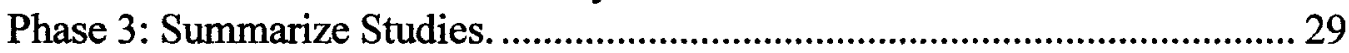

Phase 4: EPA Review and Data Call-In........................................................ 30

Phase 5: Re-registration Decisions. ................................................................ 30

3.4.2 Re-registration Eligibility Decisions (REDs) …………………………….... 30

3.5 Consessions by Registrants....................................................................................... 33 


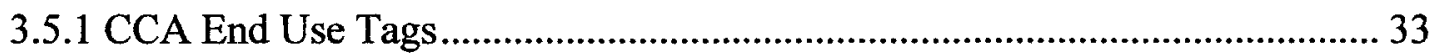

3.5.2 Consumer Information Sheets (CIS)........................................................... 34

3.5.3 Material Safety Data Sheets (MSDS) …………………................................... 34

3.6 Disposal and Exemptions..................................................................................... 35

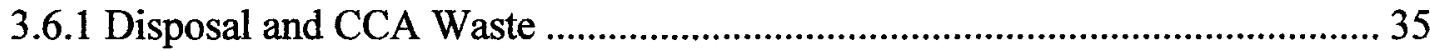

3.6.2 Construction and Demolition Waste Sites ......................................................... 36

3.6.3 The EPA's Current Stance on CCA Solid Waste ............................................ 37

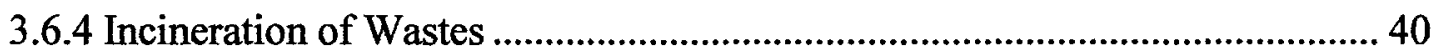

CHAPTER FOUR: LITERATURE SEARCH ............................................................. 41

4.1 CCA Toxin Studies........................................................................................... 41

4.1.1 Removal of Metals from CCA Waste.............................................................. 46

4.1.2 Leachate from Construction Waste............................................................... 46

4.1.3 Groundwater Polluted by Municipal Landfills ................................................... 47

4.1.4 Biological Treatment ........................................................................................ 51

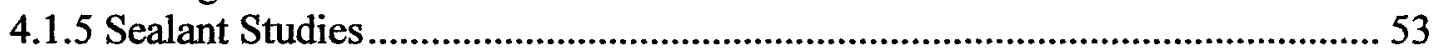

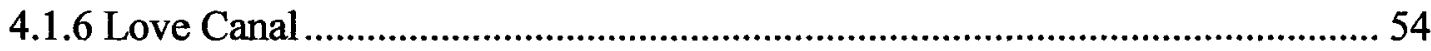

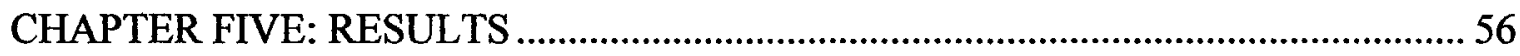

5.1 Exposure to Chromated Copper Arsenate.............................................................. 56

5.2 The Life Cycle of CCA Wood Products ..................................................................... 56

5.2.1 Manufacturing................................................................................................... 57

5.2.2 Distributors Handling and Delivery Personnel and CCA Exposure................. 58

5.2.3 Demolition Experts............................................................................................ 59

5.2.4 Construction Personnel Exposed to CCA and ACC.......................................... 60

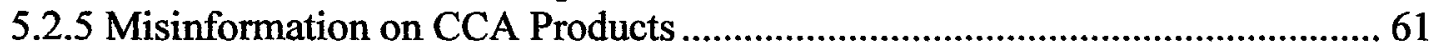

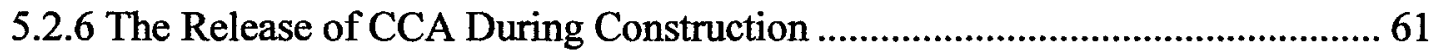

5.2.7 Lumber Yard and Sawmill Employees Have Some Protection......................... 62

5.3 Existing Structures; End Users ................................................................................. 63

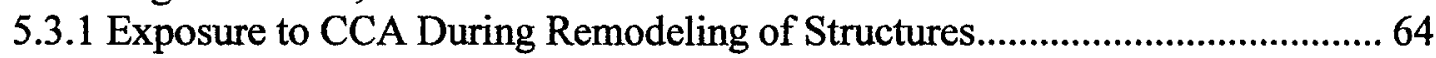

5.3.2 Risks to Agricultural Workers and Livestock...................................................... 64

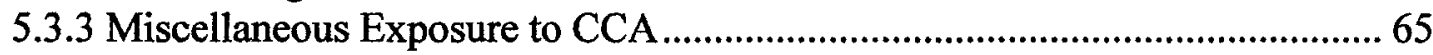

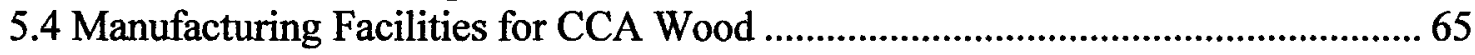

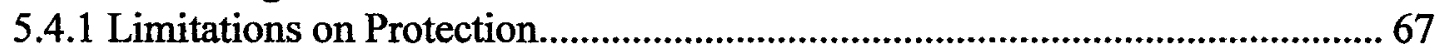

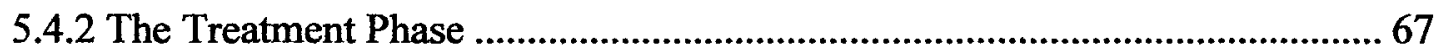

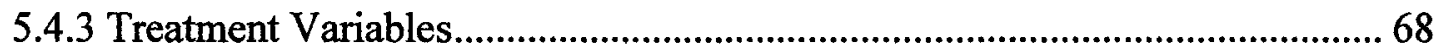

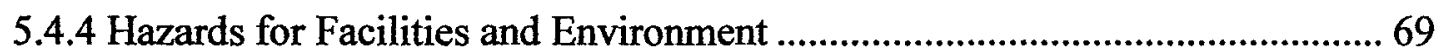

5.4.5 The National Priority List (NPL) .................................................................... 70

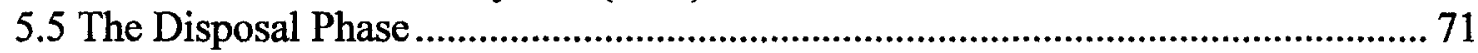

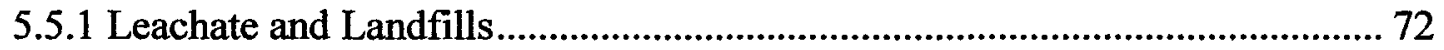

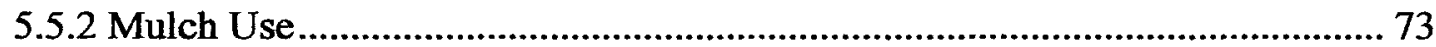

5.6 Legal Cases Related to CCA Prodcuts................................................................ 73

5.6.1 Toxicological Report ................................................................................... 74

5.6.2 Insider and Task Force EPA Memos ...................................................... 77

5.6.3 Cancellation of the Registration of CCA ………............................................. 78

5.6.4 ACC Faces Legal Action by the EPA.......................................................... 80 


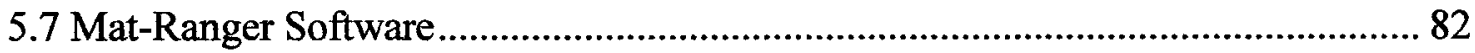

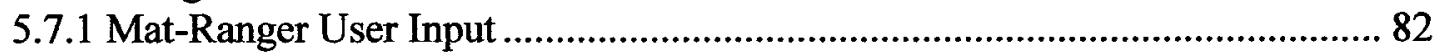

5.7.2 Mat-Ranger Output ................................................................................... 84

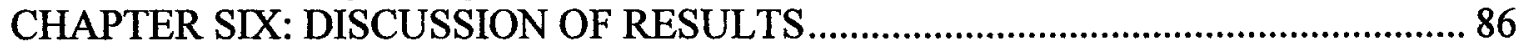

6.1 Voluntary Withdrawal of CCA Products............................................................... 86

6.1.1 Acid Copper Chromate (ACC) Denied Registration ......................................... 87

6.2 The Registrants' Position........................................................................................ 89

6.3 Discussion of Legal Documents ......................................................................... 91

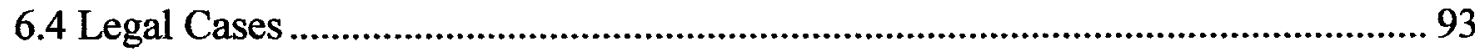

6.5 Disposal Challenges.............................................................................................. 94

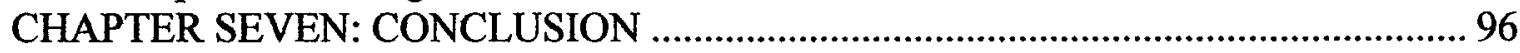

7.1 Production Use and Disposal of CCA ………………….......................................... 96

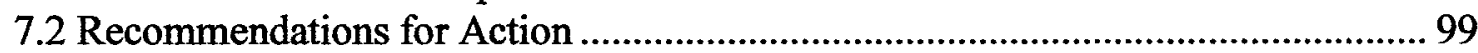

7.2.1 EPA Authority Related to CCA..................................................................... 99

7.2.2 Catalogue CCA Structure Locations in Municipalities ..................................... 99

7.2.3 Home Owners Warnings..................................................................................... 99

7.2.4 Reverse Hazardous Waste Exemption for CCA .............................................. 100

7.2.5 Separation Technologies................................................................................. 101

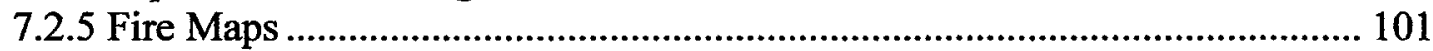

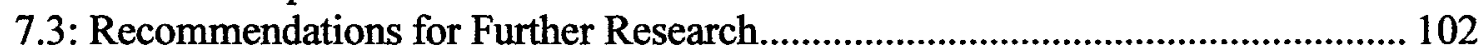

7.3.1 National Environmental Policy Act (NEPA) .............................................. 102

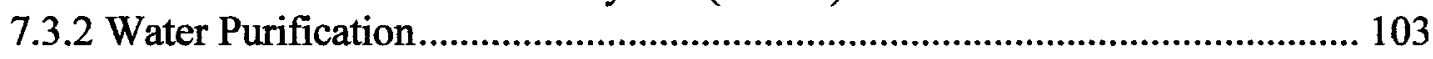

7.3.3 Group Health................................................................................................ 103

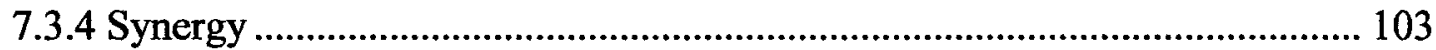

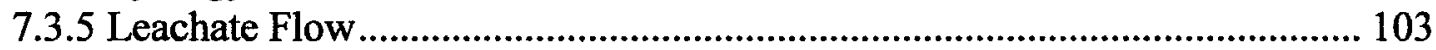

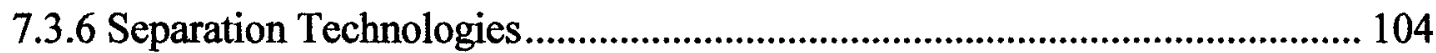

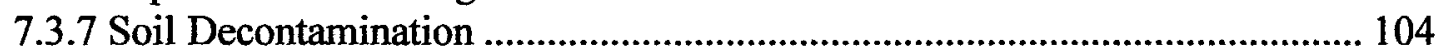

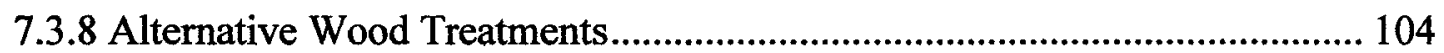

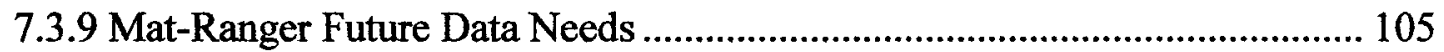

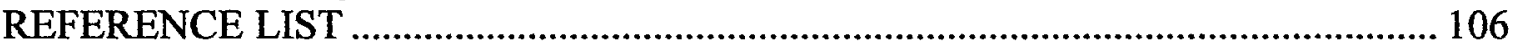

APPENDIX A: GLOSSARY ............................................................................. 113

APPENDIX B: RELATED RESEARCH SOURCES ................................................... 119

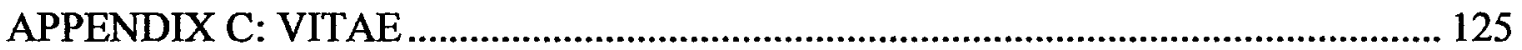




\section{CHAPTER ONE:}

\section{INTRODUCTION}

As part of the Civil Engineering Code of Ethics engineers have to make sure that employees, contractors, and the general public are not exposed to known dangers that result from their labors or potential hazards. The purpose of this paper is to inform industry professionals, and the general public, about the carcinogens that are in Chromated Copper Arsenate (CCA), a wood preservative that is applied to wood building materials.

It is a hot summer day and the researcher is working as a carpenter on a large deck. As the circular saw cuts along the edge of the deck, a swift breeze comes up, blowing a small cloud of sawdust into the researchers face. There is a metallic taste in his mouth. No thought was given to the metallic taste for another eight years until it was discovered that arsenic was one of the elements in the wood and exposure to it can cause damage to the neurological system. This exposure could have been avoided if information on the hazards of working closely with CCA had been readily available. As a carpenter with over fifteen years experience it was inconceivable to the researcher that known carcinogens would not be more strictly regulated by the government.

Wood has been a popular building material for centuries due to its being lightweight, readily accessible, inexpensive, and relatively easy to use. However, the destructive force of nature causes the useful lifespan of wood to be substantially shortened. A variety of chemicals have been used to preserve wood since the 1930's. The utility, railroad, and agricultural industries were among the first to make widespread use of chemically treated wood products. Many of the early chemicals that were used to treat wood turned out to be hazardous to both humans and to the environment. 
In the twentieth century petroleum-based products, such as creosote, were replaced by a water-based wood treatment called Chromated Copper Arsenate (CCA). Chromated Copper Arsenate is a preservative that is applied to lumber and other wood building products. CCA treatment provides wood with a combination of fungicide, pesticide, herbicide, and insecticide protection. The use of CCA prolongs the service life of wood building products that are exposed to destructive forces such as water, soil, fungi, mold, or insects and this helps to save forest and other economic resources. In some cases treating wood with CCA might extend its useful life from five years to thirty or forty years.

\subsection{THE PURPOSE OF THE STUDY}

The purpose of this study was to investigate the wood preservative Chromated Copper Arsenate (CCA) and its impact on construction workers and the environment. The manufacturing of CCA, the application of it to wood, and the delivery methods used for the preserved products are all precursors to the exposure of construction workers to the constituents in CCA and these are also examined in this research investigation. In service CCA wood was also investigated since its use exposes construction workers, and the general public, to known carcinogens. The consequences of unregulated dumping of spent CCA material was also examined in this work. The research also developed a computer Decision Support System (DSS) that can be used to warn construction personnel about the hazards associated with using different building materials. 


\subsection{RESEARCH OBJECTIVE}

The research objective was to determine whether the following hypothesis is true or false: The fixation process undertaken during wood treatment renders the toxic elements of CCA inert, thus making CCA treated wood safe for use by construction workers and the general public.

Research in the area of pressure treated wood, and the adverse effects it has on the environment, is not a new topic. There are many sources referenced in this research investigation that studied CCA leaching and ground water contamination. There are some studies available that have determined that construction workers using CCA wood during construction operations are exposed to arsenic and chromium. However, this research project examined the cradle to grave consequences of using CCA and it presents information on all of the phases of its manufacturing, use, and disposal including occupational, environmental, and human health issues. The data collected as part of this research project were used to determine the potential hazards associated with CCA and to provide recommendations about its proper use and disposal and about future actions that might prevent negative consequences for construction workers who work with CCA and that could help prevent environmental degradation. This paper also discusses a Decision Support System (DSS) called Mat-Ranger that was developed as part of this research effort that assists construction personnel when they are trying to select materials. The program provides information on the benefits and drawbacks that are associated with each potential material decision. 


\subsection{LIMITATIONS OF THE STUDY}

The study was limited to investigating the effects of using CCA treated wood products in the construction industry. Although CCA products are used in other industries, such as the agriculture and maritime industries, this investigation concentrated only on the hazards of using treated wood products in building construction in order to confine the research to investigating the negative health effects on construction workers and the toxic effects on the environment. The scope of the study was limited in this manner because it was self-funded and it was undertaken as a master's thesis not a Ph.D. dissertation.

\subsection{ORGANIZATION OF THE STUDY}

Chapter Two provides a discussion of the methods that were used to conduct this research project. Chapter Three discusses the toxic chemicals used in CCA building materials, what the health effects of these are for humans, and how they are regulated by the Environmental Protection Agency (EPA). Since arsenic and chromium in CCA are elements known to cause cancer, and are thus registered chemicals, the EPA licenses registrants to use these chemicals for applications as well as in registered products. When a product contains registered chemicals it must also be registered through the EPA and this will be discussed in Chapter Three. To accomplish CCA registration, the registrants were required to show that the benefits of using CCA products outweigh, or exceed, the risks. Registration, also includes evaluation of the economic and environmental costs and benefits of the products use. CCA products were registered prior to 1984 and they have been used for treating wood since the 1930's. As of March 
of 2007 CCA treated wood is still not classified as a hazardous material. This status is due to exemptions in the hazardous waste laws presented in the Chapter Three. Chapter Three also presents information on alternative technologies that might help to control CCA waste in the future. Chromated Copper Arsenate solid waste exemptions granted by the EPA in the early nineteen eighties create environmental hazards (Khan and Jambeck, 2006). The exemptions for arsenical treated wood in the Federal Solid Waste Laws have affected how CCA treated wood is handled at construction and demolition sites. Moreover, Chapter Three provides a historical perspective to how these exemptions evolved over time. Hundreds of thousands of tons of arsenic and chromium are handled improperly for two main reasons: 1) the preserved wood is buried in unlined and unmonitored landfills throughout the United States, and 2) the hazards associated with CCA products are overlooked by handlers because it is considered safe to handle. Even though Customer Information Sheets (CISs) and warning labels are required to accompany CCA construction materials these often do not accompany the materials to the disposal stage.

Chapter Four discusses studies that have shown that toxic chemicals in CCA leach out of wood when they are exposed to water or soil (Khan and Solo-Gabriele, 2006). This leachate composed of arsenic and chromium migrates from landfills into water supplies and this process is discussed in Chapter Five. Waste from construction sites is typically buried directly under and on top of unprotected soil. This procedure for the disposal of CCA wood waste has been used for decades; therefore, suggestions on alternative dumping procedures are provided in Chapter Six. 
Chapter Five presents information on the consequences that the chemicals used in CCA wood treatment have on both humans and the environment as multiple layers of exposure are created during the manufacturing, use, and disposal of CCA wood products. In addition to front line construction workers being at risk construction activities also create exposure pathways to all flora and fauna in proximity to jobsites. Contaminated areas around CCA manufacturing facilities within CCA-inclusive structures, and disposal sites, are also discussed in Chapter Five. The active ingredients contained in CCA are water-soluble and there are various ways for it to leak that create additional problems along with the vapors from the process contaminating the air and carrying arsenic particles away from the source of CCA wood production facilities. Runoff from treatment sites and landfills pollute surface and underground water sources and this issue is illustrated in Chapter Five in the discussion on National Priority List (NPL) sites.

Over the last thirty years the Occupational Safety and Health Administration (OSHA) has promulgated new, more protective, standards for occupational exposure to arsenic and chromium that is found in CCA. In order to comply with the OSHA policy of, limiting employee exposures to carcinogens to the lowest level feasible many new laws are in effect to protect the employees of the wood treatment industries. While arsenic and chromium are carefully regulated as individual chemicals due to their toxicity, the regulation of $\mathrm{CCA}$ has historically been much less restrictive for all occupations that use CCA once the treatment has been applied to the wood. Currently, there are precautions and suggested Personal Protective Equipment (PPE) for CCA use supplied by registrants of CCA, but the EPA or the OSHA requires no mandatory 
occupational protection beyond the treatment phase. Chapter Five tries to clarify the regulatory position of these agencies.

Chapter Six discusses cases that have been settled in favor of workers who had sustained CCA related occupational injuries. An analysis of some of the evidence that was presented in a case that had a jury verdict in favor of a construction worker exposed to CCA sawdust is also presented. Doctors and toxicologists have written reports that characterize $\mathrm{CCA}$ as a hazardous material when used with power tools and equipment and their research is discussed in Chapters Five and Six. Inhaling sawdust, or having skin contact with CCA treated wood, were the main concerns in the reports but contaminated food and tobacco products are also exposure pathways to be aware of if one is working with CCA. This and other exposure pathways for arsenic and chromium are also discussed in Chapter Four.

In 1988 the EPA began re-evaluating product registrations granted before 1984 as was mandated by the Federal Insecticide, Fungicide, and Rodenticide Act (FIFRA). Part of that process for products containing chemicals with registrations is called product reregistration. As of 2007, CCA re-registration proceedings are in their thirtieth year. Throughout the re-registration debate the EPA, which is the current governing body for pesticides in the United States, has continually taken a stance in favor of CCA use under its current registration. However, this agency is presently involved in a six-phase Reregistration Eligibility Decision (RED) involving the dangers associated with CCA products. If CCA registrants are granted positive re-registration status, this does not mean that the pesticide is not hazardous but it may mean that the economic benefits of a 
pesticide are great enough that the risk should be tolerated (EPA, 2005a). Due to public pressure and high visibility since the year 2000 the registrants of CCA decided to voluntarily terminate registration of CCA for some residential uses such as children's play sets.

Chapter Five discusses Acid Copper Chromate (ACC), a wood treatment that has been previously registered for the same types of residential construction and agricultural applications as CCA. When the wood treatment industry came under scrutiny in the late nineteen nineties, both $\mathrm{CCA}$ and $\mathrm{ACC}$ requested a voluntary removal of their product for residential uses. Once CCA registrants cancelled their residential registration a large market was opened for residential treated wood. The registrant of ACC applied for a new registration that included residential uses. However, the combination of chromium, and other constituents in the wood, was found to be extremely dangerous to workers with occupations in construction and for the environment during waste disposal; therefore, ACC was denied registration in 2007. Chapter Six discusses injury cases, wood preservative industry opinions, and the chemical similarities of ACC and CCA-both of which contain chromium.

\subsection{JUSTIFICATION FOR THE RESEARCH}

As part of this research investigation a computer program was developed called the Mat-Ranger. This program may be used by construction industry professionals to help them make decisions on what materials to select for their construction projects. It also provides them with data on environmental consequences, or the cost impacts, of each material selected for a project. An Access database was combined with a Visual Basic 
interface, in order to create a Decision Support System (DSS) to assist developers and construction specialists in specifying materials for construction projects. The DSS provides instant feedback on the tangible and intangible costs associated with different material choices. The Mat-Ranger calculates the cost of a selected material in dollars, labor cost for installation, and presents environmental impact data. With this tool it is possible to compare the use of a recycled material with a non-renewable or highly toxic material.

Once fully developed the Mat-Ranger will have the capacity to operate as a material estimation tool. The Access database will also contain a large variety of material alternatives for construction projects. Templates will be provided for walls, decks, and fences to assist estimation personnel in performing project takeoffs. Materials are matched with their current market value and with the environmental and human exposure consequences related to the use of each product. The output presents three choices of materials ranked according to user preferences. This selector tool will have the latest scientific assessments of materials for toxicity and user cautions and warnings. The Mat-Ranger computer program is another source of information that could assist construction personnel in pursuing safe work sites and maintaining a healthy workforce. The Mat-Ranger program can be used to help alert construction workers to the hazards associated with preserved wood products. 


\section{CHAPTER TWO:}

\section{METHODOLOGY}

In order to conduct the research investigation the following tasks were performed in different phases.

\subsection{PHASE ONE}

The researcher investigated documents and texts on environmental indicators with the goal of locating resources for tracking arsenic and chromium in the water supply, soil, and air. This phase was accomplished by searching key words such as arsenic and environmental indicators in engineering journals. In addition, past environmental regulations were investigated along with how they have affected the rules governing the current topic of CCA and its pollution footprint. For example, in 2002, during a study of environmental indicators it was discovered by reviewing EPA water quality documents that arsenic and chromium are in many aquifers and public drinking sources.

In order to conduct an indicator study it was necessary to create an indicator and then connect it to a current environmental issue. In 2003 an article on CCA solid waste leaching was published in the St. Petersburg Times in Tampa Bay Florida (Hauserman, 2001). This was corroborated by research conducted at several Universities in Florida and it lead to an indicator that would measure the amount of CCA placed in landfills as an indication of down gradient water quality, specifically contamination with arsenic and chromium. Chromated Copper Arsenate wood preservatives were previously being used for children's play structures and in relation to them terms such as pressure treated, salt treated, or green wood were being mentioned in literature. 
Expanding the literature search produced results that included information on the Rubuttable Presumption Against Re-registration (RPAR) that is discussed in Chapter Three and the proposed voluntary withdrawal of registration for CCA. Other sources were located that provided working knowledge on registration, re-registration, RPAR, and the Federal Register. In the construction industry carpenters, and other construction workers, use treated wood (CCA) as if it were any other wood and this topic was investigated by reviewing journal articles in the American Society of Civil Engineers and other professional periodicals for construction worker exposure to CCA and its health consequences but no information on this subjects was located in these journals.

\subsection{PHASE TWO}

In this phase literature was reviewed that was written by the American Wood Preservers Institute (AWPI) and the American Wood Preservers Association (AWPA) including conference proceedings from the Environmental Impacts of Preservative-Treated Wood conference held in Orlando, Florida in 2004. Members of these organizations are registrants of CCA or their consultants.

In order to investigate regulations related to CCA to ascertain which agencies monitor its use, and to develop an understanding about Re-registration Eligibility Decisions (REDs), the researcher made visits to the EPA office in San Francisco. Access to the Federal Register, via a computer link, was available in their library and the Federal Register was used to investigate exemptions for arsenical treated wood.

The next research tasks were investigating studies on leaching CCA in landfills and legal databases with query capabilities. A lawsuit called Sipes $v$. Osmose was located 
that is cited in Chapter Five. The researcher telephoned the plaintiff's attorney for the Sipes case in Indiana several times in the Spring of 2006 to discuss his cases. In the summer of 2006, the researcher met with the attorney who provided depositions, transcripts, toxicological reports, and medical reports from his cases. Along with the court documentation received from the plaintiff's lawyer two large volumes containing warning labels, end use tags, Material Safety Data Sheets, and Customer Information Sheets written by CCA manufacturers and distributors were used to cross-reference the research materials.

\subsection{PHASE THREE}

Information from the following government agencies was reviewed to locate additional information on CCA such as:

- California Department of Pesticide Regulation (CDPR)

- Consumer Product Safety Commission (CPSC)

- Environmental Protection Agency (EPA)

- National Toxicology Program (NTP)

- Occupational Safety and Health Administration (OSHA)

- United States Department of Agriculture (USDA)

- Clean Air Act

- Clean Water Act

\subsubsection{Water Issues}

Data obtained from the EPA, the Santa Clara Water District, and the California Department of Health Services indicated that arsenic is found in water supplies 
throughout California. Research was also undertaken to locate technologies available for the removal of arsenic from water and soils. Personal visits to the American Canyon Water Treatment Plant in California were used to investigate waste treatment technology. The Green Building Conference that was held in San José California on April 13, 2006 by the Green Construction Council was also used to investigate other technologies for water treatment, current waste policies, and alternative building techniques. Also researched were data about materials for the Mat-Ranger Decision Support System (DSS).

\subsubsection{Scientific Advisory Board, Children's Exposure to CCA}

The researcher conducted an examination of the scientific advisory board's involvement with CCA by reviewing meeting minutes (FIFRA, 2003) and memos involving play sets containing CCA. A large part of these studies focused on the future action required for municipalities and federal and state parks with CCA structures. This included soil samples and wipe test samples along with the possibility of coating CCA wood with paints and sealers.

\subsubsection{Conference Papers and Articles}

The Ph.D. dissertation "A Strategy for Evaluating Hazardous Waste Site Remediation" by Dr. Rita Meyninger, who was the Regional Director of the Federal Emergency Management Administration (FEMA) for the east coast region of the U.S. under President Jimmy Carter and President Clinton, was reviewed and it presented insight into the political process of waste clean up and protocol (Meyninger, 1992). It also discusses the effects of exposure to multiple toxic chemicals all at once, which was 
pertinent to the CCA study as both arsenic and chromium are present in the wood, and discussed leachate and dispersion of toxic chemicals.

The National Priorities List (NPL) of toxic clean up sites was investigated by accessing the Agency for Toxic Substances and Disease Registry (ATSDR) search engine in order to determine the number of wood treatment facilities found in the U.S. The research conducted in Scandinavia dealing with CCA issues such as disposal and recycling to render the heavy metals inert was also investigated in this phase.

\subsubsection{Correspondence}

The researcher contacted Rebecca Miller, the Director of the EPA Antimicrobials Division who was in charge of CCA re-registration. She provided documentation and PowerPoint presentations during February 2007 designed to instruct registrants on current CCA rulings. Diane Isbell replaced Ms. Miller and she confirmed the postponement of Re-registration Eligibility Decisions (REDs) for CCA until the end of 2007.

\subsection{PHASE FOUR}

Due to the toxic nature of preserved wood, and the depletion of natural resources from the use of conventional wood such as cedar and redwood for exterior projects, alternative materials for construction were researched. This was accomplished by contacting material distributors and through Web searches under topics such as recycled wood, wood alternatives, and composites. At first data were analyzed by using a spreadsheet but the functionality of that interface caused inefficiency. Next, four engineers met several times to consider the best way to analyze the data and create a userfriendly interface with query capabilities. The decision was made to transfer the data to 
an Access database and to use the Visual Basic editor to connect the user interface with the data. A code writer was employed to use SQL codes to create functionality for the program. The result was the Mat-Ranger, which is a combination of a Visual Basic, userfriendly, interface with the ability to use queries for educated material selection from Access databases.

In order to complete a prototype of the Mat-Ranger for this research project, input variables for the software were limited. The user preferences were also limited in scope in this version so that fewer matrices were necessary in the database of the Decision Support System (DSS). In the current version, alternative and recycled building supplies were compared to conventional materials in order to contrast material selection choices and match them with user preferences.

\subsection{PHASE FIVE}

This phase was the writing of the thesis.

\subsection{PHASE SIX}

In this phase, the thesis was edited.

\subsection{PHASE SEVEN}

The thesis was submitted to the thesis committee for review and evaluation.

\subsection{PHASE EIGHT}

Revisions in the thesis document were made according to the input of the thesis committee, as well as a final verification of the requirements according to the San José State University Graduate Studies Office General Instructions for Master's Theses revision October 16, 2002 (SJSU GSO, 2002). 


\subsection{PHASE NINE}

The thesis was submitted to the Graduate Studies Office at San José State

University in order to complete the requirements for Master of Science in Civil Engineering degree.

\subsection{PHASE TEN}

Schedule, prepare, and defend the thesis Civil Engineering Department at San José State University. 


\section{CHAPTER THREE:}

\section{BACKGROUND INFORMATION}

\subsection{ARSENIC AND CHROMIUM}

Arsenic and chromium are known human carcinogens that have been used in the manufacturing of industrial products for decades. Arsenic occurs naturally in soil or rocks with traces of it found in water, food, trees, and plants. Arsenic and chromium are elemental heavy metals and they exist in varying valence states and containment matrices. The mediums where these metals are found are soil, water, and air. Natural events such as volcanic eruptions, erosion of rocks, and even forest fires release arsenic into the environment. Arsenic discharge is also a direct result of man-made activities such as smelting, mining, exhaust from combustion engines, the burning of fossil fuels, the incineration of wastes, pulp and paper production, wood treatment, and cement manufacturing.

In 1998 The United States used about 27,000 tons of arsenic in wood preservatives (Bleiwas, 2000). When arsenic is manufactured for industrial use, it is primarily produced as a by-product in the smelting of nonferrous metal ores such as gold, silver, lead, nickel, and cobalt. Due to its toxic nature, the production of arsenic in the United States was essentially eliminated with the implementation of the Clean Air Act amendments of 1970 due to the expense of containing the production emissions. The recovery of arsenic from the smelting of nonferrous metals takes place in seventeen countries throughout the world, with the bulk of the imported arsenic used in the United States coming from China. "In 1998, China exported...arsenic into the United States" 
(Bleiwas, 2000, p. 2). Prevalent in past agriculture use, arsenic was once employed to kill weeds, fungi, and other pests. Arsenic can still be found in common products including wood preservatives, rat poison, paints, dyes, pharmaceuticals, fungicides, pesticides, semiconductors, and some medicinal tonics. As one U.S. Occupational Safety and Health Administration (OSHA) document states, "Arsenic compounds used in agriculture as plant protection agents and pesticides have largely been replaced by metalfree compounds. In the United States, only certain preparations (e.g., those of the Ansar series) are allowed for use in some states. For wood preservatives, arsenic compounds are used solely in compound preparations. Organic arsenic compounds can be grouped into aliphatic organoarsenic compounds and aromatic organoarsenic compounds" (EPA, 1985a, p. 2).

The inorganic forms of arsenic are much more toxic to humans than the organic types found in food (WHO, 2004, p. 5):

"Association between human arsenic exposure, usually in the form of inorganic compounds containing trivalent arsenite (As III) or pentavalent arsenate (AsV), and various forms of human cancer has been established for many years. The International Agency for Research on Cancer (IARC) evaluated arsenic in 1980 and classified 'arsenic and arsenic compounds' in Group 1, which includes 'chemicals and groups of chemicals, which are causally associated with cancer in humans.' Arsenic is also known to be atherogenic, genotoxic, teratogenic, and may cause other adverse developmental effects in exposed children."

According to the Committee on Medical and Biological Effects of Environmental Pollutants, arsenic is used in medicines and it was a major ingredient in several tonics and creams used during the twentieth century. Fowler solution is made of arsenic and it has been part of medical remedies since the early 1800 's and it is prescribed especially in 
Europe for different ailments including asthma, epilepsy, and chronic skin eruptions such as psoriasis and eczema (Committee on Medical and Biological Effects of Environmental Pollutants, 1977, p. 176).

\subsubsection{Health Effects from Arsenic and Chromium}

Health issues in humans from arsenic and chromium exposure are welldocumented. According to California Proposition 65, arsenic is one of the highest ranking of 164 Developmental and Reproductive Toxicants (CA EPA, 2006). Arsenic is also seen as a Group 1 carcinogen by the International Agency for Research on Cancer (IARC) and the U.S. Environmental Protection Agency (EPA). "Evidence of significant systematic concentrations of arsenic has been found in several studies of the incidence of lung cancer in populations exposed to arsenic dust" (Committee on Medical and Biological Effects of Environmental Pollutants, 1977, p. 176).

Another consequence of direct contact to arsenic-laden dust with the mucus membranes of the nose is that it can cause a perforation of the nasal septum in only a few weeks of exposure. This perforation is seen in past cases of smelter workers and other occupations where exposure to arsenic dust exists (Committee on Medical and Biological Effects of Environmental Pollutants, 1977, p. 174). The exposure to arsenic dust can also be linked to forms of cancer, "Evidence of significant systematic concentrations of arsenic has been found in several studies on the incidence of lung cancer in populations exposed to arsenic dust" (Committee on Medical and Biological Effects of Environmental Pollutants, 1977, p. 176). Research revealed that the leaching of chemicals from Chromated Copper Arsenate (CCA) can migrate to water supplies. The 
following information was found in the Arsenic in Drinking Water report prepared for the public health goals for the Drinking Water Task Force for California in 2004 (CA EPA, 2004, p. 55):

"At relatively low acute intake levels, arsenic provokes mild gastrointestinal effects. The Feinglass 1973 Report showed the acute gastrointestinal effects...(nausea or vomiting, dryness or burning of the mouth and throat, abdominal pain, and diarrhea). One of the most common long-term indicators of acute arsenic exposure is Mees' lines: ridges that appear on the fingernails six to eight weeks after the exposure (Jenkins, 1966)...On a unit body weight basis, the trivalent form of arsenic appears to be about four times as toxic as the pentavalent form. Victims of lethal oral arsenic poisoning generally followed one of two clinical patterns. "Acute massive intoxication" occurs when the victim takes a large dose of arsenic on an empty stomach, and may be fatal within a few hours as a consequence of cardiac failure (Jenkins, 1966). In the more typical cases involving the ingestion of a lesser amount of arsenic, the first sign of poisoning occurred from half an hour to several hours after the ingestion. Initially there is throat constriction, a metallic taste in the mouth, and a garlicky odor in the breath, followed by acute gastrointestinal effects, including severe abdominal pain, vomiting, and diarrhea, sometimes with muscular cramps and headache. Finally, 24 hours to several days after the initial exposure, there is a general vascular collapse leading to shock, coma, and death...The most common were gastrointestinal and cardiac disturbances, muscle cramps and facial edema (World Health Organization, 1981)."

In another work it was discovered, "of greater concern, however, was the observation of increased incidence of mental retardation, epilepsy, and other findings that suggested brain damage in the arsenic exposed children" (Committee on Medical and Biological Effects of Environmental Pollutants, 1977, p. 187).

Chromium is also hazardous in water supplies. Exposure to continuous doses of chromium as in drinking water, or a major intake due to accidents or occupations, is possible. The International Agency for Research on Cancer stated, "human data would place hexavalent chromium compounds into Group 1, meaning there is decisive evidence 
of the carcinogen properties of those compounds in humans" (OSHA, 2006, p. 9). "Skin exposures to hexavalent chromium for children contacting treated wood surfaces exceed the OSHA level of concern for skin sensitization" (EPA, 2007a, p. 2).

\subsection{NATIONAL PRIORITY LIST (NPL) AND WATER QUALITY}

Arsenic occurs naturally in soil, food, and in many aquifers. Typically it is measured in water by assessing parts per billion (ppb). Since it has been shown that it is carcinogenic it has been monitored in municipal drinking water supplies for decades. Arsenic is expensive to remove from water and in most cases the process creates toxic waste. Arsenic and chromium are found at most National Priority List (NPL) sites, as both are within the top eighteen in the Agency for Toxic Substances and Disease Register (ATSDR) ranking system. This prevalence is also supported by the water quality research done on Class 1 carcinogens for California drinking water supplies. This study ranked arsenic as the number one contaminant found above Maximum Containment Levels (MCL) in most individual sources, "the chemical most often detected above its MCL in public water systems is arsenic" (California Department of Health Services, 2005, p. 3). The EPA has stated the following regarding arsenic in drinking water (EPA, 2006a, p. 1):

"Non-cancer effects can include thickening and discoloration of the skin, stomach pain, nausea, vomiting; diarrhea; numbness in hands and feet; partial paralysis; and blindness. Arsenic has been linked to cancer of the bladder, lungs, skin, kidney, nasal passages, liver, and prostate. The EPA has set the arsenic standard for drinking water at .010 parts per million (10 parts per billion) to protect consumers served by public water systems from the effects of long-term, chronic exposure to arsenic. Water systems must comply with this standard by January 23,2006 , providing additional protection to an estimated 13 million Americans." 


\subsubsection{Agency for Toxic Substances and Disease Register (ATSDR)}

The Agency for Toxic Substances and Disease Register (ATSDR) produces toxicological profiles for hazardous substances found at National Priorities List (NPL) sites. The frequency of occurrence at NPL sites, toxicity, and potential for human exposure are categories that create a ranking system for the 275 chemicals profiled by congressional mandate. These profiles are to be used by the U.S. Department of Defense and the U.S. Department of Energy when the contaminants are found on federal sites. Arsenic and chromium are prevalent contaminants at these NPL sites. Many pressure treatment facilities are on the NPL list due to large amounts of arsenic and chromium present in the soil and water at these facilities. In fact, the ATSDR priority list of hazardous substances for 2005 ranked arsenic at number 1 and hexavalent chromium at number 18 out of the 275 hazardous chemicals.

\subsubsection{Toxicological Profiles}

Toxicological profiles are created for substances found at National Priorities List (NPL) sites. These profiles are developed in two stages (ATSDR, 2006, p.1):

“(1) DRAFTS: The ATSDR Division of Toxicology announces in the Federal Register the release of these draft toxicological profiles for a 90day public comment period. (2) FINALS: After the 90 day comment period, ATSDR considers incorporating all comments into the documents and finalizes the profiles. The National Technical Information Service (NTIS) distributes them".

The NPL is prepared as part of the amendments to the Superfund Act that were preceded by the Comprehensive Environmental Response, Compensation, and Liability Act (CERCLA). These have established certain requirements for the EPA and for the Agency for Toxic Substances and Disease Registry (ATSDR) with regard to hazardous 
substances that are most commonly found at facilities identified by CERCLA. "Section 104(i)(2) of CERCLA, as amended (42 U.S.C. 9604[i][2]), requires that the two agencies prepare a list, in order of priority, of at least 100 hazardous substances that are most commonly found at facilities on the NPL" (ATSDR, 2005, p. 9). It is up to these agencies to use judgment in determining known or suspected exposures for humans. The agencies were then required to identify another 175 toxic chemicals in the coming years. A second priority list of 100 additional substances was published on October 20, 1988 (Federal Register 53, 1988, p. 41280), to bring the total to 200 at that time. It was also in 1988 that the revised procedure for preparing the second priority list was summarized. Federal Register 60 changed requirements so the priorities update list was required every two years (Federal Register 60, 1995, p. 16478).

Each substance on the CERCLA Priority List of Hazardous Substances is a candidate to become the subject of a toxicological profile prepared by ATSDR. These can subsequently be considered as candidates for identification as hazardous substances that need even stricter control. Once identified, these substances are considered the most significant potential threat to human health. If a hazardous substance was found at a Superfund site, the chemical received a ranking. An algorithm prepared to rank hazardous substances at these sites quantifies the substances present and the number of sites where they occur. Information on the frequency of a contaminant's occurrence, and the potential for human exposure to the substances at NPL sites, is available in ATSDR's Hazardous Substance Release Database (HazDat). This database was developed in 1991 and it contains information from public health assessments, site files, health 
consultations, toxicological profiles, and health studies. ATSDR developed HazDat to store information on hazardous substances found at NPL and non-NPL waste sites or from emergency events. HazDat provides health effects of hazardous substances on human populations.

Using this database, ATSDR and EPA developed a revised approach and algorithm for ranking substances. A notice announcing their intention to revise and rerank the Priority List of Hazardous Substances was published on June 27, 1991 (Federal Register 56, 1991, p. 29485). Subsequently, the 1991 priority list and the approach to generate it were published in the Federal Register on October 17, 1991 (Federal Register 56, 1991, p. 52166). The NPL sites throughout the United States are identified as part of the CERCLA program established in the 1980's. The priority list of hazardous substances has grown to 275 during the 1980's and 1990's (ATSDR, 2005).

\subsection{EPA REGULATION OF ARSENIC AND CHROMIUM}

Initially, monitoring and controlling arsenical acids was under the authority of the U.S. Department of Agriculture a natural choice for its location as this industry was the largest user of arsenic for herbicides. In the early 1970's, the use of arsenical acids for pesticides and herbicides in agriculture was eliminated due to the Clean Air Act, Clean Water Act, and the myriad of acts aimed at environmental protection. "All registrations of inorganic arsenic pesticides for food crops have been canceled by the EPA" (CA EPA, 2006, p. 12). In 1972, the recently created EPA was granted the authority for controlling arsenic and chromium use in consumer and industrial products. 


\subsubsection{The Occupational Safety and Health Administration (OSHA) and Arsenic}

Arsenic and occupational exposure hazards are well-documented by the Environmental Protection Agency (EPA) and Occupational Safety and Health Administration (OSHA). In 1978, the U.S. Department of Labor produced new rules for permanent exposure to inorganic arsenic and reduced the Permissible Exposure Limits (PEL). Through a directive published by the OSHA in 1978, it was written that the PEL "include arsenic, all arsenic-containing, inorganic compounds and arsine among the substances in the 'High Hazard Health' category...respiratory protection is required against any of the substances included or specified in the list that follows: (i) Arsenic trichloride, (ii) Arsenic trifluoride, (iii) Arsenic pentafluoride, (iv) Arsenic tribromide, (v) Arsenic triiodide, (vi) Arsenic monophosphide" (OSHA, 1978, p. 2). This directive applied to many industries but several exemptions to the new rules were included. The document cited occupations that would not benefit from the new laws. " 29 CFR 1910.1018 does not apply to the treatment of wood with any type of arsenic-containing preservatives and application of any type of arsenic-containing pesticides...to exposures resulting from utilization of arsenically preserved wood" (OSHA, 1978, p. 3). These rulings took place before the 1988 Insecticide, Fungicide, and Rodenticide Act (FIFRA) re-registration program for products with hazardous constituents. During part of the extended re-registration period for CCA, agreements were made between the EPA and CCA registrants to create an information campaign. This campaign included creation of Customer Information Sheets along with literature containing occupational use 
information. Material Safety Data Sheets (MSDS) were made available for occupational exposure to CCA that will be discussed later in this section.

\subsubsection{The OSHA and Chromium}

The OSHA assistant secretary found that workers exposed to levels of chromium (VI) much lower than the $2004 \mathrm{MCL}$, "face a significant risk to their health" and "are at increased risk of developing lung cancer (Federal Register 69, 2004, p. 59305). Occupational exposure to $\mathrm{Cr}$ (VI) may also result in asthma, damage to the nasal epithelia (membrane tissue), and skin" (Federal Register 69, 2004, p. 59305). However, the use of chromium as a wood preservative is regulated occupationally to a limited extent. The majority of occupations exposed to chromium including preserved wood distributors, carpenters, and demolition crews still remain unprotected by the OSHA.

\subsubsection{Insecticide, Fungicide, and Rodenticide Act (FIFRA) and Registration}

The Federal Insecticide, Fungicide, and Rodenticide Act (FIFRA) mandates that all pesticides and fungicides must be registered with the EPA. The EPA may issue registrations, which allow registrants to use controlled substances in consumer and commercial products. Registration applicants must demonstrate that products perform their intended functions without causing adverse effects on the environment-unless the benefits of the product's use can be shown to exceed its risk. Studies and public comments are welcomed during the registration process and may influence EPA decisions on product registration. 


\subsubsection{Rebuttable Presumption Against Re-registration}

As part of FIFRA, the Office of Pesticides Programs in 1978 evaluated the benefits and risks of wood preservatives to determine hazards associated with arsenicalbased wood preservatives. This review called the Rebuttable Presumption Against Registration (RPAR) is a process that accompanies registration through FIFRA and the EPA. The RPAR process was instigated to assist in the control of registered chemicals and pesticides. The focus of RPAR is to ensure current information is available on the dangers associated with a past registered product. Since CCA was originally registered before 1984, and it contains hazardous chemicals, it qualified for a review to determine if registration needed to be modified. The RPAR for CCA commenced in 1978 and was never completed due to extensive scientific reviews and concessions made by the registrants for product registration. However, a settlement in 1986 between the EPA and the CCA registrants required the registrants to provide Customer Information Sheets.

\subsubsection{The EPA Registrants}

Registrants are entities that may apply to the EPA for registration of products containing registered chemicals. Chemicals and elements are classified as hazardous due to the adverse effects they have on the environment or to human and animal health. Acts of Congress have helped to control these hazards by creating a registration procedure administrated by the EPA for their use, as mentioned previously. In the case of CCA, the registrants are chemical companies that use arsenic and chromium in water-soluble mixtures to treat wood. The American Wood Preservers Association (AWPA), the American Wood Preservers Institute (AWPI), the Society of American Wood Preservers 
Inc. (SAWP), and the National Forest Products Association (NFPA) are organizations created to help the registrants of CCA through the intricacies involved with registration. These entities represent the wood treatment registrants during legal proceedings and act as representatives during interactions with government agencies. They also may serve in a public relations capacity and assist treated wood manufacturers in marketing campaigns.

\subsection{RE-REGISTRATION OF TOXIC PRODUCTS}

During the 1980 's, as information about known hazardous substances grew, it was deemed necessary by the U.S. Congress to review products previously registered. "The 1988 amendments to the Federal Insecticide, Fungicide, and Rodenticide Act (FIFRA) authorized the EPA to conduct a comprehensive pesticide re-registration program to contain dangerous chemicals in products as additional data about their toxicity became available" (EPA, 2005a, p. 1). The re-registration process for pesticides includes an evaluation of current scientific studies and a myriad of other procedures. Further explanation of these follows in the next section.

The EPA plays a large role in the registration process and must approve all product registrations. CCA contains two registered chemicals, so it was required by FIFRA to undergo the re-registration process. During re-registration, registrants for CCA made several concessions, to be discussed later, to preserve their market share. Instead of requesting a complete registration, they requested a voluntary termination of registration for most residential uses of CCA. The EPA accepted this request in 2004 and granted amended use for CCA registrants. This amended use status has allowed continued 
production and sale of $\mathrm{CCA}$ for many of the remaining registered uses including industrial, some residential, and pressure treated wood export.

\subsubsection{Re-registration Phases}

The re-registration program established by FIFRA 1988 consisted of five phases which included deadlines and responsibilities for both the EPA and pesticide registrants. The EPA completed the first four phases by the end of 1993, and since then it has been developing Re-registration Eligibility Decisions (REDs) as part of phase 5. The five phases are (EPA, 2005b, p. 3):

Phase 1: List Active Ingredients.

- "The EPA published re-registration lists within ten months of FIFRA 1988.

- Registrants requested to identify pesticides intended for re-registration.

- Phase 1 was completed on October 24, 1989.

Phase 2: Declare Intent and Identify Studies.

- The EPA received notice from registrants about intended product re-registration.

- Registrants identified and committed to providing necessary new studies.

- Registrants paid the first installment of the re-registration fee.

- The EPA guided registrants for preparing phase 2 and 3 responses.

- Phase 2 was completed in 1990.

Phase 3: Summarize Studies.

- Registrants submitted summaries, identified studies indicating adverse effects, re-committed to satisfying data requirements, and paid the final installment of the re-registration fee. 
- Phase 3 ended in October 1990.

Phase 4: EPA Review and Data Call-In.

- The EPA reviewed phase 2 and 3 submissions; required registrants to meet unfulfilled data requirements within four years.

- Phase 4 was completed in 1993.

Phase 5: Re-registration Decisions.

- The EPA continues to review the studies supporting re-registration.

- The EPA is deciding whether each case is eligible for re-registration-that is, whether the database is substantially complete and pesticides can be used without unreasonable adverse effects on people or the environment.

- The Agency is considering whether pesticides meet the new Food Quality Protection Act (FQPA) of 1996.

- Results of the Agency's reviews are presented in Re-registration Eligibility Decisions (REDs). Even after REDs are completed, pesticides still must complete product re-registration to implement labeling changes and risk mitigation measures."

- This deadline was recently extended to December 2007 (EPA, 2007b).

\subsubsection{Re-registration Eligibility Decisions (REDs)}

A RED is a six-phase process undertaken by the EPA during re-registration of pesticides. Rebecca Miller of the EPA's Antimicrobials Division supplied the researcher via email on June 15, 2006 with a condensed list of a RED process provided below (Miller, 2006):

- Phase 1: The EPA sends risk assessment to technical registrants for an error correction review.

- Phase 2: The EPA considers errors identified by the registrant(s) and completes the risk assessments for public release.

- Phase 3: The EPA publishes a Federal Register notice announcing availability 
of the risk assessments and related documents from the public docket and the EPA's Web site, and opens a 60-to 90-day comment period.

- Phase 4: The EPA considers public comments from Phase 3, revises the risk assessments as necessary, prepares a preliminary benefits characterization if needed, and works on initial risk reduction options. The EPA may host a Technical Briefing and/or stakeholder meeting(s) to discuss the revised risk assessments, the preliminary benefits characterization, and initial risk reduction options.

- Phase 5: The EPA publishes a Federal Register notice announcing availability of the revised risk assessments, preliminary benefits characterization and response to comments while inviting public comments for the next 60 days. Federal agencies begin a dialogue with stakeholders on risk reduction and risk management.

- Phase 6: The EPA considers comments and risk management ideas submitted with input from other agencies and stakeholders, the EPA develops a risk management decision. The EPA releases the decision, including a benefits discussion/assessment as needed.

Once the EPA has issued a RED the pesticide is then eligible for re-registration decision. If end use products contain pesticides they also must be registered through the product registration process. In some cases the products may be required to have labels or warning literature accompany products as part of the registration agreement. Memoranda of agreements may also be used to aid in risk reduction measures before product re-registration is completed. The re-registration and the RED process for CCA are both in the fifth phase.

Many decisions have been delayed regarding CCA due to ongoing scientific studies and moves by registrants to restrict uses of their product or to create warning literature. These actions by CCA registrants during the process have had the effect of convoluting objectives for the EPA. However, the Pesticide Registration Improvement Act (PRIA) of 2003 became effective on March 23, 2004. Among other things, PRIA 
directed the EPA to complete REDs for pesticides with food uses and tolerances by August 3, 2006 (EPA, 2007b), and to complete REDs for all remaining non-food use pesticides by October 3, 2008" (Isbell, 2007).

All the food uses and tolerances REDs were completed by December of 2006 according to Diana Isbell, the Acting Team Leader for CCA re-registration of the EPA Antimicrobials Division (Isbell, 2007). Also, the ongoing REDs for non-food uses were delayed due to the deadline imposed by the Pesticide Registration Improvement Act for food tolerances. The outlook for completion by the October 2008 deadline is positive; however, a depleted staff must complete more than 160 REDs. Possible actions during the RED process before a product is eligible for re-registration are (Isbell, 2007):

- Voluntary withdrawal of registration

- Restricted use pesticide classification

- Personal Protective Equipment (PPE)

- Restricted Entry Intervals (REI)

- User safety requirements and recommendations

- Improved use directions and precautions

- Ground or surface water safeguards

This condensed list includes the terms that are most applicable for pressure treated wood. As mentioned above, some of these actions have been instigated by CCA registrants prior to December 2006. 


\subsection{CONSESSIONS BY REGISTRANTS}

Although established links between CCA and human illness exist, currently no laws ban the use of CCA. However, through the course of re-registration and RPAR proceedings, the registrants of CCA have made concessions to try to alert consumers about their products and they have voluntarily withdrawn residential CCA re-registration.

\subsubsection{CCA End Use Tags}

End use tags identify a registered product after a construction site or a distributor receives the product. These tags trace the product to its source and allow end users to locate the type and concentrations of chemicals included in it. The pertinent compositions of the mixtures, and the percentages of the active ingredients such as arsenic and chromium, are also listed on the tags. Each piece of CCA-treated lumber must have a tag attached to it. The front side of the tag identifies the end use purpose for the material and the back side contains the warnings. Most tags describe the explicit formula of CCA for certain types of construction applications. See Figure 3.1 for an example of an end use tag (AWPA, 2004). 


\begin{tabular}{|l|}
\hline MARINE PILING \\
CCA 2.50 AWPA C3 \\
ANYTOWN, USA \\
ABC TREATING CO. \\
See reverse side for safety information \\
2004-2005
\end{tabular}

$2004-2005$
- Caution: Arsenic is in the pesticide applied to this wood

- Some chemical may migrate from treated wood and may also be dislodged from the wood surfaces on contact

- Never burn treated wood

- Wear a dust mask and goggles when cutting or sanding wood

- Wear gloves when working with wood

- Wash exposed parts of body after working with treated wood

- Obtain safe handling information by calling 800-282-0600 or at www.ccasafetyinfo.com, and request a Material Safety Data Sheet from your supplier/employer

Figure 3.1: An Example of an End Use Tag

\subsubsection{Consumer Information Sheets (CIS)}

Consumer Information Sheets (CIS) are part of registration and RPAR requirements for CCA. The CISs are created for products containing hazardous constituents in order to inform product users of potential health risks. CCA, Acid Copper Chromate (ACC), and other wood treatments were shown during registration periods to be potentially harmful to human health or the environment. As part of the EPA's plan to prevent unnecessary exposure to the chemicals in CCA they require manufacturers to provide information to consumers. This information supplies methods for safe handling of CCA and some use precautions. These sheets are mandated by the registration process and are required to be distributed with the treated wood. The registrants and distributors of CCA are required to supply this information to potential CCA users (EPA, 2005b).

\subsubsection{Material Safety Data Sheets (MSDS)}

Material Safety Data Sheets (MSDS) inform interested parties about products and possible hazards associated with the handling, use, and storage of products. Safety and 
emergency information is also provided in the literature. The MSDS, in its current form, was an evolution from a series of past similar documents. The origins may have been from chemists exchanging information about experiments and chemicals. They became federally-mandated documents in the mid-1980's in their present form. The MSDS is required to accompany all products with hazardous constituents and employers must have them available for workers at job sites and manufacturing facilities. The MSDS for CCA has changed content many times due to discoveries about hazards presented by arsenic and chromium since the 1970's. This topic is discussed further in the Chapter 5.

\subsection{DISPOSAL AND EXEMPTIONS}

\subsubsection{Disposal and CCA Waste}

Arsenic, chromium, and copper are regulated at waste sites due to their hazardous classification, but when these constituents are present in wood treatment, or wood waste, solid waste laws do not regulate them. Disposal of these potentially hazardous materials is permitted due to exemptions in the Hazardous Solid Waste Rules. The exemptions are based on the fact that soil contact is consistent with registered uses of CCA-treated wood. The direct burial method for solid waste has been equated with soil contact, which is legal for CCA. Hence, direct burial is the permitted method of disposal for CCA wood and preservative operation waste. Using this method of disposal means that hundreds of thousands of tons of waste products from CCA wood, such as cut off pieces and sawdust, are placed in landfills. Thus, the dangerous chemicals in the wood increase the amount of toxic chemicals reaching soil and water tables. 
Since many landfills are not lined, water percolates through the waste into surrounding soils. A combination of chemicals, organic composting compounds, liquids, mixtures, and water found at waste sites create leachate. Toxic leachate is an issue at waste sites, in surface water, and in aquifers. The leachate travels through the waste into the soil and it eventually reaches the subsurface water. Recent studies in Florida indicate the amount of arsenic in water supplies down gradient from landfills is consistently increasing over time. This contamination of water supplies is predicted to spread as a result of unmonitored CCA disposal (Khan and Jambeck, 2006).

\subsubsection{Construction and Demolition Waste Sites}

Construction and demolition (C\&D) waste is measured by tonnage, or by the cubic yard, and most landfills charge a flat fee for disposal of these materials. The gross tonnage of arsenic treated lumber disposed of in landfills is not available because it is not tracked as a separate waste. Construction and Demolition landfills accept a large array of materials and have less governmental scrutiny than public facilities. This is demonstrated by the materials permitted to enter these sites (EPA, 2006b, p. 4):

"These landfills accept C\&D debris such as concrete, asphalt, brick, wood, drywall, asphalt roofing shingles, metals, and some types of plastics generated during the construction and demolition of homes, commercial buildings, and other structures. C\&D landfills are subject to less stringent standards than municipal solid waste landfills due to the relatively inert nature of C\&D debris materials."

This policy allows construction companies to dispose of construction waste with relative impunity. It is recognized that "wood" in the above list of C\&D acceptable items includes pressure treated CCA lumber. A study conducted by H. M. Solo-Gabriele at the University of Miami states that the wood waste "in the C\&D wood can contain up to wt. 
$30 \%$ " (Khan and Jambeck, 2006, p. 994). These landfills are not monitored for leachate and other possible emissions after they reach capacity and are closed to further dumping. Therefore, the landfills present a large quantity of heavy metals for assimilation to soil and groundwater. "Leachates are a main source of groundwater pollution and therefore they must be contained properly at landfills" (Holtz, 2006, p. 634). Many dumpsites have no liners and in others the liners are deteriorating. Landfill liners may have soil compositions such as thick rock, compacted clay, aggregate, or even thick layers of dense soils with a combination of fabrics or concrete. These liners are necessary for containment of leachate, a highly concentrated mixture produced from the condensation and the decomposition of materials buried in landfills. Mitigation of toxic runoff water at landfills, and a separate lined dumping area for waste that contains arsenic, would be beneficial. Control measures are in place to restrict the dumping of creosote-treated lumber and similar measures for CCA are included in future California, Connecticut, Florida, and other state dumping laws (EPA, 2006b). Currently, no laws exist for CCA waste, as numerous exemptions apply in solid waste rules for these materials.

\subsubsection{The EPA's Current Stance on CCA Solid Waste}

In 1980, CCA lumber was nearly reclassified by the EPA as a hazardous material based on new standards for extraction procedure toxicity. In May of 1980, the Extraction Process (EP) toxicity rule became effective. In July of 1980 , the American Wood Preservers Institute (AWPI) stated in their recorded public docket comments, "possibly some wood treated with arsenical-based preservatives exhibits the characteristics of Extraction Process (EP) toxicity and therefore might be classified as a hazardous waste 
when disposed of. The AWPI therefore requests a delay in the regulation's effective date with respect to arsenical-treated wood" (Federal Register 45, 1980, p. 78530).

Other comments received from the AWPI in response to the EP toxicity claimed that preserved wood is "not hazardous" and asked the EPA to "clarify its regulations to indicate that all types of preserved wood, including arsenical-treated wood, do not constitute hazardous waste when disposed" (Springer, 2004, p. 1). Two reasons were given for this request: (1) The burial method for disposal of wood treated with arsenicalbased preservatives is identical to the registered uses of the treated wood namely, ground contact. (2) The Office of Solid Waste should wait for the outcome of the pending examination of the wood preservative. The EPA granted the AWPI request and created an exemption to the EP for arsenical wood preservatives in 1980 , but the ruling and exemption were to be temporary. "It should be noted that the decision to await further progress of the RPAR review does not signify that discarded arsenical-treated wood and wood products will be excluded permanently from all Subtitle C requirements" (Springer, 2004, p. 1).

"The Environment Protection Agency is amending the hazardous waste regulations (40 CFR 261.4(b)(9)) (Springer, 2004, p. 1) to provide that all arsenicaltreated wood or wood products which are generated by people who utilize such wood for its intended end use, and which constitutes hazardous waste solely because it fails the test for the characteristic of Extraction Procedure toxicity, is not subject to regulation under 40 CFR Parts 262 throughout 265 or parts 122 through 124 or the requirements of section 3010 of RCRA" (Federal Register 45, 1980, p. 78530). This exemption will be effective 
until the Office of Pesticide Programs progress in its review of arsenical-treated wood preservatives; there are no deadlines. This temporary exclusion from subtitle (c) is in effect as of November 1980 for arsenical-treated wood waste. The Federal Register exemption for CCA wood waste states: “(b) Solid wastes which are not hazardous wastes...waste which consists of discarded arsenical-treated wood or wood products which fails the test for the Toxicity Characteristics for Hazardous Waste Codes D004 through D017 and which is not a hazardous waste for any other reason if the waste is generated by persons who utilize the arsenical-treated wood and wood product for these materials' intended use" (Federal Register 45, 1980, p. 33119).

However, the EPA "believes that Subtitle C requirements should apply immediately to arsenical-containing wood wastes such as waste generated by sawmills or by facilities at which arsenical preservatives are applied to wood...these generators' waste may be in the form such as sawdust which presents a risk dissimilar to those which the RPAR review will analyze" for the typical dimensional CCA building materials (Federal Register 45, 1980, p. 78531). Chromated Copper Arsenate treated wood fails the EP for not only arsenic, but also chromium as well. This conflicts with subpart D of the rules. If waste products fail the EP for chromium, they are not to contain another chemical, which also fails EP and still qualify for the exemption. To clarify the exemption, the Federal Register states, "(6)(i) Wastes which fail the test for the toxicity characteristics because chromium is present... which do not fail the test for the toxicity characteristic for any other constituent" (Federal Register 45, 1980, p. 33119) may be 
considered exempt. However, the CCA wood fails the EP test for both arsenic and chromium and might be in violation of subpart D (Federal Register 45, 1980, p. 33119).

\subsubsection{Incineration of Wastes}

Incineration of disposed material is a means of condensing waste. However, the hazards of burning CCA wood are numerous; for example, the combustible fumes produced when burning CCA-treated wood waste are toxic. This procedure produces emissions that are hazardous to humans and the environment. In the United States, burning CCA-treated materials without proper safeguards violates the Clean Air Act due to the arsenic released in the smoke. Incinerated CCA wood produces an ash that contains concentrated arsenic and chromium that is acutely toxic to humans and consists of highly concentrated arsenic, chromium, and copper found in the same ratios as in the wood preservatives (EPA, 2007a). 


\section{CHAPTER FOUR:}

\section{LITERATURE SEARCH}

\subsection{CCA TOXIN STUDIES}

In the "Release of Arsenic to the Environment from CCA-Treated Wood: Leaching and Speciation during Service" study, it stated that, "We found average arsenic concentrations of 600 micrograms a liter in rain water runoff from a CCA-treated deck, more than 100 times higher than in runoff from an untreated deck" (Khan and SoloGabriele, 2006, p. 988). In this study, it was also determined that the amount of arsenic contained in the soil under the structures was at least 15-30 times higher than in a control deck. It was also reported that toxins migrated through the soil under the deck.

Also of issue was the amount of arsenic that was still present in the wood after it had leached a significant amount. Treated wood continues leaching chemicals even after long periods of time such as up to twenty or thirty years. The team then estimated that once a structure is taken out of service, $60 \%$ of the chemicals remain in the wood. These chemicals end up in landfills and they migrate with the leachate into the groundwater. The situation in Florida is especially dangerous where these studies were undertaken because of the close proximity of the groundwater table to the surface of the soil.

At Miami University in Florida, decks of CCA wood were built to simulate residential and industrial use to ascertain the degree of exposure that current deck users are experiencing. The wood is exposed to ultraviolet radiation by natural sunlight and to rain. Runoff water was collected and tested for arsenic levels. The results of this study 
show conclusive evidence of leaching CCA chemicals in the runoff (Khan and SoloGabriele, 2006).

Several test procedures were created to determine the chemical salt residue available on the surface of CCA-treated wood. This surface residue is easily absorbed through the skin. Therefore, to determine the amount of arsenic and chromium released into the surface of the wood during normal wear and weather patterns, the testing methods were calibrated and standards were determined to set a base line. The issue was to determine if swab tests for the chemicals in pressure-treated wood are effective in determining the levels of the chemicals released in typical skin to wood contact. The result of the swab tests show the different swab methods were not consistent in measurement; however, all swabs produced levels of arsenic from CCA much higher than control wood swabs.

In a collaboration undertaken at three Florida Universities: the University of Miami, the University of Florida Gainesville, and Florida International University researchers studied the amount of arsenic released from CCA wood during its use as deck boards (Khan and Solo-Gabriele, 2006). High levels of arsenic found at 10-100 times the regulated amounts where present under all decks built with CCA-treated wood with the control decks leaching no significant amount. The soil under the CCA decks was severely contaminated. The results of the research suggest that the chemicals continued leaching from the wood for the entire in-service period because the older decks had larger quantities of CCA chemicals in the soil samples. This discovery prompted the researchers to initiate a data analysis of the annual CCA wood production in Florida. The 
data collected in this study were analyzed using statistical methods to estimate the amount of arsenic introduced into the Florida environment from in-service wood. Another statistical method was then employed to determine how much arsenic remains in the wood at the time of disposal. The analysis determined the amount of the chemicals expected to reach groundwater exposed to landfill leaching in the near future. The results indicated that most wood will only leach $40 \%$ of the chemicals during in-service years (approximately thirty years) and the rest will come out of the wood in the leachate at landfills. Wood that is taken out of service early obviously will have a higher chemical content that will leach into the landfills.

In the same article, it states that "arsenic is added to the wood in its pentavalent oxidation state...arsenic accounts for $22 \%$ of the CCA chemical by weight and concentration in the treated wood that can range from 1,900 to 19,000 $\mathrm{mg} / \mathrm{kg}$ " (Khan and Solo-Gabriele, 2006, p. 988). The concentration level discovered in the lab was confirmed by the American Wood Preservers Association (AWPA) and then used as a baseline for determining the quantities listed in the results of the study. The results from this study demonstrate that toxic chemicals are bound for landfills in Florida where an exceptionally shallow groundwater table exists since the chemicals could easily migrate into the water table.

Another study called "Release of Arsenic to the Environment from CCA-Treated Wood: Leaching and Speciation during Disposal," focused on the disposal of CCA waste in construction and demolition solid waste landfills and municipal solid waste sites (Khan and Jambeck, 2006). Lysimeters were constructed and typical landfill material was 
placed inside in an effort to simulate the conditions at construction and demolition landfills. The resulting runoff was tested for arsenic and other chemicals with a focus on the speciation of arsenic and the concentration levels due to CCA waste. Consistently, the levels of arsenic were hundreds to thousands of times higher than the control lysimeters that contained no CCA waste. The speciation of arsenic was beyond the scope of the research investigation, but the study revealed that several different inorganic and two organic species of arsenic were present in the leachate studied during the research.

In another part of the study, groundwater was tested in twenty-one Construction and Demolition (C\&D) debris sites. Water samples were taken from groundwater above and below the gradient of the sites with significant arsenic concentrations revealed in several of the down gradient samples. The results were not as significant as expected due to several factors: the distance that arsenic can travel through soils in a short time, the composition of the soil medium, and the extraction of arsenic from the wood is relatively constant similar to a timed-release formula.

The migration of leachate through the debris into the soil below a site is continuous. Once the leachate reaches the soil layers, the distance the contaminants travel in a certain time will vary due to soil classification, temperature, and the constituents of the leachate. This migration, along with the relatively slow release of arsenic from the wood, are the main factors cited for the lack of extensive contamination in the water sources study results. However, the study estimates the problem of arseniccontaminated groundwater will not reach its apex until the year 2100 when most water supplies below landfills will contain large levels of arsenic from CCA waste. 
A formula was developed to extrapolate the amount of arsenic found currently in the soil into a future projection. This formula projects high levels of toxins for the future groundwater in the vicinity that is below the landfills for the next hundred years.

In the "Variability in Evaluating Environmental Impacts of Treated Wood" study, toxic exposure to non-target organisms from pressure-treated lumber, and the accumulation of toxins in the environment, was the topic of this work produced for the preservative-treated wood conference held in February of 2004 (Lebow and Cooper, 2004). One of the papers presented at the conference differentiated between in-service tests of existing structures and the observational and controlled experiments typically performed in laboratories. This study dealt with many variables, as is the nature of the science of wood preservation and any comprehensive study. The variables included (Lebow and Cooper, 2004):

- The species of wood

- The type of wood preservative

- The type of treatment equipment and techniques

- The temperature the process is completed in

- The percentage of active ingredients

- Drying systems

- The preservative's ability to assimilate to the different parts of the wood, such as heartwood

This paper also examined a broad range of past experiments on leaching and preservative fixation along with the difficulties experienced in the treatment process. It illustrates the wide range, and varying skill, of the labs or scientists performing 
experiments. This paper acknowledged the difficulties with treating the various types of wood and the numerous issues that affect results such as grain, end grain, sap wood, and heartwood moisture content. The $\mathrm{pH}$ levels of the soil, and the acid content of the water used in the runoff simulations, also were noted as reasons for inconsistencies in the results (Lebow and Cooper, 2004).

\subsubsection{Removal of Metals from CCA Waste}

Carol A. Clausen and William R. Kenealy produced a work called "Scaled-Up Remediation of CCA-Treated Wood" in which they discussed a technique available for neutralization of toxic elements of CCA wood waste (Clausen and Kenealy, 2004). Bioremediation is one technique to remove arsenic, copper, and chromium from treated wood waste. This technique is at least $94 \%$ effective in removing arsenic and the results for chromium show even more efficacy. This technique is a two-step sequence of oxalic acid extraction and bioleaching with a metal-tolerant bacterium. The wood waste is placed in a chipper, ground down, and then sent through the process with the potential to recover the metals for re-use or safe disposal. The method is cost prohibitive for largescale projects but the author of the study claims it will become economically feasible if CCA waste disposal is restricted or regulated in the near future. Hazards exist in the chipping and grinding processes as large quantities of small contaminated particles are created.

\subsubsection{Leachate from Construction Waste}

The Journal of Environmental Engineering published an article in March of 2002 about the leaching of arsenic and chromium from the disposal of CCA-treated lumber 
into unlined landfills (lida, 2004). The article discusses an experiment that was performed to determine the constituents' levels that exceed the allowable limits in water quality standards. Among the constituents over the allowable limits was arsenic. The arsenic in these samples was determined to be present due to the leaching of CCA-treated lumber. The conclusions of the study included a discussion regarding the need to contain this waste in lined landfills and the amount of dilution and attenuation necessary to prevent the constituents from exceeding water quality standards. The abstract of this article stated, "Leachate from unlined landfills poses a potential risk to groundwater quality" (Weber, 2002, p. 237).

The arsenic from the CCA is contributing to the leachate in landfills and will continue to leach toxic constituents as the wood is exposed to moisture. The pollution of groundwater in proximity to unlined landfills is dangerous due to the toxic leachate created at unlined landfill facilities. "Arsenic was the only primary water quality standard that was exceeded" (Weber, 2002, p. 237).

\subsubsection{Groundwater Polluted by Municipal Landfills}

According to the work called "Groundwater Pollution by Municipal Landfills: Leachate Composition, Detection and Water Quality Significance," the leachate compositions from municipal landfills are causing irreparable harm to domestic water supplies. Additionally, current treatment processes do not restore water quality (JonesLee and Lee, 1993). This necessitates prevention of contamination from the Municipal Sanitary Waste Landfills and leachate containment. Another concern is the 55,000 U.S. landfills $75 \%$ of which are polluting groundwater. These numbers do not include the 
thousands of construction and demolition waste sites that have fewer restrictions. These sites have accepted construction wastes considered "inert;" however, once exposed to leachates, they become mobile. The groundwater detection systems at waste site were also considered ineffective at monitoring leachate, and were only valuable after a severe groundwater contamination had occurred. This article's authors were in favor of better monitoring of the constituents entering landfills since current procedures do not detect small containers of hazardous waste. In addition, a new standard for determining hazardous waste should include not only the Toxicity Characteristic Leaching Procedure (TCLP), but also the exposure to leachate (Jones-Lee and Lee, 1993).

The "Abstract-Control of Chromated Copper Arsenate Wood Incineration Air Emissions and Ash Leaching Using Sorbent Technology" article focused on the leaching of arsenic and chromium from ash created during combustion of CCA wood. In an effort to contain these volatile metals in the ash, experiments were preformed where constituents were added to CCA lumber during the combustion process (Iida, 2004). Calcium-based sorbents successfully contained up to $85 \%$ of the arsenic and slightly less chromium in the leaching of the ash. The toxic fumes during the process of combustion were not addressed in this experiment, but the results show possibilities for future disposal technologies of CCA (lida, 2004).

The "Alternatives to Chromated Copper Arsenate (CCA) for Residential Construction" article by Stan Lebow, examines many alternative wood treatments. Mr. Lebow undertook this research while the U.S. government employed him; therefore, the results are public domain information and not subject to copyright (Lebow, 2004). The 
research focused on the need for alternative products to replace the CCA preservatives currently experiencing voluntary withdrawals from registrants for residential uses. This withdrawal will increase the need for alternative treatment products. The alternatives investigated in this study include:

- Acid Copper Chromate (ACC)

- Alkaline Copper Quaternary (ACQ)

- Copper Azole (CBA-A and CA-B)

- Copper Citrate (CC)

- Copper dimethyldithiocarbamate (CDDC)

- Copper HDO (CX-A)

The author of this study states that the retention rate for the chemicals in the wood is equivalent to that of the CCA product. However, since these are typically copperbased, and the other components have not been identified as mammalian carcinogens, these alternatives should be readily accepted by consumers for replacement of CCA in residential applications.

The article also discusses the removal of CCA for some residential uses and clearly states that CCA will continue to be used for other purposes such as (Lebow and Cooper, 2004):

- Residential permanent wood foundations

- Sawn structural piles used to support residential structures

- Sawn building poles and piles and posts used in agricultural applications

- Wood of all dimensions used in salt water subjected to marine borer attack 
- Utility pole cross arms in residential neighborhoods

- Engineered wood products e.g., glue laminated beams, timbers, and plywood.

The challenge of developing a new wood preservative received a great deal of attention in this article. The limited amount of information available on most of the alternatives has created an atmosphere in which testing and studies are rapidly progressing to assess the possible drawbacks or hazards to alternative treatments. For most of the alternative products the release of active ingredients are unavoidable and the degree of the effect on the surrounding environment and animal species could be significant.

According to Lebow and his co-authors, the research was to determine the proper treatment requirements needed for each specific wood application. In the past, CCA chemicals were concentrated to levels far beyond what was necessary for their intended use. In the specialization of preservatives for specific locations, and the ability to effectively prescribe less hazardous and less concentrated chemicals, one can reduce the release of toxicants to the environment. In other words, the use of a building material can be matched with the proper level and type of chemical treatment so that the release of hazardous chemicals is potentially reduced. Another objective in the study was to develop non-toxic alternatives to preserved wood and other building products.

Thermochemical conversion for CCA waste was the subject of a paper written by Lieve Helsen and Eric Van den Bulck at Katholieke University in Belgium (Helsen, 2004). In the introduction to their work, they state that many European nations regulate the disposal of CCA and the waste stage has a significant impact on the life cycle 
assessment of CCA products. The chemical processes and technique for extraction of the metals in the CCA waste were beyond the scope of this research, but the authors claim the results are promising (Helsen, 2004).

\subsubsection{Biological Treatment}

Biological treatment designed to remove arsenic from soil, waste, and water is an emerging remediation technology. The references located identified only a limited number of projects treating arsenic biologically. However, this technology promotes precipitation/coprecipitation of arsenic in water or leaching of arsenic in soil and waste. The leachate from bioleaching requires additional treatment for arsenic before disposal (EPA, 2002).

Electrokinetic treatment is a remediation technology designed to remove heavy metal contaminants from soil and groundwater that is most applicable to soil with small particle sizes, such as clay. Electrokinetic treatment is less applicable when multiple contaminants exist. Applications of this technology to arsenic are limited but effective. Low density current is applied to the soil in order to mobilize the contaminants. This can be accomplished by submerging electrodes into the medium then applying a current. The result is a movement of ions, water, and other elements. According to the "Arsenic Treatment Technologies for Soil, Waste, and Water" article contaminants reach the electrodes and can be removed by "electroplating or electrodeposition, precipitation or coprecipitation, adsorption, complexing with ion exchange resins, or by pumping of water (or other fluid) near the electrode" (EPA, 2002, p. 12). 
Phytoremediation "involves the use of plants to degrade, extract, contain, or immobilize contaminants in soil, sediment, and groundwater" (EPA, 2002, p. 12). This technology is limited to contaminants near the surface where plant roots can reach them. The various types of plants that can be used effectively for this process are poplar, sunflower, cottonwood, Indian mustard, and corn. However, because phytoremediating can cause plants to accumulate high levels of arsenic, they require additional treatment before disposal. This method has been used for groundwater, surface water, soil, leachates, and municipal wastewater with varying degrees of success.

Viable alternatives for CCA are being tested to determine if they will withstand the natural hazards found in the environment. One study analyzed the performance of a new alternative preservative when it is subjected to termites. In the past, tests have lasted up to five years to determine the effectiveness of combating the destructive insects. In the analysis of Coptotermes formosanus (a type of termite), testing techniques were created in 2005 by W. Ramsay Smith and Jay Curole at Louisiana State University. They worked in tandem with the "Louisiana Forest Products Development Center to determine if more intensive laboratory testing may be used to shorten the field testing time for effectiveness against $C$. formosanus by increasing the termite intensity in small scale designs" (Smith and Curole, 2005, p. 1). The results of the study show that it does not appear to be possible to increase the field-testing rate without disturbing the results. Therefore, the true performance of CCA alternatives will not be known until they can be studied in the field for many years. 
The MSDS Pocket Dictionary is a guide for understanding Material Data Safety Sheets (Genium, 1993). It is designed to instruct workers and employers on how to use the MSDS to its greatest potential. The dictionary explains the order of information in the MSDS sheets, and where to find handling or equipment requirements. It also defines acronyms that are used by the OSHA, the EPA and others commonly found in MSDS sheets. An excerpt from the second section of the dictionary is provided here to give insight into the contents of the dictionary (Genium, 1993, p. 10).

"Exposure levels are set for healthy adult workers, based on an average of 150 pound male, age 25-44. Lower exposure levels are necessary for people at higher risk; i.e., those who are young or elderly, pregnant, smokers, etc., or workers who have been exposed to other materials for which exposure limits have been set. Exertion increases the effects of exposure. Exposure to more than one hazardous substance at a time can be especially harmful, because the combined effects of more than one material can prove more damaging than the additive effects of each material (e.g. $2+2=10$ ). This is called synergy."

\subsubsection{Sealant Studies}

Studies conducted by the U.S. Department of Agriculture's Forest Products Laboratory on the ability of painting products to penetrate CCA-treated wood indicate poor penetration. The EPA and Consumer Product Safety Commission (CPSC) have indicated paints, which do not penetrate surfaces, create a film that might cause paint to peel or chip. This is undesirable because consumers will scrape or sand the chips releasing arsenic and chromium laden dust. The studies were conducted with painted CCA wood exposed to rainfall. Even though the paint may crack or peel, the short-term effect was to contain $99 \%$ of the CCA chemicals. Desired coatings are sealants that penetrate the surface of the wood. "It was suggested that the effectiveness of the coatings 
was related to their ability to limit water movement into and out of the wood" (EPA, 2006c, p. 1).

In the "Studies Provide Public with Updated Information on CCA-Treated Playground and Decks" article it states that (EPA, 2006c, p. 1):

The "EPA and the U.S. CPSC are providing updated information on the effectiveness of sealants and stains in reducing potential exposure to arsenic from CCA-treated wood used in residential settings. For homeowners and others who want to reduce their potential arsenic exposure from their decks or other CCA-treated wood structures, new studies show that use, at least once a year, of an oil- or water-based, penetrating sealant or stain can reduce arsenic migrating from the treated wood. The data show that oil- or water-based sealants or stains that can penetrate wood surfaces are preferable to products such as paint, because paints and other film-formers can chip or flake, requiring scraping or sanding for removal, which can increase exposure to arsenic. Consumers should consider the required preparation steps (e.g., sanding, power washing, etc.) before selecting a product to minimize potential exposure to arsenic, both for initial application and re-coating."

\subsubsection{Love Canal}

Health effects caused by exposure to a combination of toxic chemicals were the main reasons the area surrounding the Love Canal in Niagara, New York was evacuated in 1978. The homes in the surrounding area of the Love Canal were purchased by the Federal Government and demolished. The canal was going to be turned into a commerce avenue but it was never completed. However, a large excavation was completed on this project. Love Canal was used as a landfill and an unmonitored chemical waste dump for many years after the canal was abandoned. The mixture of chemicals created leachate, which was exposed to seasonal water flow through the canal. The combination of water ebb and flow and leachate was responsible for a large contaminated area surrounding the canal. In times of heavy rain, the leachate surfaced in backyards and it also migrated to 
basement sump pumps. These incidents caused an increase in the number of health issues (cancer and miscarriages) experienced in the residents that lived near the canal. The EPA and other agencies undertook a massive clean up effort and planned a health study of the individuals from the area. It would have been the largest study of toxic exposure pathways undertaken on any population in U.S. history. Most studies only undertake the impact of one chemical or toxin at a time. This study would have revealed some of the health issues experienced by exposure victims when there is a combination of contaminants involved simultaneously. However, the budget for this study experienced some difficulties and the money was never allocated (Meyninger, 1992).

At the University of Wollongong in Australia, a report of detailed research by Professor Sharon Beder shows that in-place structures such as picnic tables, home decking, handrails, grape vine stakes, and garden edging all contain arsenic that dislodges on contact and is spread to more sensitive areas such as water or in the human body. She stated that "children who play on CCA structures are particularly vulnerable because of their hand-to-mouth activity" (Beder, 2003, p. 34). She also voiced concerns about the ubiquitous treatment of CCA in Australia where the lumber is sold in hardware stores without any warnings (Beder, 2003). 


\section{CHAPTER FIVE:}

\section{RESULTS}

\subsection{EXPOSURE TO CHROMATED COPPER ARSENATE}

Wood treatment industry workers are exposed to concentrated levels of arsenic and chromium in CCA when they apply the treatment to lumber products. When construction personnel work with these products, they are being exposed to known carcinogens and they may not be aware of it. This exposure may cause illness, and other negative health effects, to workers (Johnloz, 1995). Nonetheless, the use of CCA as a wood preservative continues in many commercial, agricultural, residential, and governmental construction projects. As discussed in Chapter Three, some residential uses of CCA have been voluntarily terminated due to the connection to adverse health effects but most industrial and commercial construction workers are being exposed on a daily basis to arsenic and chromium.

\subsection{THE LIFE CYCLE OF CCA WOOD PRODUCTS}

The progression of toxic exposure due to the use of CCA as a wood preservative is multifaceted. The most hazardous exposure to CCA occurs during the manufacture of the treatment and during the delivery of arsenical acid and chromium. The next occupational exposure in the progression happens during the wood treatment phase where the concentrated CCA is applied to wood in vats or by hand brushing. All levels of employees in the distribution process are exposed to CCA during warehousing and delivery. Members of the construction industry face many hazards associated with CCA. The cutting, nailing, and placement of the treated wood releases heavy metals that are 
absorbed through the skin, the eyes, the mouth, the nose, and the lungs. Demolition workers face many of these same hazards but they may be less aware of the proper handling procedures due to their inability to identify CCA treated products. The disposal of CCA-treated materials causes sawdust, splinters, and wood exposure to landfill workers.

\subsubsection{Manufacturing}

Manufacturing preserved wood is a dangerous procedure since it uses toxic chemicals in a highly concentrated form during application. The technique used in the application of these substances creates opportunities for the release of toxins into the environment and creates hazards for workers in factories. Workers are susceptible to toxic spills and fumes at all points of the wood treatment process. High concentrations of both arsenic and chromium have been found in both factories and the grounds adjacent to them. Faulty application techniques and failure to follow regulated manufacturing procedures are not uncommon which further increases the risk of exposure (ATSDR, 2006).

Through the OSHA, some federally mandated protection exists for CCA treatment personnel. The OSHA guidelines include mandatory protective clothing and the use of personal protective equipment (PPE) during the treatment process. However, the protection provided at certain steps in the procedure end after the wood leaves the treatment vats, or brushing stands, where the water based CCA chemicals are applied. The wet treated wood is handled after treatment with no mandated occupational protection and is placed on interior or exterior drip pads. "Neither EPA or OSHA 
regulations hold beyond the holding vessel" (OSHA, 1978, p. 1). It was stated in the 1978 OSHA Program Directive, "Based on available scientific evidence, the Occupational Safety and Health Administration (OSHA) concludes that employees exposed to elemental arsenic and to inorganic compounds containing trivalent and pentavalent arsenic have an increased risk of developing cancer" (OSHA, 1978, p. 2). It was after this announcement that stronger laws were implemented for wood preservative industry workers who apply CCA. Unfortunately, many of the treated lumber industry employees will not receive this protection due to exemptions as noted here, "Workers in manufacturing facilities that make finished wood products also can be potentially exposed to hexavalent chromium by contacting wood surfaces and by inhalation resulting from sawing operations. Since treated wood products are exempt from FIFRA regulation as treated articles they do not have detailed label instructions that could require that these persons wear respirators" (EPA, 2007a, p. 2).

\subsubsection{Distributors Handling and Delivery Personnel and CCA Exposure}

The production and transport of CCA chemicals and preserved wood creates opportunities for exposure to concentrated carcinogens for transport and delivery industry workers. As stated by the EPA, "Retail and transport workers could be exposed to some residues of hexavalent chromium via skin contact with wood surfaces that exceed the Agency's level of concern" (EPA, 2007a, p. 1). Handling of the wood creates skin contact, resulting in absorption through the epidermal level. The CCA material is typically stacked into units, strapped together, and then stored in yards or loaded onto trucks and trains. These units may have wet, or poorly affixed, chemicals on the wood 
that may be dislodged when exposed to wind or water. There also may be residual sawdust from milling shavings that stick to the wood. This is hazardous due to the arsenic and chromium attached to small particles that may become airborne and inhaled or deposited into the soil or water. Sawdust and other residue may contaminate equipment or clothing. The lots and yards where the wood is stored become toxic sites due to the sawdust and water that drips off the chemically treated wood.

Delivery drivers may not change clothing before returning to their vehicles after strapping down loads of CCA. The insides of vehicles are then contaminated from the activity and the drivers will continue to be exposed to the arsenic. Other parts of the trucks, such as the truck bed and the exterior part of the cab, are also contaminated. Once a truck or train is moving, the dust or runoff from rains will cause air, water, and soil contamination. When the vehicles are off-loaded at lumberyards and other wholesalers the same exposure is repeated. Some of these sites will stack lumber were it will be exposed to the elements. The wood will leach its surface chemicals when it is exposed to rain thus creating a toxic site where numerous people may later be exposed to the trace heavy metals.

\subsubsection{Demolition Experts}

Demolition experts, and other construction workers, are unable to identify CCA once the signature green color has worn down, faded, or been painted over. Therefore, demolition workers may unknowingly be exposed to carcinogens. This makes it difficult for these workers to be aware of the need to use proper protective clothing and other safety equipment, as suggested in the consumer information sheets that are supplied to 
construction workers that use the new materials. Once the wood is removed from existing structures and placed in waste bins and dump trucks it is taken to construction and demolition landfills. The entire load is dumped and then landfill employees separate it by hand to salvage usable items such as metal or structurally sound large timbers. These land filling and recycling activities cause unneeded exposure to humans to the spent pressure treated wood and sawdust, both of which are known to be toxic.

\subsubsection{Construction Personnel Exposed to CCA and ACC}

Carpenters, electricians, plumbers, masons, and landscape professionals are all exposed to carcinogens from CCA during the installation or maintenance of wood structures. Utility workers are constantly exposed to CCA treated poles and pilings. Road and bridge construction crews work with CCA on most projects as do agricultural and railroad workers. CCA is also impacting electricians and plumbers during material installations where holes and channels are cut in the CCA wood for wire and pipe installations. Roofers using wood shingles treated with CCA may inhale sawdust and have skin contact with the materials. Rain runoff after CCA roof installation dislodges small particles that contain chemicals from the shingles. After construction, smaller debris is washed into surrounding landscape areas and into storm drains. Some of the occupations that expose workers to CCA after manufacturing and delivery include: carpenters, handymen, state and federal employees, painters, gardeners, park and building maintenance crews, electricians, plumbers, power washers, landscape professionals, and laborers. 


\subsubsection{Misinformation on CCA Products}

At construction sites where CCA is cut or shaped, the sawdust is highly concentrated with harmful arsenic and chromium. If the proper handling or safety precautions are not observed workers will be exposed to carcinogens in the form of arsenic and chromium dust. Construction, or milling, of CCA indoors is hazardous but not regulated as of 2007. Customer information sheets recommend workers to perform construction activities with CCA wood outdoors but these sheets are not always available to construction crews. In other cases the warnings are not followed due to misinformation and the poor distribution of warning literature. Although some construction workers handling CCA may be aware of risks, warnings are often not taken seriously in the industry if safety equipment is not required which is the case with CCA according to the Environmental Protection Agency, January 2007 (EPA, 2007a, p. 2):

"The Agency believes that there are no labeling requirements that could reliably reduce exposure to acceptable levels either in the occupational or residential setting. Labels for CCA and ACC products have required placement of tags on wood in an attempt to provide some information to end users. However, they may not always be put on the treated wood, they can fall off, their current limited size could preclude the inclusion of detailed safety information, and there is no evidence that users pay any attention to them. Respirators are not considered a feasible mitigation measure for do-it-yourself residents. While some contractors might be able to correctly use this equipment, it is not likely that they regularly use such personal protective equipment."

\subsubsection{The Release of CCA During Construction}

Field workers at construction sites are exposed to carcinogens in CCA because of the close contact that takes place during the performance of their tasks. However, construction personnel at job sites, or in adjacent trailers and temporary offices, also are 
exposed to airborne toxins. "Soil particles can be carried by winds and inhaled. This is often a major source of contamination during construction operations at a site" (Meyninger, 1992, p 28). The use of large quantities of CCA materials that are shaped, cut, or sanded leave sawdust particles that are blown around by the wind or washed into surface drains during rains or water clean up tasks. Saws and power tools create sawdust and other particles that are inhaled, or that lodge in eyes, and the toxins are absorbed through the skin as fine particulates. The EPA has become more responsive to the hazards of CCA as can be seen in their January 2007 decision on ACC treated wood which states, "Risks to manufacturing workers making finished wood products exceed the Agency's level of concern for both the cancer and non-cancer effects due to inhalation exposure to wood dust containing hexavalent chromium" (EPA, 2007a, p. 1).

Skin contact takes place if proper handling precautions and safety equipment are not used during construction or other related activities such as hauling, stacking, or millwork. When CCA materials are exposed to water, heavy foot traffic, or UV radiation it creates more airborne treated wood fibers. This increases the chances for transdermal or gastrointestinal absorption for anyone who may come into contact with the wood or surrounding areas.

\subsubsection{Lumber Yard and Sawmill Employees Have Some Protection}

The Occupational Safety and Health Administration is part of the U.S. Department of Labor and it enforces laws in the lumber and saw mill industry in an effort to prevent arsenic and chromium poisoning for these occupations. It was determined that employees in this industry require protection due to the high levels of contaminates 
which may be found in their work areas. When treated dimensional lumber is machined the sawdust is highly concentrated with $\operatorname{Ar}(\mathrm{III})$ and $\mathrm{Cr}(\mathrm{VI})$ and the small particles contain the constituents in a toxic vapor. The accumulation of these pollutants in work areas of specialty industries can elevate concentration levels well beyond maximum allowable limits. Due to the concentrated sawdust in this industry the OSHA has made Personal Protective Equipment (PPE) mandatory, since the OSHA determined that proper use of these PPEs reduces exposure to arsenic and chromium.

\subsection{EXISTING STRUCTURES; END USERS}

The construction industry uses preserved wood for many applications where exposure to harsh elements necessitates protection of the wood from moisture and wood destroying pests. After CCA structures are built the durability of the wood allows the CCA members to be left unpainted or unsealed. Carpenters and construction personnel may walk, sit, or lean on the lower part of buildings and walls during the construction of projects exposing their body parts to pressure treatment chemical residues. During the cutting and nailing of CCA treated wood there is risk of high-level exposure to the hazardous constituents in the material. However, once the product is in place the exposure to chemicals continues for its final users. Since there is still a risk of skin contact and leaching, the dangers from CCA are still present after construction is complete. Anyone using or contacting decks, telephone poles, bridges, docks, retaining walls, or garden beds are exposed to arsenic and chromium. Since the wood stays highly concentrated for its useful life, care must be taken at all times (PMRA, 2005, p. 2):

"Scientific studies suggest that arsenic, over time, slowly leaches from CCA-treated wood products. The amount and rate at which arsenic 
leaches depends on many factors including the species of wood, amount of rain, the acidity of the rain and soil in contact with the wood, and the age of the structure. In general, the concentration of arsenic in soil leached...may also be dislodged from the surface of wood."

\subsubsection{Exposure to CCA During Remodeling of Structures}

Many structures containing CCA wood are renovated, remodeled, or retrofitted creating additional exposure to $\mathrm{CCA}$ components. During demolition, workers experience exposure to arsenic and chromium at dangerous levels from sawdust, skin contact with the wood, and gastrointestinal absorption. Maintenance crews and painters power wash, sand, or scrape existing structures, thus releasing toxic dust. In the course of their occupation it is necessary for carpenters, painters, electricians, masons, and other industry professionals to crawl under structures where the soil is potentially contaminated by arsenic. These activities promote skin contact to contaminated soil and air borne arsenic from the dust.

\subsubsection{Risks to Agricultural Workers and Livestock}

Past use of arsenic in agricultural settings has increased the possibility of exposure for farmers and their livestock. Agricultural workers are potentially exposed to high levels of arsenic in fields. Dermal contact with pressure treated fence posts, decks, wood foundations, retaining walls, or piers may increase the possibility for hand to mouth contamination. Other cross-contamination with chemicals is possible if the proper safety equipment is not used while working with CCA treated wood products. High concentrations of toxins may be present in the soil due to naturally occurring arsenic or from the past use of herbicides and fertilizers containing arsenic and chromium. These can become airborne from wind or agricultural tasks such as tilling, weeding, or other 
uses of heavy equipment. The amount of arsenic in this setting may be above maximum contaminant levels in areas where pesticide tanks, or stacks of old pressure treated lumber, are stored. Old sheds, bridges, water tanks, posts, grape vine stakes, poles, outhouses, and barns built with CCA are also hazardous. These structures and waste piles may be burned causing toxic fumes or the wood may be reused by unsuspecting and thus, unprotected farm workers.

\subsubsection{Miscellaneous Exposure to CCA}

The use of tobacco products while handling CCA wood creates two possible exposure paths: 1) The use of chewing tobacco with contaminated hands transfers chemicals to the mouth and 2) Arsenic and chromium are transferred from the fingers to the paper of cigarettes and as the paper burns highly toxic smoke is released. Another issue is the lack of proper hygiene at construction sites that may result in exposure to carcinogens during mealtime. Skin or clothing contamination may allow toxins to migrate to the stomach and intestinal track via ingested foods. Skin-penetrating slivers from woodworking are common in construction. CCA slivers cause infection as the toxic wood, once inside the skin, slowly releases arsenic and chromium.

\subsection{MANUFACTURING FACILITIES FOR CCA WOOD}

Arsenic, chromium, and copper are the three main elements used in the manufacturing of CCA wood treatment. Spills from these water-soluble chemicals during the wood preservation process and vapors from wood treatment create environmental hazards. Studies have shown that run-off water from treatment sites pollutes surface and underground water sources (Schroeder, 2004). 
Pressure treating facilities are sometimes small rural sites and they may function anonymously. Wood preserving equipment is affordable and the process can be preformed in a relatively small area. These factors have opened the wood treatment industry to small business owners who operate in rural facilities. There are over three hundred wood treatment sites throughout the United States.

Chromium is a major constituent in CCA and also in Acid Copper Chromate (ACC) wood preservatives. Like Arsenic, it exists in two different valence states when applied to pressure treated wood, $\mathrm{Cr}$ (III) and $\mathrm{Cr}$ (VI). The latter, Hexavalent Chromium, is the most toxic to humans. Chromium is critical in the fixation process in which CCA chemicals are applied to wood products. Studies conducted show that both forms of chromium leach from CCA materials during use (Lebow and Cooper, 2004). The leaching process is accelerated if the treatment process is performed in adverse conditions such as cold weather. If the temperature during wood pressure treatment is below a certain threshold, the chromium (VI) does not function properly as a fixing agent. The result is the valence state of the chromium stays in the Hexavalent form instead of shifting to the less toxic $\mathrm{Cr}$ (III). The arsenic in the CCA requires the shift in chromium valance to adhere properly to the wood fibers. Poor fixation causes more chemicals to remain on the surface of the wood after treatment, providing an opportunity for chromium, arsenic, and copper to be transferred from the wood to the surrounding environment when it is exposed to water, soil, or skin. 


\subsubsection{Limitations on Protection}

The effects of CCA wood treatment chemicals on humans and the workers who manufacture treated wood, are well-documented throughout the Federal Register and the OSHA regulatory documents. The OSHA has emphasized the protection of workers at wood treatment facilities in order to try and avoid chromium and arsenic related injuries. An exposure to these chemicals increases the risk of illness and other serious health problems. It is well-established that both (As) and (Cr) are known human carcinogens and it is desirable to limit occupational exposure to them (OSHA, 2006). However, the OSHA only requires protection for treatment facility workers until the wood leaves treatment vats. There are no occupational safety, or EPA, laws related to CCA wood that is used during construction or during the disposal phase (OSHA, 1978).

\subsubsection{The Treatment Phase}

Exposure to the toxic chemicals in CCA wood begins during the treatment process. Members of the OHSA have stated that that the wood preservative industry consists primarily of small, highly hazardous workplaces (OSHA, 1986). The surfaces of CCA products contain residuals from the treatment process that are easily transferred to clothing or skin. Spillovers or natural events such as heavy rain, and high winds and flooding cause contamination incidents at treatment sites.

Mandatory protective clothing, respirators, and hygiene stations were a part of the 1978 OSHA program directive to reduce the risk of occupational exposure to arsenic. Since wood preserving industry workers are exposed to high levels of arsenic and chromium during treatment operations they usually have these protections. However, 
this extra protection is only required while applying the CCA chemicals to the wood. Once the preservation process is complete personal protective equipment and handling techniques for worker protection are no longer mandatory. The OSHA directive, "29 CFR 1910.1018 does not apply to exposures resulting from utilization of arsenical preserved wood" (OSHA, 1978, p. 1). This utilization clause impacts all workers with occupational exposure to CCA. Once the treated wood leaves the pressure treatment vats there is limited OSHA protection for worker safety due to exposure to CCA. However, in a recent assessment of ACC, the EPA stated in January of 2007, "Risks due to inhalation exposures to hexavalent chromium for treatment plant workers exceed the Agency's level of concern for both cancer and non-cancer effects" (EPA, 2007a, p. 1). This information has not translated into mandatory use changes, but the acknowledgement of the hazards may promote future action.

\subsubsection{Treatment Variables}

There are some known difficulties in the CCA treatment process that have significant consequences. As was mentioned previously, at low temperatures the chromium fixation process is retarded. This results in an incomplete process and the wood fiber absorption of the arsenic and copper is incomplete. This leaves a toxic powder residue of arsenic and chromium on the surface of the wood. This is potentially released the first time the wood is exposed to water or it is dislodged with skin contact. The moisture content of the wood being treated is also a factor in the effectiveness of the chemical affixing process. The type of wood, as well as the physical part of the tree, must also be considered. The heartwood is typically denser and has a higher moisture 
content making the fixation process more difficult. Variations in CCA treatment techniques, mixture composition for different regions or uses, and the type of preserving equipment create many variables. These factors, and the use of different wood species, combine to create difficulties in the science of wood preservation and may contribute to higher concentrations of exposure to carcinogens for the construction personnel handling the wood (Lebow, 2004).

\subsubsection{Hazards for Facilities and Environment}

Some of the difficulties in regulating the wood treatment industry are the sheer number of sites and the variety of treatment facilities. Contamination at sites is difficult to manage due to the variability in size and scale of the various facilities. This makes holding periods for the proper fixaction of chemicals difficult to supervise. The EPA recently elaborated on some of these difficulties (EPA, 2007a, p. 2):

"The typical turnover of treated wood in the market place results in treated wood leaving the treatment site and entering retail outlets within as little as seven days of treatment. Issues include: Cost of carrying inventory, size of storage facilities needed and cost of construction, existence of treatment-service-only operations that do not buy wood but simply treat wood for an outside customer, generally with minimal holding periods."

Spills and natural events like heavy rain, high winds, or floods cause problems at treatment sites and add to the contamination found in soils at sites. The treatment facilities located throughout rural America, and in other parts of the world, are having a large impact on the surrounding environment by releasing combinations of toxic chemicals into the natural environment and watersheds. Not all treatment plants confine their operations to the inside of buildings. The different holding methods for the drip and runoff chemicals post application vary. One such technique involves the elimination of 
excess water that makes the mix more concentrated. Then the recycled chemical bath is collected in a holding pond and from there it is diverted to evaporation ponds. From these ponds the chemicals are piped back into the active treatment tanks and reused. The sludge, which settles out, continues to concentrate and may cause serious problems at some point in the process. In a public health assessment on a treatment plant in Arkansas these holding ponds became a serious issue. "In 1987, the dike surrounding the holding pond was breached allowing wastewater and sludge containing PCP and CCA to enter the adjacent drainage ditch, Porter Creek, and wetlands along the creek. EPA conducted a removal action in 1988 to alleviate releases from the recovery holding pond" (ATSDR, 2002, p. 3). This effort was mostly successful but caused serious expense, the loss of water supplies, and major environmental degradation.

\subsubsection{The National Priority List (NPL)}

There are highly polluted (Superfund) sites throughout the country that are polluted with arsenic and chromium from CCA lumber production. The equipment and the grounds of these preservation facilities have elevated toxicity levels. Rainwater at these treatment facilities washes chemicals off the freshly treated wood and wood chips and the pieces that are dislodged from the wood flows into storm drains. Evaporation and holding ponds for the spent chemicals are also a concern. Contamination of these wood treatment facilities is a problem for local communities. Regulatory actions against owners of wood treatment facilities for contamination have required polluters to pay for clean up efforts in a few cases. One small town confronted with toxic releases from a CCA 
facility was supplied with drinking water due to the heavy metal content found in their drinking water.

In the EPA region nine national priorities list it stated that the pine mountain site was used as a wood treatment facility for fifty years; it is still causing environmental issues and it is a public nuisance, "Groundwater on property, contains...heavy metals including copper, chromium, and arsenic. Off-property down gradient groundwater risks...include drinking contaminated groundwater, or excavating soil below five feet on site. An alternative drinking water supply was provided to residents with the potential for contaminated domestic groundwater wells" (ATSDR, 2002, p. 1).

\subsection{THE DISPOSAL PHASE}

The sludge waste from arsenical wood treatment facilities is exempt from hazardous waste laws as are construction wastes as mentioned in the Chapter 3 . These wastes are highly concentrated with arsenic and chromium and as of March 2007 waste from treatment facilities may be disposed of in unlined landfills. Construction and demolition waste also creates disposal hazards for the environment and human health. Waste from construction and demolition sites are loaded by personnel and then transported, which exposes workers to potential hazards. Dust from the waste may contaminate clothing, skin, or eyes. Soils or surface drains collect chemicals as unsuspecting employees wash vehicles. Dust and winds at landfills along with interactions between CCA waste, water, and other chemicals create leachates. These may contaminate the soil and migrate to groundwater (Khan and Jambeck, 2006). 
The demolition of CCA structures exposes construction workers and landfill workers to toxic dust, splinters, and wet chemicals. The CCA wood does not hold its green appearance due to wear, exposure to weather, paint, and stains. Therefore, it is difficult for workers to identify the CCA and may not use the proper safety equipment. The labels, end uses tags, Material Data Safety Sheets (MSDS), and Customer Information Sheets (CIS), supplied during manufacturing are no longer accessible in most demolition and remodeling projects (EPA, 2007a).

\subsubsection{Leachate and Landfills}

Unmonitored dumping of dangerous wastes is creating potential environmental hazards at landfill sites and adjacent lands. A study conducted in Florida concluded that toxic leachate from buried CCA wood, and other wastes in landfills, seeps into down gradient watersheds, aquifers, and municipal wells resulting in high levels of arsenic contamination (Khan and Jambeck, 2006). As was observed by Dr. Meyninger at the Love Canal hazardous dumpsite, "Surface water contamination can occur both from surface runoff from the site itself, from leachate from the site, and from plumes in the groundwater which recharge waterways both near and distant from the site...ground water is of major concern because one half of the population of the United States uses ground water aquifers as a source of potable water supply and this represents a widespread opportunity for human exposure to toxic chemicals" (Meyninger, 1992, p 31). Even though exemptions for CCA disposal are still active, the attitude toward pressure-treated wood in landfills may be changing as is noted by the EPA, "Introduction of ACC-treated wood into the residential marketplace would have hazardous waste 
generation and disposal implications" (EPA, 2007a, p. 2). The main reason for this comment was that ACC and CCA contain high levels of $\mathrm{Cr}$ (VI). This may indicate a new EPA attitude relative to solid waste disposal in the future.

\subsubsection{Mulch Use}

The use of CCA waste as a mulch is not legal since this involves grinding treated wood into small pieces after it is taken out of service. The chips are mixed with other organic matter or are painted brown to create landscape mulch. The mulch is then used in gardens, play areas, and other landscaping applications. Disposal exemptions created special circumstance for CCA and a ruling over its use in mulch was anticipated due to the extreme difference between the leaching of full dimensional lumber and the increase of leachable surface area of wood chips. A clarification on using CCA wood as mulch from the Office of Solid Waste in January 6, 2004 stated that, "CCA-treated wood used to produce wood mulch is not the "materials' intended end use;" therefore, wood mulch produced from CCA-treated wood is not exempt from regulation as a hazardous waste under 40 CFR 261.4(b)(9). This is because the intended end uses of the CCA-treated wood products are as building materials, not for manufacturing mulch (Springer, 2004).

\subsection{LEGAL CASES RELATED TO CCA PRODCUTS}

There was a jury verdict in favor of an employee who experienced injury while working with $\mathrm{CCA}$ and there were several monetary settlements paid to the plaintiff by registrants of CCA (Sipes v. Osmose, 1992). This case may change the regulatory attitude and require more appropriate warnings to be supplied for CCA use. A forest service worker named James Sipes won a lawsuit against Osmose after being exposed to 
CCA that caused him serious health consequences. The doctor's reports and a toxicological study on the CCA wood were included as evidence in his case. The plaintiffs' lawyer made these available to the researcher and they are discussed in the next section.

\subsubsection{Toxicological Report}

Toxicologist H.A Peters, in a collaborative article produced at the University of Wisconsin medical school, discussed occupational exposure to pressure-treated wood. Dr. Peters states in his article that exposure to CCA in an occupational setting causes illness after repeated exposure "It seems apparent that working with CCA-treated lumber with power equipment in an enclosed area poses a very severe health hazard" (Peters, 1983 , p. 42).

This article also reviewed the exposure experience by a family who burned CCA-treated wood in their home for heat in the winter. It was determined that all of the family members suffered from arsenic poisoning and the following health issues were reported. "Symptoms included recurrent alopecia (hair loss) in the winter (that grew back in the summer), dermatitis, muscle cramps, malaise, blackouts, paresthesias, recurring respiratory symptoms, thrombocytopenia, and colic. Concentrations of arsenic in the hair of the patients were 12-87 parts per million (ppm) and levels of 105-5,006 (ppm) were found in the fingernails of family members. The living area of the home was heavily contaminated with ashes containing over $1000(\mathrm{ppm})$ pentavalent arsenate" (Peters, 1983, p. 39). 
Another case reviewed in the same article found that skin irritation resulted when workers were installing bulkheads using CCA plywood. The article also states that appropriate warnings need to be supplied to carpenters to avoid chronic rashes and acute poisoning as well as a possibility of cancer (Peters, 1983). A detailed report by Dr. Johnloz on the examination of a forest worker who used CCA-treated wood to construct picnic tables during consecutive winters in 1983 and 1984 provides insight into the affects of CCA on carpenters.

In Dr. Johnloz's report the condition of the worker is explained in detail, including the adverse health effects he experienced and the results of the tests that were needed during the examinations. The arsenic levels in his hair and nails were extremely elevated. At one point in the first exposure cycle he was coughing up so much blood that he needed seven pints in a transfusion to stabilize his condition. Damage to his spleen and kidneys, as well as sore joints and atrophy of the legs, were reported. There were muscle cramps, body aches, skin, and urine discoloration as well as disorientation and short-term memory loss. The condition became so severe he was unable to continue performing construction work. Even though some of the symptoms dissipated once he was no longer exposed to the CCA sawdust, his health never returned to his pre-exposure condition.

The next winter, 1984, he went back to the same workshop and commenced cutting and drilling of CCA wood. His symptoms from the previous winter returned almost immediately (two days), starting with heaviness in the chest and shortness of breath. On the third day after he returned to work in the winter of 1984 a coughing fit 
and sore throat as well as an acute gastrointestinal (GI esophageal varices) hemorrhage ensued. The worker woke up vomiting blood and was hospitalized, and this time four pints of blood were required to stabilize his hemoglobin. A diagnosis of his condition was made and abnormal skin findings were indicative of liver disease and cirrhosis. $\mathrm{He}$ experienced long periods of chest pain and pains in his upper quadrant consistent with scarring and fibrosis of the liver and these symptoms may be related to arsenic poisoning.

After the second episode Mr. Sipes was unable to return to his construction position with the forest service. In the words of his doctor, the fatigue he experienced will be present for the rest of his life and any kind of exertion will exacerbate his condition. Dr. Johnloz also wrote, "It is obvious that this patient will never be completely healthy and runs a high risk of future complications and life threatening episodes including the possibility of recurrent bleeding encephalopathy and death" (Johnloz, 1985, p. 40).

There was also a coworker exposed to similar conditions in both of the occasions mentioned above. She suffered from similar symptoms but not as severe. She also was diagnosed with arsenic poisoning and her health issues subsided when the CCA exposure was discontinued. The coincidence of these workers experiences has been ruled out due to the second exposure for them both the following year. The doctor in the case of the male worker wrote, "He will never be physically completely well. He will always have easy fatigability and not be able to do manual type of task that he has done all his life...he will not have a normal life expectancy" (Johnloz, 1985, p. 5). 


\subsubsection{Insider and Task Force EPA Memos}

The plaintiff's lawyer who handled the forest worker's case that was mentioned previously provided the memo in the discussion that follows. The memo suggests that employees of the registrants for CCA knew of health complications caused by their product as early as 1977 and the information was neither supplied on the MSDS nor relayed to the EPA. Mr. Robert D. Arsenault was an employee of a CCA registrant in 1977. On July 25,1977 he wrote an interoffice correspondence memo to file on the subject of CCA dust toxicity. The memo stated, "For the record I have decided to name three instances that I know of concerning CCA dust toxicity to workers who were exposed constantly by either sawing, sanding, or planning the material" (AWPI, 1977, p. 1). The memo reported nose bleeds and coughing up blood as a result of sanding and milling CCA-treated wood. Other complications noted consisted of general illness, respiratory illness, and skin rashes. The occurrences mentioned in the memo were from three distinct sources. One was a pattern shop where a worker became ill in 1968, the second was a prefabrication construction company building CCA wood foundations, and the third was a group of college students working in a laboratory in Colorado. The last two incidents occurred in January and July of 1977. The information about these CCA hazards, and others associated with typical woodworking practices, was not relayed to the EPA nor added to consumer information sheets or MSDS.

In August of 1977, just two months after the Arsenault memo, the Environmental Programs Task Group Subcommittee Number One prepared a memorandum for the Office of Pesticide Programs of the EPA. This memo was prepared with the intention of 
moving forward with negotiations for the registration of arsenical-based preservatives that was being considered by the EPA. The content of the memo assures the EPA agency of the inert nature of CCA wood. Mr. Arsenault, who wrote the internal memo about consumers exposure to toxic dust, was not only a member of this committee, but he was also the chair of the committee yet the following task force quote was in the memo, "Inorganic pentavalent arsenic has been used as wood preservatives in substantial quantities for more than 35 years with no reports of adverse effects...wood treated with arsenical preservatives is highly leach resistant. The permanence of the preservative in the wood fiber makes the treated wood extremely durable, non-phytotoxic, and safe to handle or use in all applications" (AWPI, 1977, p. 1). These statements are in direct conflict with the internal memo written by Arsenault, mentioned above. Facts about CCA use complications were not reported and it put them in direct violation of FIFRA, that states "if at anytime after the registration of a pesticide the registrant has additional factual information regarding unreasonable adverse effects on the environment...the registrant shall submit such information to the administrator," this new information could be "not only derived from new scientific studies, but also incidents of adverse effects resulting from the use of pesticide products" (EPA, 2006c, .p. 2).

\subsubsection{Cancellation of the Registration of CCA}

The February 22, 2002 volume 67, number 36 page 8244-8246 of the Federal Register contains the receipt of requests from registrants of CCA to cancel some of the registered uses. These cancellations were for treated wood use in residential construction. This voluntary request was followed by an amendment to terminate uses by 
the EPA and was recorded in the Federal Register (Federal Register 67, 2002, p. 8244). The voluntary withdrawal of uses for a registered product meant a new use label was required. As stated in Federal Register 68, "The new label does not allow the use of CCA for virtually all wood use at residences, including wood used in playground structures, decks, picnic tables, landscaping timbers, residential fencing, patios and walkways/boardwalks. The label authorizes use of CCA in industrial and commercial applications specified therein" (Federal Register 68, 2003, p. 3).

As of February 2007, the EPA has not changed its position on the legality of CCA products. The RED review of CCA, as mentioned in the Chapter Three of this paper, is being conducted to assess hazards of using the preserved wood but a voluntary withdrawal of CCA registered products from four registrants is the only restrictive action ever taken on the product excluding customer information sheets. The cancellation order restricts the manufacture of specific CCA materials for use in residential buildings but it will not halt the production of CCA or it being used in construction. The cancellations were to be in force as of September 7, 2005 (EPA, 2004). Due to the nature of voluntary terminations, there was no urgency for the EPA to pursue their studies or rule on the legality of using CCA products. In this case, the voluntary withdrawal of registration removes hazardous products from circulation for certain uses and accelerates the bureaucratic process but it does not promote new laws. The acceptance of the withdrawal, and subsequent termination by the EPA for residential uses of CCA, left a large market share available for a replacement product for residential applications. 


\subsubsection{ACC Faces Legal Action by the EPA}

Acid Copper Chromate (ACC) has been used to treat lumber in many of the same applications as CCA. When the registrants of CCA notified the EPA about their request to terminate residential uses of their product, the registrants of ACC followed with a request of their own. The Federal Register states, "September 29, 2003 Notice of Receipt of Requests by registrant of pesticide products containing Acid Copper Chromate (ACC) to voluntarily cancel certain pesticide registrations and/or to amend to terminate certain uses of affected products. Specifically...the sole registrant of $\mathrm{ACC}$, is also requesting to immediately cancel the registration for its product with no provision for existing stocks" (Federal Register 67, 2002, p. 8245). This cancellation was to become effective December 31,2004 . However with a shortfall in the treated wood commodities market ACC registrants rescinded their voluntary request for termination of their product and reapplied for registration.

The EPA initiated the registration process between 2004 and 2007. One EPA document in 2007 stated that the "EPA is taking legal action to deny all applications for registration of Acid Copper Chromate, known as ACC, as a wood preservative pesticide intended for residential use. ACC contains hexavalent chromium, which is a skin irritant and sensitizer and a known human carcinogen when inhaled" (EPA, 2007a, p. 1). The document goes on to discuss other information that supports the EPA's decision to deny registration and it states that, "residential uses of ACC would pose cancer, and noncancer risks of concern to workers during the manufacturing process and non-cancer risks to contractors and residential users. The Agency is concerned that the proposed uses 
would pose skin irritation risk...to children who come in contact with the treated wood" (EPA, 2007a, p. 2). This concern about treatment facilities workers, contractors, and children is derived from the fact that hexavalent chromium is highly toxic and it causes health problems to anyone that is exposed to it.

Disposal of ACC was also mentioned as a concern in the registation of $\mathrm{ACC}$ as stated in the EPA document in 2007, "disposal of the ACC-treated wood by either contractors or residential users after its useful lifespan could require that it be handled and disposed of as a hazardous waste since the wood could contain high levels of chromium. This evaluation has also concluded that the risks of concern associated with the proposed residential uses of ACC outweigh the minimal benefits" (EPA, 2007a, p. 2). These statements are in line with the concerns about containing dangerous chemicals before they reach landfills. The EPA supplied the following information as a summary of its findings in the registation procees for ACC (EPA, 2007a, p. 1):

- The human health risks of the proposed use of ACC to treat wood for use in residential applications are high.

- The widespread use of ACC in residential applications, as proposed, would pose unacceptable risks to workers and residents.

- Wood treated with ACC raises disposal issues that could add to the cost of ACC-treated wood and/or could result in health and environmental impacts.

- The risks associated with the proposed residential use of ACC outweigh its benefits.

- ACC does not meet the standard of registration under FIFRA Section 3.

- Risks to manufacturing workers making finished wood products exceed the Agency's level of concern for both the cancer and non-cancer effects due to inhalation exposure to wood dust containing hexavalent chromium. 
Also discussed in the ACC order was that "retail and transport workers could be exposed to some residues of hexavalent chromium via skin contact with wood surfaces that exceed the Agency's level of concern" (EPA, 2007a, p. 2). Now that these concerns have been expressed it should be noted that CCA also contains large quantities of chromium and the same results should apply to it as to ACC.

\subsection{MAT-RANGER SOFTWARE}

As part of this research investigation the Mat-Ranger software was created to assist construction personnel when they are selecting materials for building projects. Unlike other estimation tools on the market the Mat-Ranger provides impact and user hazard data for materials. The Mat-Ranger computer interface underwent testing for functionality, the user preference and estimation tools were assessed for their ease of use. Troubleshooting of this software was completed and the results indicate the continued development of the Mat-Ranger is a valid enterprise for future marketability.

A brief description of the user interface and user preference selections for MatRanger are presented in this section of the work. The templates for activity estimation and worksheets are provided as screen shots for ease of discussion. Mat-Ranger recommendations for materials come ranked with pros and cons for each material choice in the output screen. The durability of each material is also displayed for an added user benefit.

\subsubsection{Mat-Ranger User Input}

As was discussed in Chapter Two the Mat-Ranger Version 1.0 is scaled back as a prototype to complete the study. The user preferences in this version are related to 
assessments of materials for the following characteristics: renewable, recyclable, natural resource conservation, processing or manufacturing emissions, off gassing, and pollution impacts. Also, the economic user preferences were simplified into three choices; use the least expensive and most accessible material, the green (ecologically-friendly) materials over conventional, or the highest quality and most durable materials.

After the user enters preferences into the interface of the decision support system the Mat-Ranger displays activity menus. The user selects an activity and the appropriate template is displayed for material estimation. See Figure 5.1 for the Mat-Ranger menu entitled Activities.

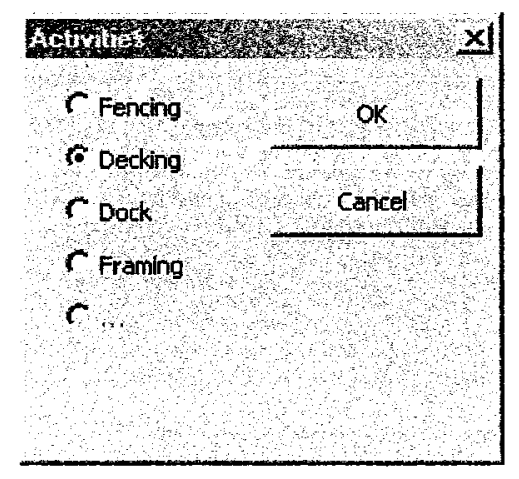

Figure 5.1: Mat-Ranger Activities Menu

After selecting an activity the user of the Mat-Ranger may enter the length of a dimensional material in the components menu. The templates receive the data then the DSS calculates material and labor cost estimates. The database of the Decision Support System software includes labor cost estimations from 2003 cost means data. The MatRanger template for decking components is presented in Figure 5.2. 


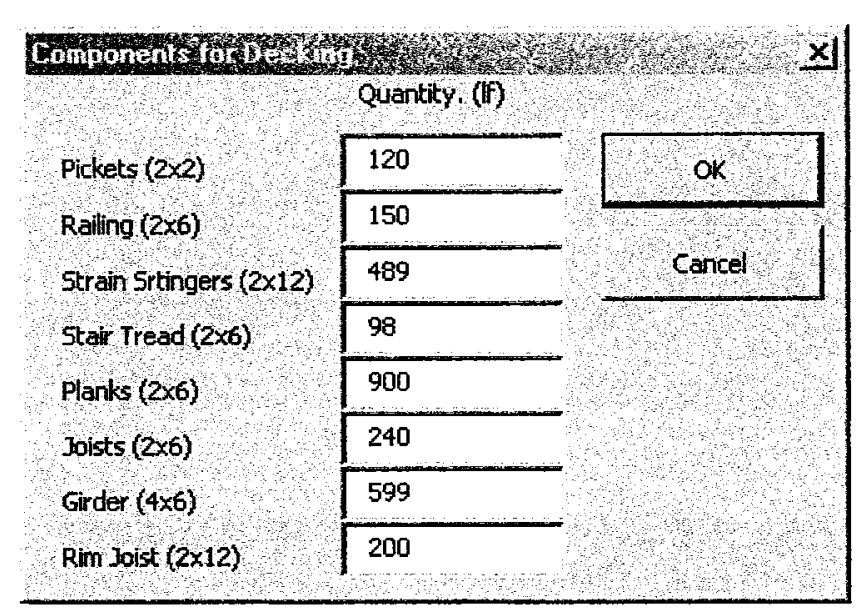

Figure 5.2: Mat-Ranger Template for Decking Components

\subsubsection{Mat-Ranger Output}

The output of the Mat-Ranger presents the material options ranked one to three according to user preferences. Material cost, labor cost, durability, and the advantages and disadvantages of each material are displayed in the Mat-Ranger component-ranking screen. See Figure 5.3 for an example of Mat-Ranger's output.

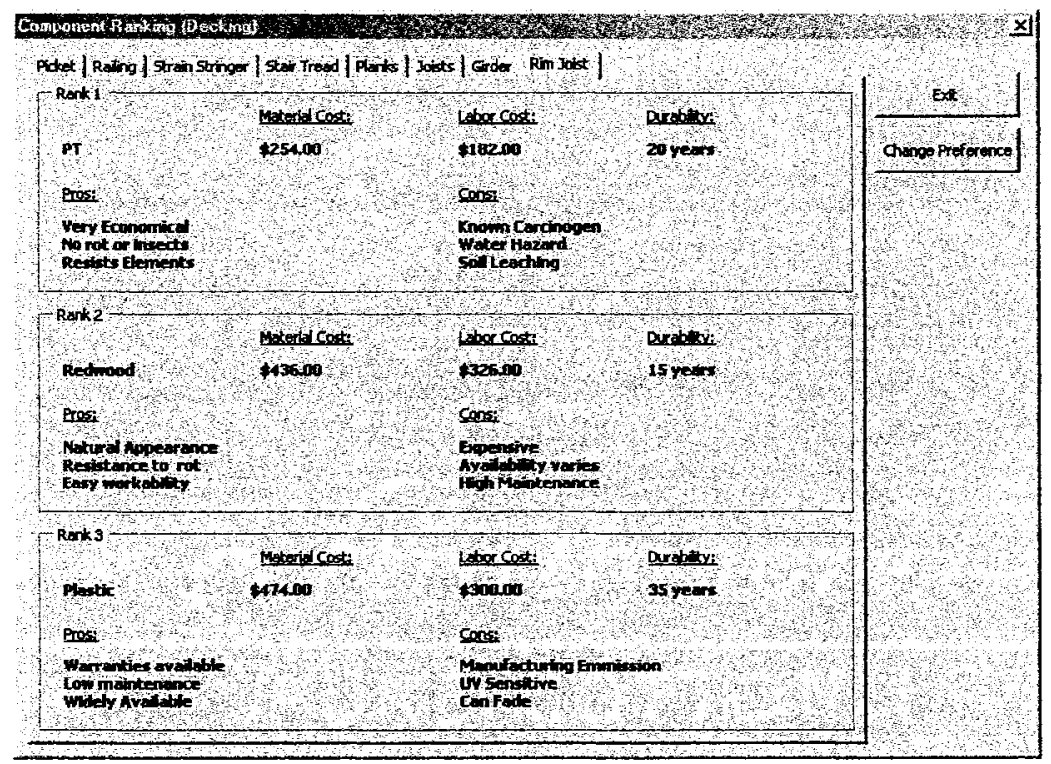

Figure 5.3: Example of Output by Mat-Ranger: Component Ranking (Decking) 
In the future version of the Mat-Ranger, the output screens will include material warnings for hazards and any special handling precautions necessary for the given material suggestion. Safety concerns for users and any safety equipment necessary for use will also be relayed through the output screens.

The Mat-Ranger templates for estimation were effective in small project takeoffs. More functionality for the program is necessary for large-scale project estimation as compatibility to other estimation software is a future endeavor. 


\section{CHAPTER SIX:}

\section{DISCUSSION OF RESULTS}

\subsection{VOLUNTARY WITHDRAWAL OF CCA PRODUCTS}

Results from scientific studies refute the stance of members of the wood preservative industry that claim that chemicals do not leach from CCA products once the treatment process is complete. Although the wood treatment industry has reacted to the negative publicity with a voluntary withdrawal of registrations for some uses of CCA wood in residential construction, there still has been no conclusive decision by the EPA about the overall safety of CCA-treated products. As a result, the wood treatment industry has continued to produce and sell their products for non-residential use.

The voluntary withdrawal of registration by registrants, and residential exclusions of treated wood, are a starting point for regulation, but arsenic and chromium are still used in some residential, and many industrial, structures. This exposes construction workers to carcinogens, as their work tasks require them to saw, drill, and cut holes in CCA-treated wood. The CCA structures that are on public property are exposing people who work in these structures to toxic chemicals and the responsibility of dealing with the preserved wood issues is now on homeowners, municipalities, state agencies, and federal employees. The agencies and services that oversee parks and schoolyards have inherited the responsibility for dealing with the potentially hazardous CCA products that are in the form of construction materials, wood waste, existing structures, and contaminated soil and water due to the leaching of chemicals. This situation will continue to affect private 
and public lands, federal, state, and city parks, and all other structures that contain CCA wood for many years to come.

The deadline for completion of the RED studies on CCA has been extended at least three times. The first EPA posting of the RED results was due in December of 2003. This deadline was extended to December of 2006 and the most recent date, and the new target date for Re-registration Eligibility Decisions (REDs), is December of 2007 for the CCA RED studies (EPA, 2007b). The latest postponement is another delay in a process that has been ongoing for the last thirty years. A final decision on the legality of future CCA use is crucial to the U.S. preserved wood industry and to the health of construction workers. The continuous delays in issuing the results of the RED studies have allowed CCA products to remain in use, the contamination of environmental resources continues, and humans are still being exposed to arsenic and chromium. Without a definite ruling on the use of CCA products the general public is confused about the hazards associated with CCA. In a phone conversation with Diane Isbell of the EPA on February 28, 2007, who is the Acting Team Leader for the CCA RED proceedings stated that, as more risks associated with the use of CCA products are brought to the attention of the EPA, they will be incorporated into the decision process and this will extend the review process even further into the future (Isbell, 2007).

\subsubsection{Acid Copper Chromate (ACC) Denied Registration}

The EPA declined registration to ACC products for residential use was on January 8, 2007 (EPA, 2007a). This decision was made because of the hazards from the chromium present in the sawdust released during the sawing or sanding of ACC wood. 
Also, disposal of the ACC product introduces chromium into landfills and raises disposal issues for the treated wood, which result in health and environmental impacts (EPA, 2007a). The wood preservative CCA contains not only chromium, but also arsenic which is a combination of two carcinogenic constituents that invoke the synergy equation introduced in Chapter Three; therefore, if the EPA approves re-registration of an even more hazardous product than the ACC that was just denied re-registration it would defeat the purpose of no longer allowing ACC products to be used in residential construction.

At the Consumer Products Safety Commission Hearing on CCA in March 2003, the Office of Pesticide Programs Associate Director of the Antimicrobials Division Jack E. Housenger stated that, "The agency considers the voluntary moves toward arsenic-free wood treatment products as a positive step, particularly for our nation's children. The agency believes that reducing the potential residential exposure to a known human carcinogen is desirable" (EPA, 2003, p. 1). He continued, "It is important to note also that EPA has not concluded that CCA-treated wood poses unreasonable risks to the public for existing structures made with CCA-treated wood. We are continuing to evaluate potential risks from structures already in place and will continue to evaluate those remaining uses that are not included in the voluntary actions" (EPA, 2003, p. 2).

During the comment period of the re-registration decision process, and the ensuing extensions, more than 6,700 official comments were recorded in the public docket (Federal Register 68, 2003). These came from wood preservative industry representatives, public officials, the scientific community, business owners, employees, and the general public. The voluntary restriction of CCA use for most residential 
purposes took place as a result of this process, but ironically the voluntary nature of the process meant no laws were created for CCA use and there is no impetus for either removing existing hazardous structures or enforcing the implementation of safety procedures.

\subsection{THE REGISTRANTS' POSITION}

The American Wood Preservers Association, and other representatives of the registrants, have lobbied to have CCA products registered for many different uses. The Rebuttable Presumption Against Re-registration process is still not complete despite having started in 1978 with the decision by the EPA under Federal Insecticide, Fungicide, and Rodenticide Act to re-evaluate the use of CCA products. A Notice of Settlement Agreement between the AWPI and the EPA was reported in 1985. (EPA, 1985b). Throughout the review process, the EPA has expressed an interest in having manufacturers and distributors of CCA products supply warnings and use precautions along with the treated lumber they were selling. The registrants have continually alleged that the use of CCA lumber materials does not need to have federally mandated safety precautions because there is no proof that there are adverse effects to the health of CCA product users.

Samples of responses to requests for information from CCA registrants by the EPA were included in a memorandum from the EPA. It stated that users of CCA should be required to wear gloves. The American Wood Preservers Institute responded that for "arsenical-treated wood...it has been shown there is no skin penetration and absorption through the skin...thus handling treated wood is not hazardous due to the highly 
insoluble surface residue" (AWPI, 1981, p. 5). In the same document, the EPA requested the use of dust masks capable of trapping $80 \%$ of particles greater than 5 microns in size for individuals who use saws to cut CCA products. The response from the AWPI was, "This request is unwarranted. Inhalation exposure to the preservative while sawing and handling pesticide-treated wood will be negligible and will not result in any risk of adverse effects to health or the environment...health effects to end users from the preservatives is virtually non-existent" (AWPI, 1981, p. 5). The AWPI went on to state that, "EPA's proposal to recommend dust masks therefore completely lacks any basis related to treated wood and is unnecessary...no hazard is posed by treated wood which would justify a specific TSCA rulemaking" (AWPI, 1981, p. 6).

The EPA also proposed prohibiting the use of CCA indoors and in animal pens, barns, and other places livestock would come into contact with the wood. The rebuttal from the AWPI states that, "no health risk can be posed by interior uses of arsenicaltreated wood...to require a TSCA label...is totally unnecessary, as is its related proposal for a FIFRA label" (AWPI, 1981, p. 8). The next request from the EPA in this memorandum was to make sure that CCA products are not used in a manner where they could become a constituent of food sources, drinking water, vegetable stakes, or feedlot bins. However, the "AWPI has established that the use of arsenical-treated wood in vegetable stakes, grape stakes, and mushroom trays does not result in any increase in arsenic in these commodities" (AWPI, 1981, p. 9). Also, "warning on this subject is unwarranted...limiting uses of treated wood are gross overregulation...recommending against uses of treated wood in direct contact with food, feed, water, domestic animals or 
livestock is unnecessary" (AWPI, 1981, p. 9). The EPA went on to request the disposal of treated wood in a manner consistent with registered use and not by burning. The response to the request from the AWPI was: "There is no evidence of any significant adverse effects resulting from burning treated wood...the problem aimed at by EPA's warning on burning is an aesthetic rather than a health issue" (AWPI, 1981, p. 13).

\subsection{DISCUSSION OF LEGAL DOCUMENTS}

Several documents were used in a lawsuit against CCA registrants (Sipes v. Osmose, 1989) and they will be discussed in this section. The first of these documents was a memo from an employee of one of the registrants of CCA who was also acting as chair of an action committee responsible for communicating with the EPA (Arsenault, 1977). In this memo, the author discussed three injuries that resulted from machining CCA. The second document was from a doctor who treated a forest worker after his multiple exposures to CCA (Johnloz, 1985). The third was a report from a toxicologist who undertook an experiment to determine the amount of arsenic released when using power saws on CCA products (Peters, 1983). The plaintiffs also used MSDS and Customer Information Sheets to demonstrate the level of misinformation presented to the public by the registrants. The memos and doctors reports, combined with proof of there having been a lack of pertinent information presented by the registrants to occupationally exposed workers, was enough to convince a jury to award the plaintiff a monetary decision against the registrants for wrongful injury due to CCA exposure (Sipes v. Osmose, 1989). 
The author of the memo on CCA dust toxicity exposure is Robert D. Arsenault, Chairman of the Koppers Company, Inc. a CCA registrant (Arsenault, 1977). In the course of Arsenault's employment, on at least three occasions he received notice of adverse effects from consumers of CCA products. In all three instances, the concerned workers were performing typical construction activities with CCA-treated lumber. The reports identified coughing up blood as well as general illness and fatigue after sanding or shaping the treated wood. These notifications were prior to July of 1977 . On July 25 , $1977 \mathrm{Mr}$. Arsenault sent an interoffice correspondence regarding the symptoms reported to him to other employees at Koppers Company, Inc., but the information was not relayed to the EPA (Arsenault, 1977). The timing of this incident was just prior to the Rebuttable Presumption Against Re-registration of October 18, 1978 and other ongoing negotiations with the EPA for re-registration of CCA.

Mr. Arsenault was on a task force responsible for close interaction with the EPA in late 1977 and was a representative of the AWPI that was involved with negotiations with the EPA. The purpose of the APWI task force memo dated August 1977 was in response to the February 17, 1976 Federal Register notice to meet data requirements for the support of active ingredients in pesticide re-registration proceedings (AWPI, 1977, p. 1). The memo requested conditional registration from the EPA for CCA pending the completion of long term testing and stated that the, "test data indicate that inorganic pentavalent arsenical wood preservatives do not present acute toxicity problems...in light of the nature of the formulation and treatment process, as well as the nature of the uses for treated wood, it is clear there is no significant exposure of man, domestic animals, 
wildlife, or the environment to arsenical wood preservatives" (AWPI, 1977, p. i). The AWPI also stated that: "warning rules for treated wood is a move in the wrong direction at a time when the problem of over regulation by EPA should be getting serious attention" (AWPI, 1977, p. 16). The memo from the task force went on to say that the "EPA threatens to stray into regulatory areas better monitored and handled by other agencies. Any needs for product information on treated wood can be more appropriately handled and efficiently supplied by a voluntary industry information program" (AWPI, 1977, p. 16). The EPA allowed the registrants to continue production and distribution of CCA with a promise that a voluntary program for customer notification, including distribution of Customer Information Sheets, would be monitored and carried out by the registrants (AWPI, 1982, p. 3). Eventually the registrants abandoned the program and the EPA took no action on the failure to comply with past RPAR settlement agreements made between the registrants and the EPA.

\subsection{LEGAL CASES}

A legal case involving a forest worker named Sipes, and his injuries due to CCA exposure, will be discussed in this section. The jury in this case ruled that the injuries suffered by Sipes in his occupational setting as a forest worker using CCA were preventable if the registrants had presented more information on the MSDS and Customer Information Sheets. The jury decided that the warnings supplied by registrants for using CCA products were not sufficient to protect workers from the hazards associated with using CCA. Knowledge that the registrants failed in their responsibility to inform workers about the hazards of CCA was not only verified in a court of law by the jury 
verdict, but it was also apparent when four other registrants decided to settle with Sipes before the trial. The injuries suffered by the plaintiff due to exposure to CCA were also partially due to the misinformation supplied by the marketing leaflets distributed by the registrants. If the registrants were aware of health effects from $\mathrm{CCA}$, and did not report them, it would be a breech of the agreement made between the EPA and the registrants during the RPAR re-registration proceedings for $\mathrm{CCA}$ and this breech should have terminated the CCA re-registration proceedings.

\subsection{DISPOSAL CHALLENGES}

Inadequate control of CCA waste has resulted in substantial risks to the environment because hazardous chemicals contained in the wood waste are being disposed of in unlined landfills, which is hazardous to human health and the environment (Jones-Lee and Lee, 1993). Waste from construction sites is buried directly along with CCA wood waste and post treatment sludge from manufacturing plants. This disposal procedure for CCA wood waste has been used for decades, and one registered use of CCA includes ground contact (EPA, 2006b). The EPA has equated this phrase to direct burial. Therefore, CCA and other arsenical-based wood preservatives are legally disposed of in landfills without liners. Loopholes in the disposal laws were elaborated on in the Chapter Five. The exemption placed on CCA waste was a temporary ruling. Since CCA waste creates leachate that travels through the soil at a slow rate, the current levels of arsenic found in water supplies down gradient to landfills is expected to increase over time. Current research being conducted near Florida landfills has indicated that the amounts of arsenic in the water and soil in the area are above the maximum contaminant 
levels (Weber, 2002). The recent decision by the EPA to deny ACC registration was accompanied by a justification for the decision. One of the points made in the justification for denying the registration was: "In addition, disposal of the ACC-treated wood by either contractors or residential users after its useful lifespan could require that it be handled and disposed of as a hazardous waste since the wood could contain high levels of chromium" (EPA, 2007a). Since chromium is also a major constituent in CCA the decision to deny ACC registration supports the case against CCA registration and continued disposal exemption.

Laws for the disposal of solid waste are skewed in their objective to contain waste in sanitary enclosures. There have been numerous exemptions to solid waste laws that favor a policy of leniency toward CCA-treated wood waste, as has been demonstrated by the numerous exemptions it has been granted. One of the CCA exemptions to the extraction process toxicity EP came after the law was created and enforced by the EPA. The United States Geological Survey stated that, "Because of arsenic's known adverse effects on human health, public concerns have stimulated the debate over the safety of large amounts of arsenic contained in some products, as well as their disposal... with a focus on pressure-treated wood" (Bleiwas, 2000, p. 1). However, hazardous constituents in CCA materials continue to be disposed in unprepared waste sites and, they contribute to toxic leachate in landfills. Toxic leachate will continue to pollute landfills until changes in the policies for CCA disposal are revised and implemented by the EPA and the Solid Waste Disposal Agencies. 


\section{CHAPTER SEVEN:}

\section{CONCLUSION}

\subsection{PRODUCTION USE AND DISPOSAL OF CCA}

Construction personnel are developing health issues due to being exposed to Chromated Copper Arsenate (CCA) wood products in their work. The continued use of CCA wood preservatives not only exposes construction workers to potential carcinogenic materials, but it also exposes workers who manufacture, deliver, and dispose of the toxic materials. Although the EPA has approved the production, use and disposal of construction materials treated with CCA, this research investigation has described the documented adverse effects of these building products to both humans and the environment. Protection of construction workers from known hazards is difficult due to the use of CCA. Continuing to allow arsenical-treated wood to be used as a construction material puts construction workers and other occupations in unnecessary danger. The information collected during this research project has shown that the continued use of arsenical wood preservatives creates risk to all construction workers who use power equipment and tools when preparing CCA materials for installation. It has also been demonstrated in this work that exposing construction workers to the toxic chemicals in CCA is no longer justified by the benefits gained from its use due to the debilitating injuries suffered by workers in the industry.

This research presented health effects and exposure hazards for humans and some of the symptoms to be expected during exposure to arsenic and chromium. It discussed water quality issues and the most recent EPA water standards for arsenic contamination. 
The environmental consequences of arsenic and chromium pollution in water supplies were also a topic discussed in this work.

The voluntary withdrawal of CCA registration by registrants for some uses in the residential building industry was done in 2005 (EPA, 2005b). This effectively slowed down the re-registration process as was demonstrated throughout this research, with the most recent example being the January 2007 delay in the Re-registration Eligibility Decision (RED) by the EPA, which postponed the deadline to the end of 2007 (EPA, 2007b).

Contamination of ground water from leaching CCA chemicals was discussed along with information being provided from other research projects. These research projects demonstrated that CCA waste should be reclassified as a hazardous waste and directed to lined landfills or hazardous waste dumping programs. These actions would prevent the leachate from traveling through the soil into ground water and aquifers. This research also demonstrated that hazardous waste disposed of in landfills, or improperly managed, may lead to the risk of an increase in mortality or illness, and it poses a hazard to human health and the environment.

The research presented that burning of CCA waste is highly toxic and should be avoided and that incineration of CCA during disposal should not be practiced due to the expense of fulfilling the Clean Air Act in regards to the arsenic emissions. It is therefore financially unfeasible at this point in 2007 for CCA to be incinerated on a large scale since the emissions from burning of CCA must be contained. There is also an added risk of concentrated toxins in the incineration ash from CCA wood fires. 
The research presented the Indiana jury verdict in favor of James Sipes as proof that the use of CCA for construction is hazardous to construction workers' health. The toxicological report and treating doctors' reports are also presented as evidence to support the assertion that CCA use by construction personnel is hazardous.

The AWPI has created a marketing campaign to understate the hazards posed by use of their products as was demonstrated in the conflicting memos presented in Chapter Six. This research also presented registration procedures CCA has faced since 1978 . The partial settlement of the RPAR completed in 1985 was an agreement between the EPA and the AWPI that created another two decades of CCA use to 2007. The inefficiency of the customer awareness program promised by the AWPI for the RPAR settlement and the discontinuation of the program has been discussed. The anticipated Re-registration Eligibility Decision (RED) by the EPA that was expected many times in the past is now scheduled for the end of 2007.

Currently the Mat-Ranger software is a working model as a construction material selector. Materials were assessed for toxic off gassing, impact during harvesting, and their emissions while being manufactured. The materials also were evaluated for renewable resource qualities and ecosystem depletion impacts. The potential to expand in the second version of the Mat-Ranger is built in, as that version will have scoring on construction materials and their rankings will be more detailed. The user inputs, which now have a limited scale, will offer more choices as alternative materials come available. The DSS also has the capacity to expand as more data about hazards for workers and the 
environment are implemented into the database. The health of the end user of construction materials will also be considered in more detail in the future version.

\subsection{RECOMMENDATIONS FOR ACTION}

\subsubsection{EPA Authority Related to CCA}

The EPA administrator has the authority to remove the registration of a product that it deems hazardous to the environment or to human health. This authority can immediately revoke the registration of CCA, thus shifting the burden of proof of the benefits of CCA back to the registrants instead of the current stalemate that exists. This would have the effect of preventing more CCA occupational exposures and preventing more waste from reaching the landfills while any additional research was completed.

\subsubsection{Catalogue CCA Structure Locations in Municipalities}

Municipalities, as well as federal and state park systems, should locate and identify all CCA structures under their jurisdiction in order to post warnings on them and to schedule a maintenance program to remove these structures. This is especially important for play structures where children are at risk or where sensitive habitat or water supplies are in proximity of the structures. If the budget of these agencies does not allow for removal, or sealing, of the CCA structures they should be cordoned off until the hazards can be mitigated by sealants or replacement structures.

\subsubsection{Home Owners Warnings}

The previous settlement between CCA registrants and the EPA to promote a consumer awareness program was not effective due to a lack of follow through on the part of the registrants. This agreement should be enforced by the EPA and rewritten to 
include warnings to homeowners and the general public about the dangers of CCA. These warnings should:

- Give homeowners information about testing kits for the CCA wood and the soil around structures in and around their home.

- Provide homeowners information about the most recent sealants that have been determined by EPA studies to be the most effective for sealing CCA structures.

- Disseminate information at least nationwide about the hazards of burning CCA, in particular about the danger of using CCA-treated wood in campfires and residential wood burning.

- Make available to the public the studies conducted by the Consumer Product Safety Commission (CPSC) to everyone who has purchased CCA play sets. The results of the studies, which state that children must wash their hands thoroughly after exposure to the equipment to avoid arsenic assimilation, should be common knowledge.

- Launch a nationwide campaign in all media sources, as well as a direct link from CCA play set manufactures to their consumers.

\subsubsection{Reverse Hazardous Waste Exemption for CCA}

Due to the negative impacts on landfill workers and growing environmental concerns, it is recommended that the EPA reverse the temporary hazardous waste exemption granted to CCA wood waste. The disposal of CCA-treated wood causes problems for the natural environment due to the contamination of soil and ground water. The direct burial method used in the United States has been shown to be an ineffective system for hazardous waste disposal. A large quantity of CCA waste is projected to reach landfills in the next ten years and this requires the implementation of methods to control this waste stream before the disposed wood becomes an even greater issue for clean up and future containment. At a minimum, there should be a mandatory separation 
of CCA from other construction waste, similar to the rules for creosote, with the CCA waste stream then directed to hazardous waste sites.

\subsubsection{Separation Technologies}

Separation technologies are under investigation and there are some positive results for successfully separating CCA waste from other types of wood. Visual sorting is not effective since the identifying green color fades or is covered when the products are painted or coated. A laser automation system was created in order to detect CCA from the emission signal of the chromium, and this was effective up to $95 \%$ of the time, but an inability to detect differences in saturated wood samples was a drawback. Permanent identification systems have been investigated but the use of these is still being explored to determine their viability. Suggestions for using bar codes, chips, or indelible stamps on the CCA have been made, but these would have to stand up to the life cycle of the wood.

\subsubsection{Fire Maps}

Fire maps, used by fire fighters, can alert them of possible hazards they will encounter during a fire at a particular structure. Part of this warning system is through the use of MSDS sheets provided to them from industrial and manufacturing companies as part of the "right to know" act. The classification of CCA wood on the current Material Safety Data Sheet is not sufficient to warn about toxic chemical combustion and fumes from CCA and if the wood is contained within a structure, there are no MSDS sheets required. However, with the danger of toxic fumes from CCA wood, there should be a category added to fire map plans that are used by fire fighters to identify the location of CCA wood structures or members within buildings. With this alert, the proper gear 
and handling precautions could reduce occupational exposure for firefighters to highly toxic gases. These plans may also help fire clean up crews or construction personnel who are potentially exposed to toxic ash during demolition of the remaining structure or from residual toxins from the $\mathrm{CCA}$ ash.

\section{3: RECOMMENDATIONS FOR FURTHER RESEARCH}

\subsubsection{National Environmental Policy Act (NEPA)}

There is a need for some past legislation to be reevaluated by the government. Tile 1 Sec. 101 [42 USC $\S 4331$ ] (b) of the National Environmental Policy Act of 1969, and amended several times later, stated in its first three congressional declarations that its purpose is to (NEPA, 1969, p. 2):

(1) "Fulfill the responsibilities of each generation as trustee of the environment for succeeding generations

(2) Assure for all Americans safe, healthful, productive, and aesthetically and culturally pleasing surroundings

(3) Attain the widest range of beneficial uses of the environment without degradation, risk to health or safety, or other undesirable and unintended consequences"

In order to fulfill these objectives, the continued use of toxic chemicals to treat wood building products needs to be reevaluated by the government. The use of CCA violates of all three of these declarations. The use of CCA creates a risk to workers health and safety, it degrades the environment by leaching and water contamination, and the treated wood products are leaving a footprint of environmental degradation to be passed on to future generations. This is not proper stewardship and it is not acting as an environmental trustee for future generations. 


\subsubsection{Water Purification}

The use of technology has created many new techniques for cleaning up contaminated water. A study could be conducted that compiles a list of these techniques in order to determine an inexpensive method for arsenic and chromium removal that doesn't produce an abundance of toxic byproducts.

\subsubsection{Group Health}

A study could be performed that tracks a group of construction workers who handle CCA regularly in order to determine whether there is a link between the hazardous exposure they experience and health issues. Research workers' compensation records for construction and wood preservative industry workers to see if there are any similarities to symptoms described by the plaintiff Sipes in the lawsuit. This investigation could include doctors' records for amputated fingers, boils, and cancerous cysts from treated wood slivers, hair loss, general weakness, gastrointestinal varices, fatigue, disorientation, atrophy of the legs, cramps, loss of feeling in the hands, and paralysis of the face including Bell's Palsy.

\subsubsection{Synergy}

Investigate research projects that have identified the effects of human exposure to multiple toxins simultaneously. The dissertation by Dr. Rita Meyninger addressed this issue in relation to Hazardous Waste Site Remediation at Love Canal.

\subsubsection{Leachate Flow}

Further research is recommended in the fields of Geotechnical Engineering and Water Resources Engineering on techniques that contain leachate flows in landfills and 
containment lining systems. Leachate flow through soil and rubbish has been observed in several studies carried out at Florida Universities with the use of Lysimeters and groundwater flow studies. A method to neutralize the heavy metals in the flow of leachate could be another area to study.

\subsubsection{Separation Technologies}

Investigate the latest transportation and separation techniques for CCA including a cost analysis. This could include using bar codes or an indelible stamp in order to trace the CCA lumber from cradle to grave. The best technology would be a lifetime identification system for CCA wood. There are electrical components capable of detecting arsenic in wood, but their expense makes wide scale implementation cost prohibitive.

\subsubsection{Soil Decontamination}

Research the economical techniques to remove CCA metals from soil. Investigate whether removal of contaminated soil from a site is necessary, and whether the soil can be used after treatment. What are the costs of these undertakings and how can they be incorporated for the landfill dilemma we will be facing by 2010 .

\subsubsection{Alternative Wood Treatments}

Research the alternative wood treatments that successfully prevent mold, fungus, and insect attack, but that don't have the corollary effect of current wood treatment alternatives of corroding nails, screws, and other metal building materials. 


\subsubsection{Mat-Ranger Future Data Needs}

A detailed ranking of materials is necessary for versatility in the future versions of the Mat-Ranger DSS. More detailed data on the specific construction materials effects on the environment and on the health of construction workers are also to be gathered for the next version of the software. Data on the effect of construction materials on human health during the materials in service phase will also be required.

The research gathered for this work has demonstrated a need to reclassify CCA as a hazardous material, in order to protect the construction work force, and the environment, from known dangers. It was also shown that workers using CCA are at risk and our water supplies are in danger of heavy metal contamination from landfills. In 2007 , at this instant, we have the ability to control the damage before it happens. 


\section{REFERENCE LIST}

AWPI, 1977. American Wood Preservers Institute Environmental Programs Task Group Subcommittee No. 1 to the Environmental Protection Agency Office of Pesticide Programs, Memorandum: Arsenical Wood Preservatives, August 1977.

AWPI, 1981. American Wood Preservers Institute, Correspondence, 9 June 1981. "AWPI's Response to EPA Proposal for Rulemaking Under Toxic Substances Control Act to Require Circulation of Warnings with Respect to Use of Treated Wood Products."

AWPI, 1982. American Wood Preservers Institute, et al. to Paul Lapsley, Chief, Chemical Review Branch \#4, Special Pesticide Review Division (TS-791), Correspondence, 15 September 1982.

Arsenault, 1977. Arsenault, R. D. to Koppers Interoffice Correspondence Memo to File re: CCA Dust Toxicity. 25 July 1977.

ATSDR, 2002. Arkansas Department of Health Under Cooperative Agreement with the Agency for Toxic Substances and Disease Registry. "Public Health Assessment: Mountain Pine Pressure Treating: Plainview, Yell County, Arkansas." September 24. http://www.atsdr.cdc.gov/HAC/PHA/mountainpine/mpp_p2.html (accessed December 22, 2005).

ATSDR, 2005. U.S. Department of Health and Human Services Agency for Toxic Substances and Disease Registry. "2005 CERCLA Priority List of Hazardous Substances That Will Be the Subject of Toxicological Profiles and Support Document." November 2005.

ATSDR, 2006. U.S. Department of Health and Human Services Agency for Toxic Substances and Disease Registry. "Toxicological Profile Information Sheet." http://www.atsdr.cdc.gov/toxpro2.html (accessed January 14, 2007).

Beder, 2003. Beder, Sharon. "Timber Leachates Prompt Preservative Review." Engineers Australia 75:6, June 2003.

Bleiwas, 2000. Bleiwas, Donald I. "Arsenic and Old Waste." U.S. Geological Survey. February 22. http://minerals.usgs.gov/minerals/mflow/d00-0195/ (accessed October $15,2004)$.

California Department of Health Services, 2005. California Department of Health Services. "Arsenic in Drinking Water: California MCL Status." October 17. http://www.dhs.ca.gov/ps/ddwem/chemicals/arsenic/newmcl.htm (accessed June 4, 2006). 
REFERENCE LIST, continued

CA EPA, 2004. California Environmental Protection Agency. "Public Health Goals for Chemicals in Drinking Water: Arsenic." April 2004. http://www.oehha.ca.gov/ water/phg/pdf/asfinal.pdf (accessed July 8, 2004).

CA EPA, 2006. California Environmental Protection Agency. "Office Of Environmental Health Hazard Assessment Safe Drinking Water And Toxic Enforcement Act Of 1986: Chemicals Known To The State To Cause Cancer Or Reproductive Toxicity." December 8. http://www.oehha.ca.gov/prop65/prop65_list/files/P65single120806.pdf (accessed December 15, 2006).

Clausen and Kenealy, 2004. Clausen, Carol A. and William R. Kenealy, 2004. "Scaled-Up Remediation of CCA-Treated Wood." Paper presented at the Environmental Impacts of Preservative-Treated Wood conference for the Florida Center for Environmental Studies, Orlando, FL. February 8-11. http://www. ccaconference.org/post/pdf/clausen.pdf (accessed March 30, 2005).

Committee on Medical and Biological Effects of Environmental Pollutants, 1977. Committee on Medical and Biological Effects of Environmental Pollutants: Arsenic. "Biologic Effects of Arsenic on Man." Washington, D.C.: National Academy of Sciences, 1977. http://fermat.nap.edu/books $/ 0309026040 / \mathrm{html} / 173 . \mathrm{html}$ (accessed June 7, 2006).

EPA, 1985a. U.S. Environmental Protection Agency. "NIOSH Manual of Analytical Methods." 1985. http://www.epa.gov/oamsrpod/pmrcse/ROC/R9/PWS.pdf (accessed December 12, 2004).

EPA, 1985b. U.S. Environmental Protection Agency. Correspondence from Office of General Counsel (Counsel for Respondent; Telephone 202-382-7505) in the matter of Chapman Chemical, et al. (Petitioners) "Notice of Settlement Agreement." 30 September 1985 .

EPA, 2002. U.S. Environmental Protection Agency. "Arsenic Treatment Technologies for Soil, Waste, and Water." September. http://www.epa.gov/tio/download/remed/ 542r02004/arsenic_report.pdf (accessed March 19, 2006).

EPA, 2003. U.S. Environmental Protection Agency. "Chromated Copper Arsenate (CCA): EPA Testimony on Chromated Copper Arsenate (CCA) Treated Wood." March 17. http://www.epa.gov/oppad001/reregistration/cca/ccatestimony1.htm (accessed December 5, 2004). 
REFERENCE LIST, continued

EPA, 2004. U.S. Environmental Protection Agency. "Cancellation of Residential Uses of CCA-Treated Wood." August 13. http://www.epa.gov/pesticides/factsheets/ chemicals/1file.htm (accessed April 14, 2005).

EPA, 2005a. U.S. Environmental Protection Agency. "Chromated Copper Arsenate (CCA)." May 27. http://epa.gov/oppad001/reregistration/cca/ (accessed September 19, 2005).

EPA, 2005b. U.S. Environmental Protection Agency. "Pesticide Reregistration Facts." May 25. http://www.epa.gov/oppsrrd1/reregistration/reregistration_facts.htm (accessed September 19, 2005).

EPA, 2006a. U.S. Environmental Protection Agency. "Arsenic in Drinking Water." April 19. http://www.epa.gov/safewater/arsenic/index.html (accessed May 5, 2006).

EPA, 2006b. U.S. Environmental Protection Agency. "C\&D Debris Disposal." February 22. http://222.epa.gov/epaoswer/non-hw/debris-new/disposal.htm (accessed May 5, 2006).

EPA, 2006c. U.S. Environmental Protection Agency. "Questions \& Answers on CCATreated Wood Sealant Studies (Interim Results)." July 20. http://www.epa.gov/ oppad001/reregistration/cca/sealant_qa.htm\#1 (accessed August 12, 2006).

EPA, 2007a. U.S. Environmental Protection Agency. "Acid Copper Chromate (ACC) Residential Uses Won't Be Registered." January 8. http://www.epa.gov/ pesticides/factsheets/chemicals/acid_copper_chromate.htm (accessed January 15, 2007).

EPA, 2007b. U.S. Environmental Protection Agency. "Chromated Copper Arsenate (CCA): Timeline of Major CCA Actions." March 13. http://www.epa.gov/oppad001/ reregistration/cca/timeline.htm (accessed March 15, 2007).

Federal Register 45, 1980. U.S. Environmental Protection Agency. Federal Register Vol. 45. 1980. See the EPA Library, San Francisco, CA.

Federal Register 51, 1986. U.S. Environmental Protection Agency. Federal Register Vol. 51. 10 January 1986. Page 1334. See the EPA Library, San Francisco, CA.

Federal Register 53, 1988. U.S. Environmental Protection Agency. Federal Register Vol. 53. 1988. See the EPA Library, San Francisco, CA. 


\section{REFERENCE LIST, continued}

Federal Register 56, 1991. U.S. Environmental Protection Agency. Federal Register Vol. 56. 1991. See the EPA Library, San Francisco, CA.

Federal Register 60, 1995. U.S. Environmental Protection Agency. Federal Register Vol. 60. 1995. See the EPA Library, San Francisco, CA.

Federal Register 67, 2002. U.S. Environmental Protection Agency. Federal Register Vol 67 (36). February 22. See the EPA Library, San Francisco, CA. Pages 82448246.

Federal Register 68, 2003. U.S. Environmental Protection Agency, 2003. "Response to Requests to Cancel Certain Chromated Copper Arsenate (CCA) Wood Preservative Products and Amendments to Terminate Certain Uses of Other CCA Products." Federal Register 68 (68). April 9. Pages 17366-17367. http://www.epa.gov/ EPA-PEST/2003/April/Day-09/p8372.htm (accessed June 22, 2003).

Federal Register 69, 2004. U.S. Environmental Protection Agency. Federal Register Vol. 69. 2004. See the EPA Library, San Francisco, CA.

FIFRA, 2003. FIFRA Scientific Advisory Panel Meeting. Minutes. Arlington, Virginia. 3-5 December 2003.

Genium, 1993. Genium Publishing Corporation, The MSDS Pocket Dictionary. New York: Genium Publishing Corporation, 1993.

Hauserman, 2001. Hauserman, Julie. "Arsenic Fears Rise Over Treated Wood Disposal." St. Petersburg Times. 11 March 2001.

Helsen, 2004. Helsen, Lieve and Eric Van den Bulck. "Review of Thermochemical Conversion Processes as Disposal Technologies for Chromated Copper Arsenate (CCA) Treated Wood Waste." Paper presented at the Environmental Impacts of Preservative-Treated Wood conference for the Florida Center for Environmental Studies, Orlando, FL. February 8-11. http://www.ccaconference.org/post/pdf/ helsen.pdf (accessed March 30, 2005).

Holtz, 2006. Holtz, Robert D. "Introduction to Environmental Engineering." Prentice Hall: 2006. ISBN 0130317217.

Iida, 2004. Iida, Kenjiro, John Pierman, Thabet Tolaymat, Timothy Townsend, and Chang-Yu Wu. "Control of Chromated Copper Arsenate Wood Incineration Air Emissions and Ash Leaching Using Sorbent Technology." Journal of Environmental Engineering. February 2004: 184-192. 
REFERENCE LIST, continued

Isbell, 2007. Diane, Acting Team Leader, U.S. Environmental Protection Agency Antimicrobials Division to Ken Nowak, researcher, correspondence re: CCA Re-registration, February 2007.

Johnloz, 1985. David K. M.D. (Internal Medicine Associates of Bloomington, Inc.) to McCrea, David S., correspondence re: James R. Sipes, 10 June 1985.

Jones-Lee and Lee, 1993. Jones-Lee, Anne, and G. Fred Lee. "Groundwater Pollution by Municipal Landfills: Leachate Composition, Detection and Water Quality Significance." Paper presented at the Sardinia '93IV International Landfill Symposiums, Margherita di Pula, Italy. October 11-15. http://www.gfredlee .com/lf-conta.htm (accessed April 17, 2006).

Khan and Solo-Gabriele, 2006. Khan, Bernine I., Helena M. Solo-Gabriele, Timothy. G. Townsend, and Yong Cai. "Release of Arsenic to the Environment from CCATreated Wood. 1. Leaching and Speciation during Service." Environmental Science \& Technology 2006 (40).

Khan and Jambeck, 2006. Khan, Bernine I., Jenna Jambeck, Helena M. Solo-Gabriele, Timothy G. Townsend, and Yong Cai. "Release of Arsenic to the Environment from CCA-Treated Wood. 2. Leaching and Speciation during Disposal." Environmental Science \& Technology 2006 (40).

Lebow, 2004. Lebow, Stan. "Alternatives to Chromated Copper Arsenate (CCA) for Residential Construction." Paper presented at the Environmental Impacts of Preservative-Treated Wood conference for the Florida Center for Environmental Studies, Orlando, FL. February 8-11. http://www.ccaconference.org/post/pdf/lebow. pdf (accessed March 30, 2005).

Lebow and Cooper, 2004. Stan, Paul Cooper, and Patricia Lebow. "Variability in Evaluating Environmental Impacts of Treated Wood." Paper presented at the Environmental Impacts of Preservative-Treated Wood conference for the Florida Center for Environmental Studies, Orlando, FL. February 8-11. http://www. ccaconference.org/post/pdf/lebowl.pdf (accessed March 30, 2005).

Merriam-Webster, 2007. Merriam-Webster, Inc. http://m-w.com/ (accessed March 12, 2007).

Miller, 2006. Miller, Rebecca. Director, U.S. Environmental Protection Agency Antimicrobials Division to Ken Nowak, researcher, correspondence re: CCA Reregistration, 16 June 2006. 
REFERENCE LIST, continued

Meyninger, 1992. Meyninger, Rita. "A Strategy for Evaluating Hazardous Waste Site Remediation." Dissertation in Partial Fulfillment of the Requirements for the Degree of Doctor of Philosophy (Civil Engineering), Polytechnic University, May, 1992.

NEPA, 1969. National Environmental Policy Act of 1969, as amended (Pub. L. 91-190, 42 U.S.C. 4321-4347, January 1, 1970, as amended by Pub. L. 94-52, July 3, 1975, Pub. L. 94-83, August 9, 1975, and Pub. L. 97-258, § 4(b), Sept. 13, 1982). http://ceq.eh.doe.gov/nepa/regs/nepa/nepaeqia.htm (accessed June 18, 2004).

NINDS, 2007. National Institute of Neurological Disorders and Stroke, February 12. http://www.ninds.nih.gov/disorders/bells/bells.htm (accessed February 20, 2007).

OSHA, 1978. U.S. Department of Labor. Occupational Safety and Health Administration. "Applicability of the Inorganic Arsenic Standard to Operations Involving Chromated Copper Arsenate (CCA) Wood Preservative." October 6. http://www.osha.gov/pls/oshaweb/owadisp.show_document?p_table=INTERPRETA TIONS\&p_id=18754 (accessed October 23, 2004).

OSHA, 1986. U.S. Department of Labor. Occupational Safety and Health Administration. "CSP 02-01-001 - TED 3.7 - Consultation for Wood Treatment Operations Utilizing Inorganic Compounds." September 9. http://www.osha.gov/pls/ oshaweb/owadisp.show_document?p_table=DIRECTIVES\&p_id $=1885$ (accessed July 17, 2005).

OSHA, 2006. U.S. Department of Labor. Occupational Safety and Health Administration. "Occupational Exposure to Hexavalent Chromium - 71:1009910385." February 28. http://www.osha.gov/pls/oshaweb/owadisp.show_document? p_table=FEDERAL_REGISTER\&p_id=18599 (accessed January 16, 2007).

Peters, 1983. Peters, H.A., W.A. Croft, E.A. Woolson, B. and Darcey. M. Olson from the Medical School, University of Wisconsin at Madison and United States Agricultural Research Center, Beltsville, Maryland. "Hematological, Dermal and Neuropsychological Disease from Burning and Power Sawing Chromium-CopperArsenic (CCA)-Treated Wood." Contact the U.S. Agricultural Center for additional information. 1983.

PMRA, 2005. Health Canada's Pest Management Regulatory Agency. "Fact Sheet on Chromated Copper Arsenate (CCA) Treated Wood." May. http://www.pmra-arla.gc. ca/english/pdf/fact/fs_cca-e.pdf (accessed February 14, 2006). 
REFERENCE LIST, continued

SJSU GSO, 2002. San José State University Graduate Studies Office. "General Instructions for Master's Theses." October 16, 2002v. http://www.sjsu.edu/grad studies/forms/thesisguidenew.pdf (accessed April 1, 2007).

Schroeder, 2004. Schroeder, Paul R. and Nadim M. Aziz. "Leachate Dispersion in Aquifers under Disposal Facilities." Practice Periodical of Hazardous, Toxic, and Radioactive Waste Management. 1 July 2004. 8, 142.

Sipes v. Osmose, 1989. Sipes v. Osmose Wood Preserving Company of America, Inc. 546 N.E. $2^{\text {nd }}$ 1223: Indiana Sup. Ct. (1989).

Sipes v. Osmose, 1992. Sipes v. Osmose Wood Preserving, Inc. 600 N.E. 2d: Indiana $5^{\text {th }}$ District Ct. of Appeals (1992).

Smith and Curole, 2005. Smith, W. Ramsay and Jay Curole. "Analysis of Coptotermes formosanus Testing Techniques." American Wood Preservers Association (AWPA), 2005 Colley/Hartford Research Symposium Abstracts, 2005, http://www.awpa.com/ references/documents_PDF/2005/SymposiumAbstracts.pdf (accessed March 20, 2006).

Springer, 2004. Springer, Robert (Director, Office of Solid Waste) and Jim Jones (Director, Office of Pesticide Programs) to U.S. Environmental Protection Agency Resource Conservation and Recovery Act Division Directors, Regional Pesticide Program Leads, and EPA Regions I to X), memorandum. January 6. "Wood Mulch Derived from Waste Lumber Preserved with Chromated Copper Arsenate." http://www.epa.gov/oppad001/reregistration/cca/mulch_text_only.htm (accessed August 12, 2005).

Weber, 2002. Weber, William J., Yond-Chul Jang, Timothy G. Townsend, and Steven Laux. "Leachate from Land Disposed Residential Construction Waste." Journal of Environmental Engineering. March 2002: 237-245.

WHO, 2004. World Health Organization International Agency For Research On Cancer (IARC). "Monographs on the Evaluation of Carcinogenic Risks to Humans: Volume 84 Some Drinking-water Disinfectants and Contaminants, including Arsenic." September 28. http://monographs.iarc.fr/ENG/Monographs/vol84/volume84.pdf (accessed May 22, 2006).

Yates, 1993. J. K. "Construction Decision Support System For Delay Analysis." American Society of Civil Engineers (ASCE). June 1993. 119 (2): 226-243. 


\section{APPENDIX A:}

\section{GLOSSARY}

The following definitions are for the terms and acronyms used in this thesis. These terms and acronyms are both in one alphabetically ordered list. One source for this glossary is the Agency for Toxic Substances and Disease Registry (ATSDR, 2002). Another source is the Merriam-Webster Online Search; that is, their dictionary (MerriamWebster, Inc., 2007). Other unique reference sources are noted when applicable. Lastly, other terms with their definitions are public knowledge and provided for your convenience.

ACC: Acid Copper Chromate (a CCA alternative).

ACQ: Alkaline Copper Quaternary (a CCA alternative).

Adsorption: The adhesion in an extremely thin layer of molecules (as of gases, solutes, or liquids) to the surfaces of solid bodies or liquids with which they are in contact (Merriam-Webster).

Aliphatic: An organic compound (as an alkane) having an open-chain structure. Compare to Aromatic (Merriam-Webster).

Alopecia: Hair loss.

Ansar series: The original source for this term's usage was http://www.epa.gov/ oamsrpod/pmrcsc/ROC/R9/PWS.pdf (accessed March 12, 2007).

Aquifer: Water-bearing stratum of permeable rock, sand, or gravel (Merriam-Webster).

Aromatic: An organic compound with increased chemical stability resulting from the delocalization of electrons in a ring system (as benzene) containing usually multiple conjugated double bonds. Compare to Aliphatic (Merriam-Webster).

Arsenical: Pronounced är-'se-ni-k\&l. Of, relating to, containing, or caused by arsenic; e.g., arsenical poisoning (Merriam-Webster).

ASCE: American Society of Civil Engineers. 
GLOSSARY, continued

Atherogenic: Causing abnormal fatty deposit in an artery (Merriam-Webster).

ATSDR: The Agency for Toxic Substances and Disease Registry. ATSDR is a federal health agency in Atlanta, Georgia that deals with hazardous substance and waste site issues. ATSDR gives people information about harmful chemicals in their environment and tells people how to protect themselves from coming into contact with chemicals (ATSDR).

AWPA: American Wood Preservers Association.

AWPI: American Wood Preservers Institute.

Bell's Palsy: A type of facial paralysis resulting from damage or trauma facial nerve(s) (NINDS, 2007).

CA-B: Copper Azole (a CCA alternative).

Cancer: A group of diseases which occur when cells in the body become abnormal and grow, or multiply, out of control (ATSDR).

Carcinogen: Any substance shown to cause tumors or cancer in experimental studies (ATSDR).

CBA-A: Copper Azole (a CCA alternative).

C\&D: Construction and Demolition.

CC: Copper Citrate (a CCA alternative).

CCA: Chromated Copper Arsenate.

CDDC: Copper dimethyldithiocarbamate (a CCA alternative).

CERCLA: Comprehensive Environmental Response, Compensation, and Liability Act. CERCLA was put into place in 1980. It is also known as Superfund. This act concerns releases of hazardous substances into the environment, and the cleanup of these substances and hazardous waste sites. ATSDR was created by this act and is responsible for looking into the health issues related to hazardous waste sites (ATSDR).

Chronic Exposure: A contact with a substance or chemical that happens over a long period of time. ATSDR considers exposures of more than one year to be chronic (ATSDR). 
GLOSSARY, continued

Colic: An attack of acute abdominal pain localized in a hollow organ and often caused by spasm, obstruction, or twisting (Merriam-Webster).

Coptotermes formosanus: Or, c. formosanus. A type of termite.

Coprecipitation: See the PDF's p. 74 of 132 of http://www.epa.gov/tio/download/remed/ 542r02004/arsenic_report.pdf (accessed March 12, 2007).

Creosote: A brownish oily liquid consisting chiefly of aromatic hydrocarbons distilled from coal tar and used especially as a wood preservative (Merriam-Webster).

CIS: Customer Information Sheet.

CPSC: Consumer Product Safety Commission.

CX-A: Copper HDO (a CCA alternative).

DART: Developmental and Reproductive Toxicant.

DEP: Florida's Department of Environmental Protection.

Edema: An abnormal infiltration and excess accumulation of fluid in connective tissue or in a cavity (as in a human body).

Electrodeposition: To deposit (as a metal or rubber) by electrolysis (which is the producing of chemical changes by passage of an electric current through an electrolyte) (Merriam-Webster).

Encephalopathy: Disease of the brain; especially involving alterations of brain structure (Merriam-Webster).

Environment: For the purposes of the U.S. Code Title 7 Chapter 6 Subchapter II $\S: 136 a$, environment includes water, air, land, and all plants and man and other animals living therein, and the interrelationships which exist among these.

EP: Extraction Process.

EPA: Environmental Protection Agency. The U.S. federal agency that develops and enforces environmental laws to protect the environment and the public's health (ATSDR).

FEMA: Federal Emergency Management Agency. 


\section{GLOSSARY, continued}

FIFRA: Insecticide, Fungicide, and Rodenticide Act.

FR: Federal Register.

FQPA: Food Quality Protection Act.

Green: Anything ecologically-friendly, such as materials.

HazDat: Hazardous Substance Release Database.

HEW: U.S. Department of Health, Education, and Welfare.

IARC: International Agency for Research on Cancer.

Lysimeter: A device for measuring the percolation of water through soils and for determining the soluble constituents removed in the drainage (Merriam-Webster).

MCL: Maximum Containment Level.

MRL: Minimal Risk Level. An estimate of daily human exposure by a specified route and length of time - to a dose of chemical that is likely to be without a measurable risk of adverse, noncancerous effects. An MRL should not be used as a predictor of adverse health effects (ATSDR).

MSDS: Material Safety Data Sheet.

NEPA: National Environmental Policy Act of 1969, as amended by Pub. L. 91-190, 42 U.S.C. 4321-4347, January 1, 1970, as amended by Pub. L. 94-52, July 3, 1975, Pub. L. 94-83, August 9, 1975, and Pub. L. 97-258, § 4(b), Sept. 13, 1982. An Act to establish a national policy for the environment, to provide for the establishment of a Council on Environmental Quality, and for other purposes. http://ceq.eh.doe .gov/nepa/regs/nepa/nepaeqia.htm (accessed March 12, 2007).

NFPA: National Forest Products Association.

NPL: The National Priorities List. Part of Superfund, this list kept by the U.S. Environmental Protection Agency (EPA) is of the most serious, uncontrolled, or abandoned hazardous waste sites in the country. An NPL site needs to be cleaned up or is being looked at to see if people might be exposed to chemicals from the site (ATSDR).

NTIS: National Technical Information Service. 
GLOSSARY, continued

OSHA: U.S. Occupational Safety and Health Administration.

Paresthesias: A sensation of pricking, tingling, or creeping on the skin that has no objective cause (Merriam-Webster).

PEL: Permissible Exposure Limits.

Phytoremediation: "Involves the use of plants to degrade, extract, contain, or immobilize contaminants in soil, sediment, and groundwater" (EPA, 2002, p. 12).

Phytotoxic: Poisonous to plants (Merriam-Webster).

ppb: Parts Per Billion.

ppm: Parts Per Million. A unit of measure used to express low concentrations of contaminants. For example, 1 once of chlorine in 1 million ounces of water is $1 \mathrm{ppm}$. One ppm is comparable to one drop of gasoline in a full sized car's tank full of gas (ATSDR).

PPE: Personal Protective Equipment.

PRIA: Pesticide Registration Improvement Act.

RED: Re-registration Eligibility Decisions.

REI: Restricted Entry Interval.

RPAR: Rebuttable Presumption Against Registration.

SARA: The Superfund Amendments and Reauthorization Act in 1986 amended CERCLA and expanded the health-related responsibilities of ATSDR. The CERCLA and SARA direct ATSDR to look into the health effects from chemical exposures at hazardous waste sites (ATSDR).

SAWP: Society of American Wood Preservers Inc.

Smelting: Melting or fusing (as ore) often with an accompanying chemical change usually to separate the metals (Merriam-Webster).

Sorbent: A substance that takes up and holds by either adsorption or absorption (Merriam-Webster).

Superfund: Laws and amendments after CERCLA. See CERCLA. 
GLOSSARY, continued

TCLP: Toxicity Characteristic Leaching Procedure.

Teratogenic: Causing developmental malformations (Merriam-Webster).

Thrombocytopenia: Persistent decrease in the number of platelets in the blood that is often associated with hemorrhagic conditions (Merriam-Webster).

U.S.: United States.

USDA: U.S. Department of Agriculture.

Varices: Plural of the word "varix." Abnormally dilated and lengthened veins, arteries, or lymph vessels; especially: varicose veins, (Merriam-Webster). 


\section{APPENDIX B:}

\section{RELATED RESEARCH SOURCES}

This appendix lists some of the sources researched but not used in the thesis, since they were not needed to support any assertions. See the following references for additional information on topics related to this thesis:

Bradley, Brian C., 2006 'Lethal 'Pressure-Treated' Wood." March 13. http://www. chebucto.ns.ca/Environment/RATE/Lethal_pressure_treated.html (accessed March $15,2007)$.

Brooks, William E. U.S. Geological Survey: Arsenic. Mineral Commodity Summaries. January 2005.

CCH Product Liability Report. Appendix C, p. 12322. 1989.

Christen, Kris, 2005. "Arsenic-Treated Wood May Have a Long Toxic Legacy." Environmental Science \& Technology. December 21. http://pubs.acs.org/sub scribe/journals/esthag-w/2005/dec/science/kc_arsenic.html (accessed March 15, 2007).

Dorman v. Osmose, Inc. 31 January 2003.

Evenson v. Osmose Wood Preserving Company of America, Inc. 18 April 1990.

Feldman, Jay, et al. Letter to Honorable Stephen Johnson, EPA Administrator about ReRelease of ACC Treated Wood," 2006. July 5. http://www.beyondpesticides.org/ wood/pubs/ACCltr.EPA.final.pdf (accessed March 15, 2007).

Hechler, David, 2003. "The Poisoned Wood Mystery." The National Law Journal. March 20. http://www.law.com/servlet/jsp/law/LawArticleFriendly.jsp?id= 1046833573563 (accessed March 15, 2007).

Hunt, Andrew, Andrea, Sidney and Bailey Hunt vs. American Wood Preservers Institute, Unknown Chemical Manufacturer No. One, Unknown Chemical Manufacturer No. Two, Southeast Wood Treating, Inc., Universal Forest Products, and Furrow Building Materials. Deposition of Mel Harkrader Pine. U.S. District Court, Southern District of Indiana, Indianapolis Division Case No. IP02-C-0389-M/S. I. Summary. 6 June 2002. 


\section{RELATED RESEARCH SOURCES, continued}

"Instructions to Professional Services Contract (P-500) Checklist and Transmittal Sheet." (4-04): 23. http://www.sfgov.org/site/uploadedfiles/sfport/RFPs/P500\%20 Contract\%20Instructions.pdf (accessed March 15, 2007).

Jacobs, et al. v. Osmose, Inc., et al. 25 February 2003.

Kwon, Elena, Hongquan Zhang, Zhongwen Wang, Gian S. Jhangri, Xiufen Lu, Nelson Fok, Stephan Gabos, Xing-Fang Li, and X. Chris Le. "Arsenic on the Hands of Children after Playing in Playgrounds." Environmental Health Perspectives. October 2004. 112 (14):1375-1380. http://www.ehponline.org/docs/2004/7197/abstract.html (accessed March 15, 2007).

McCrae, David. Attorney. Interviews by thesis author/researcher, San José, California, 5 July 2006, et al.

Napier v. Osmose, Inc. 14 November 2005.

National Pesticide Information Retrieval System. http://ppis.ceris.purdue.edu/htbin/ prodset.com (accessed March 15, 2007).

Oskoui, Kazem Eradat, $\mathrm{PhD}$. "Recovery and Reuse of the Wood and Chromated Copper Arsenate (CCA) from CCA Treated Wood: A Technical Paper." Paper presented at the Environmental Impacts of Preservative-Treated Wood conference for the Florida Center for Environmental Studies, Orlando, FL. February 8-11. http://www. ccaconference.org/post/pdf/oskoui.pdf (accessed March 30, 2005).

Parks, Jeffrey L. and Marc Edwards. "Preciptative Removal of As, Ba, B, Cr, Sr, and V Using Sodium Carbonate." Journal of Environmental Engineering. Vol. 132, Issue 5: 489-496. (May 2006).

Searcy, Margie Tyler, Esq. A Guide to Toxic Torts. (Matthew Bender 1987, volume 2) Chapter 28: How to Handle a CCA Lumber Case. § 28.54[1].

Steptoe \& Johnson to Document Control Officer, Management Support Division (TS393), U.S. Environmental Protection Agency, Correspondence, 10 June 1981. "OPP30000/28C; RPAR of Wood Preservatives; AWPI Response to EPA Proposal for Rulemaking Under Toxic Substances Control Act to Require Circulation of Warnings With Respect to Use of Treated Wood Products." 
RELATED RESEARCH SOURCES, continued

Stillwell, David. E., 1998. "Environmental Issues on the Use of CCA Treated Wood." The Connecticut Agricultural Experiment Station. Department of Analytical Chemistry. December. http://www.caes.state.ct.us/FactSheetFiles/Analytical Chemistry/fsAC001f.htm (accessed March 15, 2007).

The Chicago Manual of Style, $15^{\text {th }}$ ed. 2003. Chicago: Univ. of Chicago Press.

U.S. Department of Health, Education, and Welfare (HEW). National Institute for Occupational Safety and Health. "NIOSH Manual of Analytical Methods." 15 May 1985.

U.S. Department of Labor, 2004. Occupational Safety and Health Administration. Volume 69, Number 191. "Occupational Exposure to Hexavalent Chromium; Proposed Rule." October . http://www.osha.gov/FedReg_osha_pdf/FED20041004PRE.html (accessed March 15, 2007).

U.S. Department of Labor, 1994. Occupational Safety and Health Administration. "Review and Comment on Generic Labels and Consumer Information Sheets for Chromated Copper Arsenate (CCA) Pressure-Treated Lumber." August 31. http://www.osha.gov/pls/oshaweb/owadisp.show_document?p_table=INTERPRETA TIONS\&p_id=21589 (accessed March 15, 2007).

U.S. Environmental Protection Agency, 2006. “Arsenic Rule Implementation Research." May 9. http://www.epa.gov/ORD/NRMRL/arsenic/ (accessed March 15, 2007).

U.S. Environmental Protection Agency, 2006. "Arsenic Rule Implementation Research: FACT SHEET: EPA's Water Treatment Demonstration Project to Reduce Amount of Arsenic in Valley Vista, AZ, Drinking Water." March 1. http://www.epa.gov/ nrmrl/arsenic/fs/fs_vallleyvista.htm (accessed March 15, 2007).

U.S. Environmental Protection Agency, 2005. "Chromated Copper Arsenate (CCA): Alternatives to Pressure-Treated Wood." May 27. http://epa.gov/oppad001/ reregistration/cca/pressuretreatedwood_alternatives.htm (accessed March 15, 2007).

U.S. Environmental Protection Agency, 2005. "Chromated Copper Arsenate (CCA) and Its Use as a Wood Preservative." December 19. http://www.epa.gov/oppad001/ reregistration/cca/ (accessed March 15, 2007).

U.S. Environmental Protection Agency, 2004. "Chromated Copper Arsenate (CCA) Compliance Strategy." June 22. http://www.epa.gov/oppad001/reregistration/ cca/cca_strategy5.pdf (accessed March 15, 2007). 
RELATED RESEARCH SOURCES, continued

U.S. Environmental Protection Agency, 2005. "Chromated Copper Arsenate (CCA): Consumer Safety Information Sheet: Inorganic Arsenical Pressure-Treated Wood." May 27. http://www.epa.gov/oppad001/reregistration/cca/cca_consumer_safety.htm (accessed March 15, 2007).

U.S. Environmental Protection Agency, 2005. "Chromated Copper Arsenate (CCA): Cyproconazole - An Alternative to CCA." July 1. http://epa.gov/oppad001/ reregistration/cca/cyproconazole.htm (accessed March 15, 2007).

U.S. Environmental Protection Agency, 2005. "Chromated Copper Arsenate (CCA): Evaluating the Wood Preservative Chromated Copper Arsenate (CCA). May 27. http://www.epa.gov/oppad001/reregistration/cca/cca_evaluating.htm (accessed March $15,2007)$.

U.S. Environmental Protection Agency, 2005. "Chromated Copper Arsenate (CCA): Preliminary Risk Assessment for Workers Who Contact Wood Preservatives Containing Arsenic and/or Chromium and Ecological Effects Assessment: Questions and Answers." May 27. http://www.epa.gov/oppad001/reregistration/cca/cca qa_workers.htm (accessed March 15, 2007).

U.S. Environmental Protection Agency, 2005. "Chromated Copper Arsenate (CCA): Propiconazole - An Alternative to CCA." July 1. http://epa.gov/oppad001/ reregistration/cca/propiconazole.htm (accessed March 15, 2007).

U.S. Environmental Protection Agency, 2005. "Chromated Copper Arsenate (CCA): Questions \& Answers: Scientific Advisory Panel's Final Report on Preliminary Probabilistic Risk Assessment for Chromated Copper Arsenate." May 27. http://www.epa.gov/opp00001/antimicrobials/reregistration/cca/cca_sap_final_rpt_qas.htm (accessed March 15, 2007).

U.S. Environmental Protection Agency, 2006. "Chromated Copper Arsenate (CCA): Sealant Studies (Coatings)." July 6. http://www.epa.gov/oppad001/reregistration/ cca/index.htm\#sealants (accessed March 15, 2007).

U.S. Environmental Protection Agency, 2006. "Chromated Copper Arsenate (CCA): Timeline of Major CCA Actions." March 23. http://www.epa.gov/oppad001/ reregistration/cca/timeline.htm (accessed March 15, 2007).

U.S. Environmental Protection Agency, 2006. "Federal Insecticide, Fungicide, and Rodenticide Act." April 14. http://www.epa.gov/region5/defs/html/fifra.htm (accessed March 15, 2007). 


\section{RELATED RESEARCH SOURCES, continued}

U.S. Environmental Protection Agency. "List of Common HHW Products." 22 February 2006. http://www.epa.gov/epaoswer/non-hw/muncpl/hhw-list.htm.

U.S. Environmental Protection Agency. "Notice of Receipt of Requests to Cancel Certain Chromated Copper Arsenate (CCA) Wood Preservative Products and Amend to Terminate Certain Uses of CCA Products." 23 February 2006. http://www.epa.gov/fedrgstr/EPA-PEST/2002/February/Day-22/p4306.htm.

U.S. Environmental Protection Agency. "Notice of Receipt of Requests to Cancel Certain Chromated Copper Arsenate (CCA) Wood Preservative Products and Amend to Terminate Certain Uses of CCA Products; Extension of Comment Period." 23 February 2006. http://www.epa.gov/fedrgstr/EPA-PEST/2002/March/Day22/p6943.htm.

U.S. Environmental Protection Agency. Office of Prevention, Pesticides, and Toxic Substances to Chemical Specialties, Inc., memo 2 February 2004.

U.S. Environmental Protection Agency. "Pesticide Product Label System (PPLS)." 5 May 2006. http:/www.epa.gov/pesticides/pestlabels/.

U.S. Environmental Protection Agency. "Q\&A's: New Arsenic RegulationsImplementation and Compliance." May 2005.

U.S. Environmental Protection Agency. "Studies Provide Public with Updated Information on CCA-Treated Playground and Decks." 11 May 2005. http://yosemite.epa.gov/opa/admpress.nsf/d9bf8d9315e942578525701c005e573c/eab cba60dbba6cfe8525702e0059bd15!OpenDocument.

U.S. Environmental Protection Agency. "Supplemental Guidance on Interpretation of Revised Chromated Copper Arsenate (CCA) Wood Preservative Label." 16 June 2004. http://www.epa.gov/oppad001/reregistration/cca/cca awpa june.pdf.

U.S. Environmental Protection Agency. Wastes: States. 6 July 2006. http://www.epa.gov/epaoswer/osw/stateweb.htm. 
RELATED RESEARCH SOURCES, continued

U.S. Environmental Protection Agency. "Final Report for the Federal Insecticide, Fungicide, and Rodenticide Act (FIFRA), Scientific Advisory Panel (SAP)." Arlington, Virginia. 23-25 October 2001: 1-17.

U.S. Environmental Protection Agency. "Hazardous Waste Management System; Identification and Listing of Hazardous Waste." Federal Register Vol. 45 No. 229. 25 November 1980.

U.S. Environmental Protection Agency, 2006. "List of Common HHW Products." February 22. http://www.epa.gov/epaoswer/non-hw/muncpl/hhw-list.htm (accessed March 15, 2007).

U.S. Environmental Protection Agency, 2006. "Notice of Receipt of Requests to Cancel Certain Chromated Copper Arsenate (CCA) Wood Preservative Products and Amend to Terminate Certain Uses of CCA Products." February 23. http://www. epa.gov/fedrgstr/EPA-PEST/2002/February/Day-22/p4306.htm (accessed March 15, 2007).

U.S. Environmental Protection Agency, 2006. "Notice of Receipt of Requests to Cancel Certain Chromated Copper Arsenate (CCA) Wood Preservative Products and Amend to Terminate Certain Uses of CCA Products; Extension of Comment Period." February 23. http://www.epa.gov/fedrgstr/EPA-PEST/2002/March/Day-22/p6943 .htm (accessed March 15, 2007).

U.S. Environmental Protection Agency. Office of Prevention, Pesticides, and Toxic Substances to Chemical Specialties, Inc., memo 2 February 2004.

U.S. Environmental Protection Agency, 2006. "Pesticide Product Label System (PPLS)." May 5. http://www.epa.gov/pesticides/pestlabels/ (accessed March 15, 2007).

U.S. Environmental Protection Agency. "Q\&A's: New Arsenic RegulationsImplementation and Compliance." May 2005.

U.S. Environmental Protection Agency, 2005. "Studies Provide Public with Updated Information on CCA-Treated Playground and Decks." May 11. http://yosemite.epa.gov/opa/admpress.nsf/d9bf8d9315e942578525701c005e573c/eab cba60dbba6cfe8525702e0059bd15!OpenDocument (accessed March 15, 2007).

U.S. Environmental Protection Agency, 2004. "Supplemental Guidance on Interpretation of Revised Chromated Copper Arsenate (CCA) Wood Preservative Label." June 16. http://www.epa.gov/oppad001/reregistration/cca/cca_awpa june.pdf (accessed March 15, 2007). 
RELATED RESEARCH SOURCES, continued

U.S. Environmental Protection Agency, 2006. Wastes: States. July 6. http://www.epa.gov/epaoswer/osw/stateweb.htm (accessed March 15, 2007). 


\section{APPENDIX C:}

\section{VITAE}

Kenneth Steve Nowak

Cell: 831-239-0462

Email: kennowak@sbcglobal.net

\section{SUMMARY OF PROFESSIONAL ENGINEERING EXPERIENCE}

- Attained over 18 years of professional expertise in industries including engineering, construction, real estate, environmental restoration, and consulting.

- Oversee as Project Manager concurrent projects, 1993-present

- Created and presented weekly Custom Home Building Construction and Safety workshops, 1993-1999

- Introduced speakers at annual Green Conference, San José, 2006

- Co-created team report from Productivity Improvement Study to American Canyon Water Treatment Facility, in California

\section{EDUCATION}

M.S., Civil Engineering, Emphasis: Construction Engineering, San José State University, 2007

\section{PROFESSIONAL AFFILIATION}

American Society of Civil Engineers 